Linköping Studies in Science and Technology

Dissertations, No. 1992

\title{
Control of Hybrid Hydromechanical Transmissions
}

\section{Viktor Larsson}

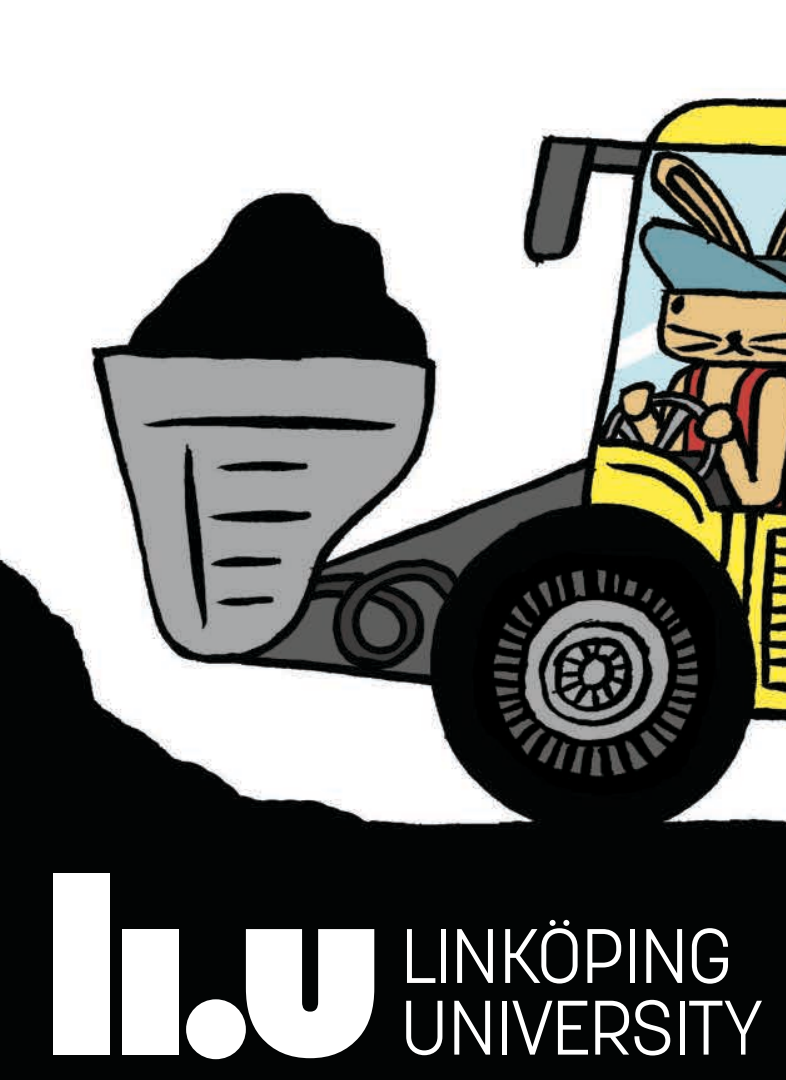




\title{
Control of Hybrid \\ Hydromechanical Transmissions
}

\author{
L. Viktor Larsson
}

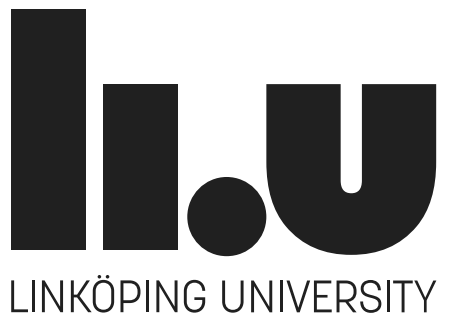

Division of Fluid and Mechatronic Systems Department of Management and Engineering

Linköping University, SE-581 83 Linköping, Sweden 
Copyright (c) L. Viktor Larsson, 2019

Control of Hybrid Hydromechanical Transmissions

ISBN 978-91-7685-051-0

ISSN 0345-7524

Cover: Nick Alston

The cover shows a wheel loader and the "rabbit holes" entered in this thesis, and illustrates three key methodological aspects of managing a $\mathrm{PhD}$ :

Work hard, think hard and stay calm.

\section{Distributed by:}

Division of Fluid and Mechatronic Systems

Department of Management and Engineering

Linköping University

SE-581 83 Linköping, Sweden

Printed in Sweden by LiU-Tryck, Linköping 2019. 
Till Mamma och Far

Utan tvivel är man inte klok

Tage Danielsson 1928-1985 



\section{Abstract}

This thesis deals with control aspects of complex hybrid hydromechanical transmissions for heavy mobile working machines. Control problems are identified and solved to facilitate the implementation and use of these systems.

Fuel prices and environmental concerns have increased the interest in hybrid hydromechanical transmissions for heavy mobile working machines. Hybridisation, the introduction of a secondary energy source in the transmission, offers attractive improvements in terms of both fuel efficiency and performance. These improvements are, in turn, enabled by software control. A complex transmission architecture has several components that need to interact in a stable manner. In addition, optimal utilisation of the added energy source is required to maximise fuel savings. Meanwhile, there is a strong trend towards automation, where many of the operator's difficult control tasks need to be managed by computers. Sophisticated control strategies are therefore needed, along with a deeper understanding of dynamic properties.

Previous research on the control of hybrid hydromechanical transmissions has primarily focussed on on-road applications. The working conditions of heavy working machines place different requirements on the transmission, which is also reflected in the control strategy.

This thesis highlights the importance of fast response of the variable displacement pump/motors used in hybrid hydromechanical transmissions. Their central position in the interface between hydraulics and mechanics makes their dynamic performance a limiting factor both for the stability of the transmission control loops and in the realisation of smooth mode shifts in multiplemode transmissions. Dynamic models and control strategies for displacement actuators are derived and validated in simulation and experiments. A linear model for dynamic analysis of a general hybrid hydromechanical transmission for heavy working machines is derived and a powertrain control strategy based on decoupled control is proposed. The strategy is verified in simulations and experiments in hardware-in-the-loop simulations, and may be used in a working machine with or without a human operator. 


\section{Populärvetenskaplig sammanfattning}

\section{Styrning av hybrida hydraulmekaniska transmissioner för arbetsmaskiner}

Arbetsmaskiner, som till exempel hjullastare, drivs idag nästan uteslutande av fossila bränslen. Allt hårdare miljökrav har därför tvingat tillverkare att se sig om efter nya lösningar för framdrivning för att minska bränsleförbrukningen i dessa maskiner.

En sådan lösning är hybridisering. Detta innebär att ett extra energilager kopplas in i maskinen för att kunna återvinna och återanvända energi. Till exempel kan rörelseenergin återvinnas när en hjullastare bromsar in, och återanvändas när den ska accelerera. I denna avhandling studeras hybridisering med hjälp av hydrauliska ackumulatorer. I dessa komponenter lagras energi i form av tryck, genom att med olja trycka ihop en gas.

För att realisera en hydraulisk hybrid behövs en hydraulmekanisk transmission för att flytta energi mellan drivhjul och ackumulator. Det är en kombinerad mekanisk och hydraulisk växellåda, där mekaniska kugghjul och axlar kopplas samman med hydrauliska pumpar/motorer (hydraulmaskiner), som kan pumpa in och ta ut oljan ur ackumlatorn. Kopplingar används mellan axlarna för att kunna köra maskinen vid olika hastigheter, som i växellådan hos en bil. Hydraulmekaniska transmissioner är komplexa system, med många olika delar som ska samspela i harmoni.

För att uppnå denna harmoni är hybrida hydraulmekaniska transmissioner beroende av datorbaserad styrning. Styrningen ansvarar både för att se till att förbränningsmotorn arbetar tillsammans med ackumulatorn så energieffektivt som mjöligt och att maskinen kan framföras på ett stabilt sätt. Det finns idag också ett stort intresse för digitalisering och automation. Det betyder att allt fler av förarens uppgifter kommer utföras automatiskt av datorer som sin tur måste veta hur maskinen ska styras.

I denna avhandling har olika strategier för styrning av hybrida hydraul- 
mekaniska transmissioner tagits fram och testats. Ett viktigt fenomen som påvisats i arbetet är hydraulmaskinernas centrala roll i styrningen av transmissionen. Deras position i gränssnittet mellan hydraulik och mekanik medför att deras snabbhet är avgörande såväl för att uppnå ett stabilt fordon som för att åstadkomma mjuka, automatiska växlingar. Datorbaserade styrstrategier för hydraulmaskinerna har tagits fram och verifierats i experiment. Dessa strategier har sedan använts i utvecklandet av en frikopplad styrstrategi för komplett fordon med förbränningsmotor, transmission och ackumulator. Denna frikoppling möjliggör individuell styrning av de ingående komponenterna, och har verifierats i simulering och experiment.

Resultaten är viktiga för utvecklingen arbetsmaskiner, så att de i framtiden kan användas på ett miljövänligt och säkert sätt, såväl med som utan förare. 


\section{Acknowledgements}

The work presented in this thesis has been carried out at the Division of Fluid and Mechatronic Systems (Flumes) at Linköping University.

I want to thank my main supervisor, Professor Petter Krus, for giving me the opportunity to do a $\mathrm{PhD}$ at Flumes. Thank you for all the inspiring discussions, for your trust in me and my work, and for helping me learn to truly appreciate the concept of less is more. I also wish to thank my co-supervisors, Doctor Liselott Ericson and Doctor Magnus Sethson, for your guidance, handson support and valuable input on this thesis.

Gratitude is due to the Swedish Energy Agency, Volvo Construction Equipment and Bosch Rexroth for their financial support in my research project. At Volvo, I especially want to thank Doctor Karl Uebel for your guidance and critical reviews of my work and Doctor Kim Heybroek for your support and encouragement. At Bosch, I wish to thank Carl-Johan Thell and Henrik Jarl for all the support with the test rig components over the years.

The administrative staff at the university have been true assets throughout the thesis work. In particular, I want to thank the workshop crew for your support with the test rig, and administrator Rita Enquist for all the bureaucratic help and for always having cookies and candy in your office.

A big thank you to Licentiate Peter Nordin and Doctor Robert Braun, for your dedicated Hopsan maintenance and support.

Thank you so much Nick Alston, for helping me out with creating the beautiful cover illustration of this thesis.

I would also like to acknowledge all the undergraduate students I have met during my time as a PhD student. I have learned so much from the teaching we have had together and you have all contributed to this thesis.

I would like to thank all my colleagues at Flumes for the friendly working environment and for all the inspiring and stimulating work days. Thank you to all my fellow PhD students, and in particular Alejandro Sobron, Ida Åberg, Katharina Baer, Robert Hällqvist and Alessandro Dell'Amico, for all the laughs, rants, open doors and open ears. 
To my family and friends, thank you for always being there for me, and for all the joy you bring into my life. A special thank you to my dear sisters, Mina, Maja and Alma, and my aunt Inger, for all your love and support, and to Kurtan $\mathbf{Y}$, for now eating my record jackets instead of my work notes when we run out of crispbread.

Finally, my deepest gratitude goes to my parents, Anna and Anders, who always believed in me and my ability. I dedicate this thesis to you, and proudly adopt your belief.

\section{Tack!}

Linköping, August 2019

Viktor Larsson 


\section{Abbreviations}

$\begin{array}{ll}\text { BMEP } & \text { Break Mean Effective Pressure } \\ \text { CHIL } & \text { Controller-Hardware-in-the-Loop } \\ \text { CVT } & \text { Continuously Variable Transmission } \\ \text { FMEP } & \text { Friction Mean Effective Pressure } \\ \text { FUMEP } & \text { Fuel Mean Effective Pressure } \\ \text { GUI } & \text { Graphical User Interface } \\ \text { HMT } & \text { Hydromechanical Transmission } \\ \text { HST } & \text { Hydrostatic Transmission } \\ \text { HWIL } & \text { Hardware-in-the-Loop } \\ \text { ICE } & \text { Internal Combustion Engine } \\ \text { ICPS } & \text { Input-Coupled Power-Split transmission } \\ \text { MIMO } & \text { Multiple-Input-Multiple-Output } \\ \text { MVEM } & \text { Mean Value Engine Modelling } \\ \text { OC } & \text { Open Circuit } \\ \text { OCPS } & \text { Output-Coupled Power-Split transmission } \\ \text { OCV } & \text { Open Circuit with Valve } \\ \text { P-controller } & \text { Proportional controller } \\ \text { P-lead-controller } & \text { Proportional controller with lead compensator } \\ \text { PHIL } & \text { Power-Hardware-in-the-Loop } \\ \text { PWM } & \text { Pulse-Width Modulation } \\ \text { SFC } & \text { Specific Fuel Consumption } \\ \text { SISO } & \text { Single-Input-Single-Output } \\ \text { TLM } & \text { the Transmission Line element Method }\end{array}$




\section{Nomenclature}

$A_{1}$

$\alpha \quad$ Swash plate angle

$\alpha_{f} \quad$ Numerical damping factor

$\alpha_{\max }$

$\alpha_{w}$ $\left[\mathrm{m}^{2}\right]$

$[\mathrm{rad}]$

$[\mathrm{rad}]$

$\left[\mathrm{W} /\left(\mathrm{m}^{2} K\right)\right]$

$\left(a_{m}, b_{m}, c_{m}, d_{m}\right)$ Transmission subsystem model speed matrix elements

$A_{w}$

Accumulator surface area

$\left[\mathrm{m}^{2}\right]$

$B_{\text {axle }}$

Vehicle axle losses coefficient

$[\mathrm{Ns} / \mathrm{m}]$

$\beta$

Road inclination angle

$[\mathrm{rad}]$

$B_{I C E}$

Engine viscous friction

$[\mathrm{Nms} / \mathrm{rad}]$

$B M E P_{\max } \quad$ Maximum break mean effective pressure

$[\mathrm{Pa}]$

$B_{p m} \quad$ Pump/motor shaft viscous friction coefficient

$[\mathrm{Nms} / \mathrm{rad}]$

$B_{v}$

Output shaft viscous friction

$[\mathrm{Nms} / \mathrm{rad}]$

C

Accumulator capacitance

$$
\left[\mathrm{m}^{5} / \mathrm{N}\right]
$$

Wave variable

$[\mathrm{Nm}]$

$c_{f}$

Filtered wave variable

$[\mathrm{Nm}]$

$c_{f r, 1 / 2 / 3}$

Engine friction model constants

$C_{p}$

Parasitic capacitance

$[\mathrm{rad} / \mathrm{Nm}]$

$c_{p} \quad$ Constant pressure specific heat capacity

$[\mathrm{J} /(\mathrm{kg} \cdot \mathrm{K})]$

$C_{q}$

Valve flow coefficient

$C_{r}$

Rolling resistance coefficient 


\begin{tabular}{|c|c|c|}
\hline$C_{s}$ & Spring capacitance & {$[\mathrm{rad} / \mathrm{Nm}$} \\
\hline$c_{v}$ & Constant volume specific heat capacity & {$[\mathrm{J} /(\mathrm{kg} \cdot \mathrm{K})$} \\
\hline$d$ & Valve spool diameter & \\
\hline$D_{(1 / 2)}$ & (Unit $1 / 2$ ) maximum volumetric displacement & {$\left[\mathrm{m}^{3} / \mathrm{ra}\right.$} \\
\hline$\delta_{a}$ & Displacement controller relative damping & \\
\hline$D_{m}$ & Rig HWIL interface motor volumetric displacement & {$\left[\mathrm{m}^{3} / \mathrm{rad}\right.$} \\
\hline$D_{\max }$ & Maximum volumetric displacement & {$\left[\mathrm{m}^{3} / \mathrm{rad}\right.$} \\
\hline$D_{s}$ & Shaft diameter & \\
\hline$\varepsilon_{(1 / 2)}$ & (Unit $1 / 2$ ) relative displacement & \\
\hline$\varepsilon_{(1 / 2), \text { ref }}$ & (Unit $1 / 2$ ) relative displacement, reference & \\
\hline$\eta_{0}$ & Final gear efficiency & \\
\hline$\eta_{i g}$ & Indicated gross efficiency & \\
\hline$\eta_{i g, c h}$ & Combustion chamber efficiency & \\
\hline$\eta_{p g}$ & Planetary gear efficiency & \\
\hline$\eta_{s g}$ & Spur gear efficiency & \\
\hline$F_{B L}$ & Baseline controller (matrix) & \\
\hline$F^{\text {diag }}$ & Diagonal controller (matrix) & \\
\hline$F_{\varepsilon}$ & Displacement controller transfer function & \\
\hline$F_{\text {ext }, v}$ & External vehicle disturbance force & \\
\hline$F U M E P_{\max }$ & Maximum fuel mean effective pressure & \\
\hline$g$ & Gravitational constant & {$[\mathrm{m} / \mathrm{s}$} \\
\hline$\gamma$ & Specific heats ratio $\left(c_{p} / c_{v}\right)$ & \\
\hline$G_{\varepsilon}$ & Displacement controller closed-loop transfer function & \\
\hline$G_{O}$ & Open-loop transfer function (matrix) & \\
\hline$G_{O, \varepsilon}$ & Displacement controller open-loop transfer function & \\
\hline$\tilde{G}_{O}$ & Decoupled open-loop transfer function (matrix) & \\
\hline$\tilde{G}_{p, c}$ & Decoupled closed pressure loop transfer function & \\
\hline$G_{s}$ & Shaft shear modulus & \\
\hline$G_{\text {sys }}$ & Diagonal state dynamics transfer function (matrix) & \\
\hline
\end{tabular}


$G_{T}$

$\tilde{g}_{i, j}$

$G_{t s, m}$

$i_{0}$

$i_{1 / 2}$

$I_{\omega}$

$i_{s g}$

$j_{c r}$

$j_{f g}$

$J_{I C E}$

$j_{p g}$

$J_{p m}$

$j_{s g}$

$J_{v}=m_{v}\left(\eta_{0} r_{w}\right)^{2}$ Vehicle equivalent rotational inertia

K

$K_{1 / 2 / 3}$

$K_{C}$

$K_{c, p m}$

$K_{D J}$

$K_{D J, 2}$

$K_{\varepsilon}$

$K_{\varepsilon, m}$

$K_{F F}$

$K_{I C E}$

$K_{P I}$

$K_{P W M}$

$K_{q}$

$K_{s}$

$k_{s}$

Turbo dynamics transfer function

Final gear ratio

Unit $1 / 2$ gear ratio

Spur gear ratio

Rolling resistance flip coefficient

Final gear efficiency flip exponent

Engine flywheel inertia

Planetary gear efficiency flip exponent

Pump/motor rotating group inertia

Spur gear efficiency flip exponent

Control gain

Disturbance rejection control gain

Displacement controller gain

Feed forward control gain

Static engine gain

Proportional integrator controller gain

Static solenoid gain

Valve flow gain

Static gain (Displacement controller)

Spring stiffness
Element of row $i$ and column $j$ of transfer function matrix $\tilde{G}$

Transmission subsystem transfer function, at mode $m$ (matrix)

Transmission subsystem model speed matrix

$\left[\mathrm{kgm}^{2}\right]$

$[\mathrm{s}]$

Proportional gain of diagonal control element $F_{1 / 2 / 3}$

$\left[\mathrm{m}^{5} /(\mathrm{Ns})\right]$

Laminar leakage coefficient (hydraulic circuit)

$\left[\mathrm{m}^{5} / \mathrm{Ns}\right]$

Pump/motor laminar leakage coefficient

$[-]$

Disturbance rejection control estimation compensation gain $[-]$

[\% Duty cycle]

Displacement mechanical control linkage gain

[m]

$[\mathrm{Nm}]$

[m/\%Duty-cycle]

$\left[\mathrm{m}^{2} / \mathrm{s}\right]$

[1/(s.\% Duty-cycle)]

$[\mathrm{Nm} / \mathrm{rad}]$ 


$\begin{array}{llr}K_{\tau} & \text { Turbo gain } & {[-]} \\ L & \text { Inductance } & {\left[\mathrm{kgm}^{2}\right]} \\ L_{p} & \text { Parasitic inductance } & {\left[\mathrm{kgm}^{2}\right]} \\ L_{s} & \text { Shaft length } & {[\mathrm{m}]} \\ L_{s p} & \text { Control piston lever (swash plate radius) } & {[\mathrm{m}]} \\ m & \text { Mode index }(m \in[1,2,3 \ldots n]) & {[-]} \\ m_{f} & \text { Fuel mass flow } & {[\mathrm{kg} / \mathrm{rad}]} \\ m_{f, \text { max }} & \text { Maximum fuel mass flow } & {[\mathrm{kg} / \mathrm{rad}]} \\ m_{g} & \text { Gas mass } & {[\mathrm{kg}]} \\ m_{v} & \text { Vehicle mass } & {[\mathrm{kg}]} \\ n & \text { Number of modes } & {[-]}\end{array}$

$n_{r} \quad$ No. of revs. per combustion cycle $\left(n_{r}=2\right.$ for 4 -stroke, $n_{r}=1$ for 2-stroke)

$\begin{array}{lll}\omega & \text { Angular velocity/frequency } & {[\mathrm{rad} / \mathrm{s}]} \\ \omega_{1 / 2} & \text { Unit } 1 / 2 \text { shaft speed } & {[\mathrm{rad} / \mathrm{s}]} \\ \omega_{1 / 2, \text { ref }} & \text { Shaft speed reference rig side } 1 / 2 & {[\mathrm{rad} / \mathrm{s}]} \\ \omega_{a} & \text { Displacement controller resonance frequency } & {[\mathrm{rad} / \mathrm{s}]} \\ \omega_{\text {carr }} & \text { Carrier wheel shaft speed } & {[\mathrm{rad} / \mathrm{s}]} \\ \omega_{F, 1 / 2} & \text { Controller lower(1)/upper(2) break frequency } & {[\mathrm{rad} / \mathrm{s}]}\end{array}$

$\omega_{F F, 1 / 2} \quad$ Feed forward lead filter upper(1)/lower(2) break frequency

$\omega_{I} \quad$ Proportional integrator controller break frequency $\quad[\mathrm{rad} / \mathrm{s}]$

$\omega_{I C E} \quad$ Engine shaft speed $[\mathrm{rad} / \mathrm{s}]$

$\omega_{I C E, 0} \quad$ Engine shaft speed, linearisation point $[\mathrm{rad} / \mathrm{s}]$

$\omega_{I C E, \text { ref }}$ Engine shaft speed, reference $[\mathrm{rad} / \mathrm{s}]$

$\omega_{\text {out }} \quad$ Transmission output shaft speed $[\mathrm{rad} / \mathrm{s}]$

$\omega_{\text {out }, 0} \quad$ Transmission output shaft speed, linearisation point $\quad[\mathrm{rad} / \mathrm{s}]$

$\omega_{\text {out }, \text { ref }} \quad$ Transmission output shaft speed, reference [

$\omega_{p} \quad$ Closed pressure control loop break frequency $\quad[\mathrm{rad} / \mathrm{s}]$ 


\begin{tabular}{|c|c|c|}
\hline$\omega_{\text {ref }}$ & Angular velocity, reference value & {$[\mathrm{rad} / \mathrm{s}]$} \\
\hline$\omega_{\text {ring }}$ & Ring wheel shaft speed & {$[\mathrm{rad} / \mathrm{s}]$} \\
\hline$\omega_{\text {sg }, \text { in } / \text { out }}$ & Spur gear input/output shaft speed & {$[\mathrm{rad} / \mathrm{s}]$} \\
\hline$\omega_{\text {sun }}$ & Sun wheel shaft speed & {$[\mathrm{rad} / \mathrm{s}]$} \\
\hline$\omega_{v}$ & Spool valve break frequency & {$[\mathrm{rad} / \mathrm{s}]$} \\
\hline$p_{0}$ & Accumulator precharge pressure & {$[\mathrm{Pa}]$} \\
\hline$p_{1 / 2}$ & Side $1 / 2$ pressure & {$[\mathrm{Pa}]$} \\
\hline$p_{c}$ & Control piston pressure & {$[\mathrm{Pa}]$} \\
\hline$p_{c, 0}$ & Control piston pressure, linearisation point & {$[\mathrm{Pa}]$} \\
\hline$p_{L}$ & Load pressure & {$[\mathrm{Pa}]$} \\
\hline$p_{\text {sup }}$ & Rig supply pressure & {$[\mathrm{Pa}]$} \\
\hline$p_{\text {sys }}$ & Transmission high pressure & {$[\mathrm{Pa}]$} \\
\hline$p_{\text {sys }, 0}$ & Transmission high pressure, linearisation point & {$[\mathrm{Pa}]$} \\
\hline$p_{\text {sys,ref }}$ & Transmission high pressure, reference & {$[\mathrm{Pa}]$} \\
\hline$p_{T}$ & Transmission tank pressure & {$[\mathrm{Pa}]$} \\
\hline$p_{T, \text { sup }}$ & Rig supply tank pressure & {$[\mathrm{Pa}]$} \\
\hline$q$ & Volumetric flow & {$\left[\mathrm{m}^{3} / \mathrm{s}\right]$} \\
\hline$q_{1 / 2}$ & Unit $1 / 2$ volumetric flow & {$\left[\mathrm{m}^{3} / \mathrm{s}\right]$} \\
\hline$q_{a c c}$ & Accumulator input volumetric flow & {$\left[\mathrm{m}^{3} / \mathrm{s}\right]$} \\
\hline$q_{\varepsilon}$ & Displacement control piston flow & {$\left[\mathrm{m}^{3} / \mathrm{s}\right]$} \\
\hline$Q_{e x t}$ & External transmission disturbance flow & {$\left[\mathrm{m}^{3} / \mathrm{s}\right]$} \\
\hline$q_{L H V}$ & Fuel lower heating value & {$[\mathrm{J} / \mathrm{kg}]$} \\
\hline$R$ & Planetary gear constant & {$[-]$} \\
\hline$r_{c}$ & Engine compression ratio & {$[-]$} \\
\hline$R_{g}$ & Gas law constant & {$[\mathrm{J} /(\mathrm{kg} \cdot \mathrm{K})]$} \\
\hline$\rho_{f}$ & Fuel density & {$\left[\mathrm{kg} / \mathrm{m}^{3}\right]$} \\
\hline$\rho_{\text {oil }}$ & Oil density & {$\left[\mathrm{kg} / \mathrm{m}^{3}\right]$} \\
\hline$\rho_{s}$ & Shaft density & {$\left[\mathrm{kg} / \mathrm{m}^{3}\right]$} \\
\hline$r_{w}$ & Wheel radius & {$[\mathrm{m}]$} \\
\hline
\end{tabular}


$S_{f w d}$

$S_{h}$

$S_{\text {rev }}$

$T$

$t$

$T_{0}$

$T_{1 / 2}$

$\tau$

$\tau_{T}$

$T_{\text {carr }}$

$T_{D}$

$T_{e, l i m}$

$T_{e, \max }$

$T_{e, n e t}$

$T_{\text {ext }, I C E}$

$T_{\text {ext }, v}$

$T_{f r}$

$T_{g}$

$T_{\text {ICE,net }}$

$T_{I C E, \text { net }}$

$T_{i g}$

$T_{\infty}$

$T_{\text {out }}$

$T_{\text {out,ref }}$

$T_{\text {ring }}$

$T_{s}$

$T_{\text {sg,in/out }}$

$T_{\text {sun }}$

Clutch used in forward ICPS mode

Clutch used in hydrostatic mode

Clutch used in reverse ICPS mode

Torque

[Nm]

Time

Accumulator precharge temperature

Unit $1 / 2$ shaft torque

$[\mathrm{Nm}]$

Time constant

Turbo time constant

Carrier wheel torque

[Nm]

Turbo-delayed engine torque

$[\mathrm{Nm}]$

Limited engine output torque

$[\mathrm{Nm}]$

Maximum engine torque

[Nm]

Net engine torque $\left(T_{D}-T_{f r}\right)$

$[\mathrm{Nm}]$

External engine disturbance torque

$[\mathrm{Nm}]$

$[\mathrm{Nm}]$

Engine friction torque

$[\mathrm{Nm}]$

Gas temperature

Net engine torque

[Nm]

$[\mathrm{Nm}]$

$[\mathrm{Nm}]$

Accumulator ambient temperature

Transmission output torque

Desired transmission output torque

Simulation time step 
$u_{I C E} \quad$ Normalised engine injected fuel $\left(u_{I C E} \in[0 \ldots 1]\right)$

$u_{P W M,(1 / 2)} \quad$ (Unit 1/2) pulse-width-modulated voltage [\% Duty-cycle]

$U_{v} \quad$ Valve spool underlap [m]

$u_{v, \text { dist }}$ Disturbance valve signal [V]

$v \quad$ Specific volume $\left[\mathrm{m}^{3} / \mathrm{kg}\right]$

$V_{0} \quad$ Accumulator volume $\left[\mathrm{m}^{3}\right]$

$V_{D} \quad$ Engine volumetric displacement $\quad\left[\mathrm{m}^{3}\right]$

$V_{g} \quad$ Gas volume $\left[\mathrm{m}^{3}\right]$

$v_{\text {veh }} \quad$ Vehicle velocity $[\mathrm{m} / \mathrm{s}]$

$v_{v e h, \text { ref }} \quad$ Vehicle velocity, reference $[\mathrm{m} / \mathrm{s}]$

$W_{m} \quad$ Decoupling matrix for mode $m$

$x_{v} \quad$ Valve spool displacement [m]

$x_{v, 1 / 2, \text { ref }} \quad$ Desired valve position, rig side $1 / 2 \quad$ [m]

$x_{v, r e f, D J} \quad$ Desired spool valve position, disturbance rejection part $\quad[\mathrm{m}]$

$x_{v, \text { ref,FF }} \quad$ Desired spool valve position, feed forward part [m]

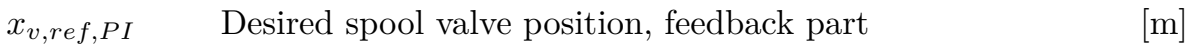

$Z_{c} \quad$ Characteristic impedance $\quad[\mathrm{Nms} / \mathrm{rad}]$ 


\section{Papers}

The work presented in this thesis is based on the following five papers, which will be referred to by their Roman numerals. In all papers, the first author is the main responsible for the work presented, with additional support from the co-authors. The papers are appended to this thesis and have been printed in their original state, with the exception of minor errata and changes in layout.

[I] L. Viktor Larsson, Karl Pettersson, and Petter Krus. "Mode Shifting in Hybrid Hydromechanical Transmissions". In: Proceedings of the ASME/BATH 2015 Symposium on Fluid Power and Motion Control (FPMC2015). Chicago, Illinois, USA, 2015. ISBN: 9780791857236. DOI: 10.1115/FPMC2015-9583.

[II] L. Viktor Larsson and Petter Krus. "Modelling of the Swash Plate Control Actuator in an Axial Piston Pump for a Hardware-in-the-Loop Simulation Test Rig". In: The 9th FPNI Ph.D. Symposium on Fluid Power. Florianópolis, SC, Brazil, 2016, V001T01A044. ISBN: 978-07918-5047-3. DOI: 10.1115/FPNI2016-1570.

[III] L. Viktor Larsson and Petter Krus. "Displacement Control Strategies of an In-Line Axial-Piston Unit". In: The 15th Scandinavian International Conference on Fluid Power (SICFP'17). Linköping, Sweden, 2017. ISBN: 978-91-7685-369-6. DOI: 10.3384/ecp17144244.

[IV] L. Viktor Larsson and Petter Krus. "A General Approach to LowLevel Control of Heavy Complex Hybrid Hydromechanical Transmissions". In: BATH/ASME 2018 Symposium on Fluid Power and Motion Control, Bath, Great Britain. 2018. ISBN: 978-0-7918-5196-8. DOI: 10.1115/FPMC2018-8877.

[V] L. Viktor Larsson, Liselott Ericson, Karl Uebel, and Petter Krus. "LowLevel Control of Hybrid Hydromechanical Transmissions for Heavy Mobile Working Machines". In: Energies 12.9 (2019). ISSN: 1996-1073. DOI: $10.3390 /$ en 12091683. 


\section{Other papers and publications}

The publications listed below are not included in the thesis but constitute an important part of the background. In paper [VI], the first three authors are the main responsible for the work presented, with additional support from the fourth author. In paper [VIII], the first author is the main responsible for the work presented, with additional support from the co-author.

[VI] Karl Pettersson, L. Viktor Larsson, K. Viktor Larsson, and Petter Krus. "Simulation Aided Design and Testing of Hydromechanical Transmissions". In: Proceedings of the 9th JFPS International Symposium on Fluid Power (JFPS'14). Matsue, Japan, 2014. ISBN: 4931070108.

[VII] L. Viktor Larsson. "Modellering och simulering av en hydraulmekanisk power-splittransmission med två moder". In: Hydraulikdagarna. Linköping, Sweden, 2015 (In Swedish).

[VIII] L. Viktor Larsson and Petter Krus. "Hardware-in-the-loop Simulation of Complex Hybrid Hydromechanical Transmissions". In: WIEFP2018 - 4th Workshop on Innovative Engineering for Fluid Power, November 28-30, Sao Paulo, Brazil. 2018. ISBN: 978-91-7685-136-4. DOI: 10.3384/ ecp1815669. 


\section{Contents}

1 Introduction 1

1.1 Aim and Research Questions ... . . . . . . . . . 2

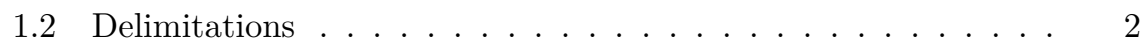

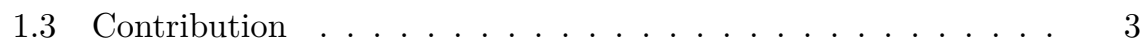

1.4 Thesis Outline ..................... 3

2 Frame of Reference $\mathbf{5}$

2.1 Hydraulic Hybrid Working Machines . . . . . . . . . . . . 5

2.1.1 Concepts and Potential . . . . . . . . . . . 6

2.2 Hybrid Hydromechanical Transmissions . . . . . . . . . . . 6

2.2.1 Hydraulic Circuit . . . . . . . . . . . . . . . . 7

2.2.2 Transmission Subsystem . . . . . . . . . . . 8

2.2 .3 Architectures . . . . . . . . . . . . . . . . . . . . . . . . .

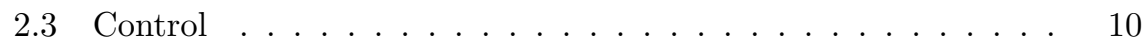

2.3.1 Secondary Control . . . . . . . . . . . . . 10

2.3.2 Displacement Control . . . . . . . . . . . . . . . . 12

2.3.3 Mode Shifting . . . . . . . . . . . . . . . . . . . . 14

2.3.4 Powertrain Control . . . . . . . . . . . . . . . . 15

2.3.5 Decoupled Control . . . . . . . . . . . . . 17

3 Methodology 19

3.1 Modelling and Simulation . . . . . . . . . . . . . . 20

3.1 .1 Hopsan .................... . . 21

3.2 Model Validation . . . . . . . . . . . . . . . . . . . 22

3.3 Control Strategy Development and Validation . . . . . . . . . 23

3.4 External Experimental Validation . . . . . . . . . . . . . 23

3.5 Hardware-in-the-Loop Simulation . . . . . . . . . . . . . 23

3.5.1 The Hardware-in-the-Loop Interface . . . . . . . . . . 25

3.6 Test Rig . . . . . . . . . . . . . . . . . . . 27

3.6.1 Hardware-in-the-Loop Implementation . . . . . . . . . . 27 
4 Contributions 31

4.1 Mode Shifting . . . . . . . . . . . . . . . . . . . . . 31

4.2 Displacement Control . . . . . . . . . . . . . . . . . . 33

4.2 .1 Linearised Model . . . . . . . . . . . . . . . . . . 34

4.2 .2 Control . . . . . . . . . . . . . . . . 35

4.2.3 Parametrisation: Pole Placement . . . . . . . . . . . . 35

4.2.4 Simulations and Measurements . . . . . . . . . . 36

4.2 .5 Summary . . . . . . . . . . . . . . . . . . . . 38

4.3 Powertrain Control . . . . . . . . . . . . . . . . . . . . . 39

4.3.1 Linearised Model . . . . . . . . . . . . . . . . . . . . . 39

4.3 .2 Control . . . . . . . . . . . . . . . . . 42

4.3.3 Simulations and Measurements . . . . . . . . . . . 47

$\begin{array}{lll}5 & \text { Discussion } & 57\end{array}$

6 Conclusions $\quad 61$

7 Review of Papers

A Hopsan Component Models $\quad 67$

A.1 Mechanical Sub-Components . . . . . . . . . . . . . . . 68

A.1.1 Shaft . . . . . . . . . . . . . . . . . . . 68

A.1.2 Gears . . . . . . . . . . . . . . . 70

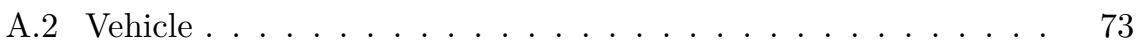

A.2.1 Linearised representation . . . . . . . . . . . . . 74

A.3 The Efficiency Flip . . . . . . . . . . . . . . . . . . . . . 75

A.4 Diesel Engine . . . . . . . . . . . . . . . . . . . 75

A.4.1 Engine Flywheel . . . . . . . . . . . . . . . . . . . 78

A.4.2 Linearised Representation . . . . . . . . . . . . 79

A.4.3 Static Characteristics . . . . . . . . . . . 79

A.5 Accumulator . . . . . . . . . . . . . . . 80

A.5.1 Linearised Representation . . . . . . . . . . . . . 82

A.6 Hydrostatic Pump/Motors . . . . . . . . . . . . . . . . . . . 84

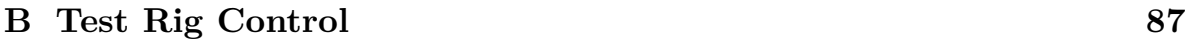

$\begin{array}{ll}\text { C Full Decoupled System Matrix } & 93\end{array}$

$\begin{array}{ll}\text { D Additional Measurements } & 95\end{array}$

$\begin{array}{ll}\text { Bibliography } & 97\end{array}$

\section{Appended Papers}

I Mode Shifting in Hybrid Hydromechanical Transmissions 107 
II Modelling of the Swash Plate Control Actuator in an Axial Piston Pump for a Hardware-In-the-Loop Simulation Test Rig

III Displacement Control Strategies of an In-Line Axial-Piston Unit

IV A General Approach to Low-level Control of Heavy Complex Hybrid Hydromechanical Transmissions

V Low-Level Control of Hybrid Hydromechanical Transmissions for Heavy Mobile Working Machines 


\section{1 \\ Introduction}

Mobile working machines, such as wheel loaders and excavators, are versatile vehicles used to perform heavy work. Currently, the combination of stricter legislation and higher demands on productivity and fuel efficiency are causing manufacturers to consider alternative solutions for the propulsion of these machines. Hybrid hydromechanical transmissions pose an interesting option, but they come at a cost, with high system complexity and new control challenges to overcome.

Vehicle hybridisation usually refers to the modification of a vehicle's driveline to incorporate a reversible energy source in parallel with an internal combustion engine. This modification offers several attractive improvements in terms of fuel savings, productivity and operability. Mobile working machines operate in rough environments in highly transient duty cycles, under high cost and productivity pressures. Consequently, hydraulics is a key enabler of power transformation in these vehicles today, thereby making hybridisation with hydro-pneumatic accumulators an interesting approach to achieve these improvements.

The basic idea of hydraulic hybridisation is simple, but its implementation is usually complex. For heavy mobile working machines, a large portion of this complexity derives from the hybrid transmission design. For this application, hybrid hydromechanical transmissions with multiple modes are often needed to fulfil the requirements of high tractive forces and wide conversion ranges. These systems are complex in the sense that they contain many components, such as pump/motors, gears and clutches, that can be combined in numerous ways, and they realise power flows in multiple directions and power domains.

To deal with this complexity, software control becomes a key enabler of hydraulic hybridisation. On an actuator level, variable pump/motors with fast, accurate displacement controllers are needed. Their position in the hydraulic/mechanical interface makes them key components in both the realisation of smooth mode shifts and the distribution of power flows. On a powertrain level, the engine and the accumulator must be controlled in a stable 
manner and simultaneously realise the operator's torque request. In addition, the powertrain control must be able to easily adapt between the modes in a multiple-mode transmission. Yet another dimension is added, considering the fact that, in addition to the driveline, a mobile working machine has work functions, such as a loader with a bucket, that require substantial amounts of power.

Meanwhile, the strong trend towards digitalisation and automation further emphasises the dependence on software control, as larger shares of the operator's work load are taken over by computers. This trend is accompanied and enabled by more affordable high-performance sensors and microprocessors that also provide extra freedom for flexible and sophisticated control solutions. This freedom does, however, present a challenge in choosing a proper strategy for its purpose. This challenge is faced in this thesis.

\subsection{Aim and Research Questions}

The overall aim of this thesis is to increase knowledge of the aspects of control of complex hybrid Hydromechanical Transmissions (HMTs) that are key to ensuring transmission functionality. These aspects are divided into mode shifting, displacement control and powertrain control. The aim may be clarified and summarised in the following research questions:

RQ1: How is the mode shifting event in complex hybrid HMTs affected by the dynamic performance of the displacement controllers?

RQ2: What are the dominating dynamic characteristics in displacement controllers that use sensor-based feedback?

RQ3: What is a suitable strategy for displacement control in hybrid HMTs?

RQ4: What is required of the dynamic response of displacement controllers used in hybrid HMTs?

RQ5: What is a suitable strategy for powertrain control in hybrid HMTs?

\subsection{Delimitations}

This thesis concerns dynamic control aspects of hybrid HMTs. Other aspects, such as energy management, energy efficiency, manufacturing and marketing are not considered. The primary application is mobile working machines with high demands for efficient and power-dense vehicle propulsion. The wheel loader is often used as an example in the thesis, but the problem formulation is valid for many other working machines as well, such as reach-stackers or telehandlers. In the dynamic analysis of displacement controllers, swash plate 
axial-piston pumps/motors are considered. For the powertrain control strategy, the focus is on the transmission and engine. Additional power consumers, such as working hydraulics, are considered as disturbance torques and flows.

\subsection{Contribution}

This thesis identifies the problem of handling mode shifts in hybrid HMTs due to the dynamics of the displacement controllers. A deeper understanding of the dynamic behaviour of displacement controllers in swash-plate axial-piston machines is provided, and novel control strategies for the displacement are proposed. The dynamic behaviour and control strategies for the displacement controller are studied in simulation and verified in experiments. A linearised model suitable for dynamic analysis of a general hybrid HMT for heavy mobile working machines is derived. A novel control strategy, based on decoupled Multiple-Input-Multiple-Output (MIMO) control, is proposed for powertrain control of a multiple-mode hybrid HMT. The strategy is tested in simulations and verified experimentally in Hardware-in-the-Loop (HWIL) simulations.

\subsection{Thesis Outline}

Chapter 2 provides the frame of reference for the thesis and aims at positioning the contributions in relation to the current state of knowledge in the field. Chapter 3 describes the methods used to assess the different control aspects. Chapter 4 summarises the contributions and main findings of the appended papers. A discussion of the methodology and the findings is provided in chapter 5 , while conclusions in relation to the research questions are drawn in chapter

6. In chapter 7 a brief review of the appended papers is given.

An overview of the assessed control aspects and the methods used for the assessments is given in the table below. The relationships between the papers and the research questions listed in section 1.1 are also illustrated.

\begin{tabular}{l|c|c|c|c|c} 
Paper & {$[\mathrm{I}]$} & {$[\mathrm{II}]$} & {$[\mathrm{III}]$} & {$[\mathrm{IV}]$} & {$[\mathrm{V}]$} \\
\hline Control aspect & & & & & \\
Mode shifting & $\mathrm{X}$ & & & & \\
Displacement control & $\mathrm{X}$ & $\mathrm{X}$ & $\mathrm{X}$ & $\mathrm{X}$ & \\
Powertrain control & $\mathrm{X}$ & & & $\mathrm{X}$ & $\mathrm{X}$ \\
\hline Method & & & & & \\
Modelling & $\mathrm{X}$ & $\mathrm{X}$ & & $\mathrm{X}$ & \\
Simulation & $\mathrm{X}$ & $\mathrm{X}$ & $\mathrm{X}$ & $\mathrm{X}$ & $\mathrm{X}$ \\
Experiments & & $\mathrm{X}$ & $\mathrm{X}$ & & $\mathrm{X}$ \\
HWIL simulation & & & & & $\mathrm{X}$ \\
\hline RQ & 1 and 4 & 2 & 2 and 3 & 4 and 5 & 5
\end{tabular}


The control aspects assessed in the appended papers may also be illustrated by the general system-of-interest shown in figure 1.1. This system has evolved during the thesis work, based on the frame of reference provided in the following chapter. In short, the states to control are the displacement settings, the accumulator pressure, the vehicle speed and the engine speed. The system pressure and the engine speed reference values are assumed to be a result of an energy management strategy. The vehicle speed reference is determined by the specific load cycle and is controlled by the operator via torque control. The operator may, in turn, be either a human or a computer.

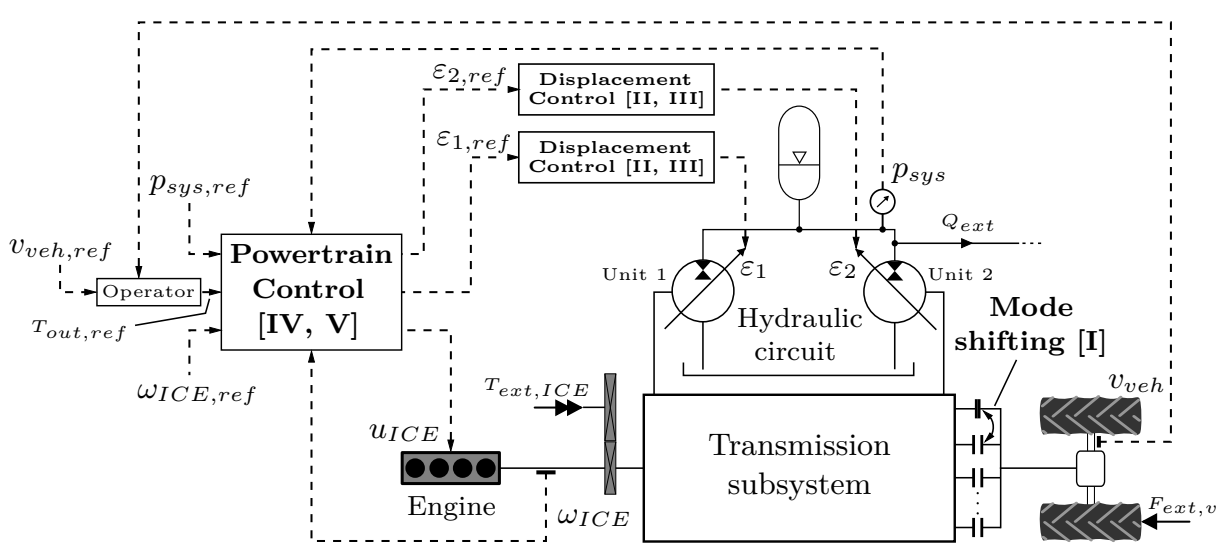

Clutches Vehicle

Figure 1.1 A general multiple-mode hybrid hydromechanical transmission with highlighted control aspects studied in the thesis. $F_{\text {ext,v }}$ is a disturbance force acting on the vehicle, for instance from a gravel pile. Additional power consumers are represented as a disturbance torque at the engine $\left(T_{\text {ext,ICE}}\right)$ or a disturbance flow $\left(Q_{e x t}\right)$ in the hydraulic circuit. 


\section{2 \\ Frame of Reference}

Although the focus of this thesis is on control rather than design, the identified control problems are consequences of the design requirements of mobile working machines. Sections $2.1-2.2$ provide a brief overview of the design challenges of hydraulic hybrid working machines in general, and how these may be handled for the driveline specifically.

\subsection{Hydraulic Hybrid Working Machines}

Hydraulic hybridisation of working machines offers several attractive features, such as kinetic/potential energy recuperation, function/system decoupling and power boost functionality [1] - features that, in turn, may lead to increased fuel efficiency, productivity and operability [2]. Compared to on-road applications, a key challenge with the hybridisation of mobile working machines is that they have several substantial power consumers: a driveline and work functions. Another important aspect is that a significant part of the control effort of these machines is carried out by an operator, who supervises and influences the two motion systems in highly transient load cycles [3]. Today, the work functions are typically actuated with a working hydraulics system based on throttle control with valves [4]. Hybridisation of the working hydraulics system is possible, but presents its own challenges. This topic is not within the scope of this thesis, but has been thoroughly investigated in [1].

The driveline of a modern working machine is most often of the hydrodynamic (torque converter) or hydrostatic type, depending on the machine's power level $[5,6]$. For hybridisation, complex hybrid hydromechanical transmissions are often required to fulfil demands for wide speed conversion ranges, high power density and acceptable cost. A key challenge in the design of these transmissions is the large design space, where simulation-based optimisation has been shown to be an important tool [5]. 


\subsubsection{Concepts and Potential}

For vehicles with propulsion as the primary power consumer, hydraulic hybridisation has been investigated with varying intensity since the energy crisis in the 1970s, see for instance [7, 8, 9] for thorough overviews. Commonly revisited applications are heavy commercial vehicles with frequent starts and stops, such as buses [10,11] and refuse trucks [12].

For mobile working machines, few commercial small-scale concepts exist today, see e.g. [13]. The potential of hydraulic hybridisation of this application has, however, been illustrated frequently in academia. For a fully hybridised large wheel loader, including the working hydraulics, energy savings of up to 50 $\%$ for a short loading cycle can be expected $[14,15]$. The majority of the savings in this example were due to eliminated torque converter and valve losses [14]. In a telehandler application, $13 \%$ fuel savings were predicted for a similar cycle when compared to a hydrostatic transmission [16]. The presence of multiple power consumers is often stressed, both in terms of management of the accumulator state-of-charge [17] and the transmission design [18, 19]. Furthermore, some authors stress the benefits of complex power-split transmissions for this application. In [17], this concept was found to facilitate optimal engine operation and decoupling between subsystems. Also, power-split hybrid HMTs may utilise the complex power flows of the power-split configuration to handle energy management in both transmission and working hydraulics in an efficient manner [18].

\subsection{Hybrid Hydromechanical Transmissions}

An HMT may be defined as a transmission that transfers power in both the hydraulic and the mechanical domain. In a mobile working machine, an HMT may be used as the driveline to transmit power from an Internal Combustion Engine (ICE) to the wheels. Figure 2.1 shows a general HMT divided into a hydraulic circuit and a mechanical transmission subsystem.

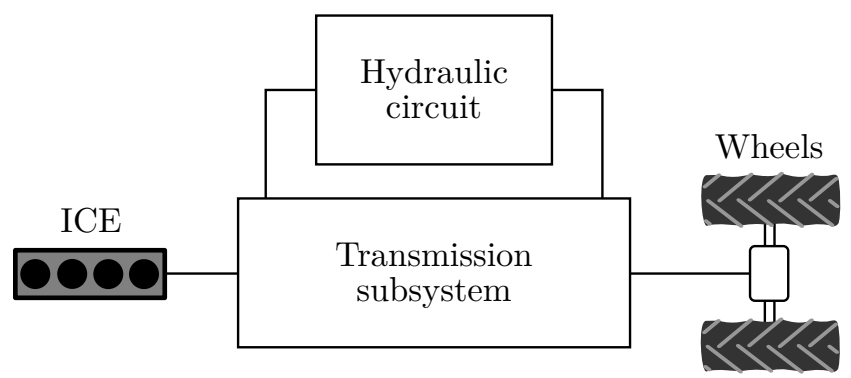

Figure 2.1 A general hydromechanical transmission, adapted from [20]. 


\subsubsection{Hydraulic Circuit}

The hydraulic circuit contains variable displacement pump/motors (units) that convert between the hydraulic and mechanical power domains. In a hybrid HMT, the circuit also has a hydro-pneumatic (gas-loaded) accumulator. Nonhybrid and hybrid representations of the hydraulic circuit are shown in figure 2.2 .

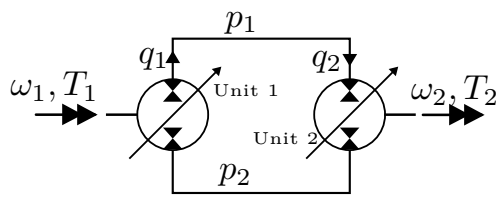

(a) Non-hybrid. The pressures change with the load.

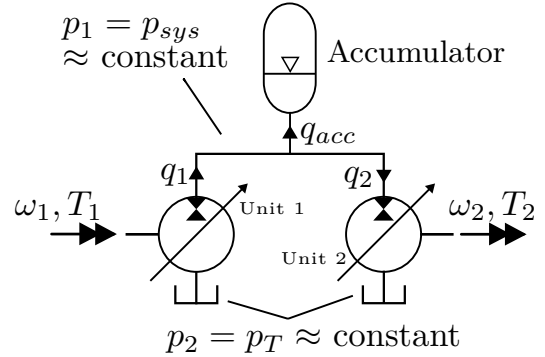

(b) Hybrid. The accumulator's state-ofcharge determines the pressure.

Figure 2.2 Non-hybrid and hybrid representations of the hydraulic circuit in an HMT. The high capacitance of the accumulator affects the dynamic behaviour of the hybrid hydraulic circuit, which has one dedicated high pressure side and one dedicated low pressure side. The low pressure side commonly has a low pressure accumulator, here represented as tanks.

For a non-hybrid HMT, the hydraulic circuit is a Hydrostatic Transmission (HST). In this concept, two hydrostatic units are connected in closed circuit and therefore experience a flow coupling $\left(q_{1}=q_{2}\right)$. The speed/torque ratio between the two shafts may then be continuously varied by varying the displacements of the hydrostatic units. A non-hybrid HMT is consequently a Continuously Variable Transmission (CVT) that uses an HST as a variator [20]. A continuously variable gear ratio, in turn, is an attractive feature for a driveline in a heavy working machine [21].

The use of accumulators in the circuit means that there is no tight flow coupling between the hydrostatic units. Rather, the difference in unit flows results in a charging or discharging of the accumulator $\left(q_{1}-q_{2}=q_{a c c}\right)$. Another important effect of the accumulator in the system is that its high capacitance causes the system pressure to be quasi-constant or impressed by the accumulator's state-of-charge [22]. As shown in figure $2.2 \mathrm{~b}$, the hybrid hydraulic circuit has dedicated high and low pressure sides, of which the high pressure side is determined by the accumulator. This is in contrast to the non-hybrid case, in which the pressure sides may alter and the total pressure difference $\left(p_{1}-p_{2}\right)$ is determined by the load. In the hybrid circuit, the impressed system pressure means that the unit displacements directly determine the unit torques, rather 
than the transmission speed/torque ratio. This concept is commonly referred to as secondary control, which is discussed further in section 2.3.1.

A gas-loaded accumulator stores energy in the form of pressure of a gas (commonly nitrogen) [7]. The gas is contained in a vessel and is separated from the oil by a piston, bladder or diaphragm [23]. The accumulator has high influence on the performance of a hybrid HMT. The thermodynamic relationship between the pressure and the volume of the gas is non-linear and gives rise to thermal losses as the gas is compressed [24]. These losses are highly affected by the frequency of charging/discharging [25], but may be reduced by using elastomeric foam in the gas volume [26]. Two other factors that affect energy recovery are the accumulator volume and precharge gas pressure [27].

\subsubsection{Transmission Subsystem}

The transmission subsystem may be divided into transmissions with single and multiple modes, where multiple-mode transmissions include clutches that enable switching between different single-mode configurations [5]. Single-mode configurations commonly mentioned in the literature are shown in figure 2.3. In a series configuration, all power is transferred via the hydraulic circuit. In a power-split configuration, planetary gear trains are used to transfer the power through the hydraulic circuit and the transmission subsystem in parallel. A power-split transmission subsystem is commonly classified based on the position of the hydraulic circuit in relation to the driveline's input and output shafts. Consequently, the hydraulic circuit is connected to the input shaft in an InputCoupled Power-Split transmission (ICPS) (figure 2.3b) and to the output shaft in an Output-Coupled Power-Split transmission (OCPS) (figure 2.3c) [28]. The compound power-split configuration (figure 2.3d) may be regarded as a combination of the input-coupled and output-coupled configurations [29]. Each power-split configuration may also be achieved in a number of ways depending on how the shafts of the planetary gear are connected [30]. The single-mode configurations have different properties that make them advantageous in different applications, see e.g. [31] and [29] for comparative analyses of non-hybrid and hybrid HMTs, respectively.

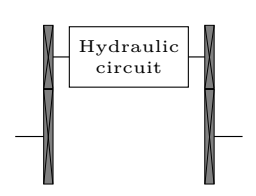

(a) Series

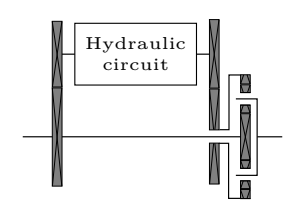

(b) ICPS

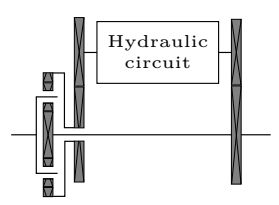

(c) OCPS

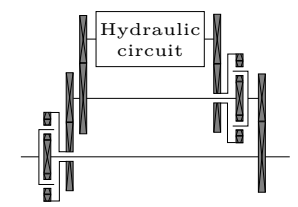

(d) Compound

Figure 2.3 Single-mode transmission subsystems, adapted from [5]. Input (engine) shaft to the left. 
For working machines with high demands for energy-efficient and powerdense propulsion, such as heavy wheel loaders, multiple-mode transmissions are often required. The idea is to utilise the best properties of each single-mode configuration and increase the transmission conversion range [5]. A common solution for compact wheel loaders is to add a gearbox in series with an HST [6]. In the case of larger machines, more complex solutions may be applicable so that one or several of the modes are of the power-split configuration. For agricultural tractors, non-hybrid multiple-mode power-split HMTs have been state-of-the-art for some time $[32,33]$ and commercialised concepts for construction machines exist on the market as well $[34,35]$.

\subsubsection{Architectures}

The approach of classifying HMTs provided in the previous sections is not unique, and the high versatility of these transmissions has resulted in many different architectures and names in the literature. For hybrid drivelines the series, power-split (complex) and parallel (add-on) topologies are often mentioned [7]. The series hybrid is equivalent to a hybrid HST, figure 2.2b, while a power-split hybrid may be realised by combining any of the power-split transmission subsystems in figure 2.3 with the hybrid circuit in figure $2.2 \mathrm{~b}$. A parallel hybrid is realised by adding a pump/motor and an accumulator to a conventional driveline. Parallel hybrids are out of the scope of this thesis but have, for instance, been investigated for wheel loaders in [36, 19].

Additional architectures are revealed if clutches and valves for manipulation of the architecture are considered. For instance, the engine can be declutched from the transmission to propel the vehicle solely from the accumulator [37], and valves can be used to switch between non-hybrid and hybrid configuration [38].

For mobile working machines, classification is difficult due to the multiple power consumers present [1,5], although a thorough attempt is made in [2]. Another aspect is that hybridisation of mobile working machines is still a fairly young technology, and there is no clear trend showing what type of architecture is optimal for this application. In this thesis, it is assumed that the requirements that have resulted in the complex multiple-mode non-hybrid HMTs being relevant for heavy working machines also motivate the choice of hybrid architecture. Consequently, the single-mode transmission subsystems in figure 2.3 combined with the hybrid circuit in figure $2.2 \mathrm{~b}$ are considered, either as complete transmissions or as individual modes in a multiple-mode concept. 


\subsection{Control}

The control of hybrid vehicles is often divided into different levels. At the highest level, the introduction of an accumulator adds an extra degree of freedom; continuously during vehicle operation, a proper decision is required as to whether the accumulator should be charged or discharged [39]. The objective of this decision-making is usually to minimise fuel consumption, and it is carried out with an energy management strategy. A great challenge in realising proper energy management is that it is limited to acting on present knowledge even though optimal (minimal) fuel consumption requires knowledge of a full cycle. This challenge has been addressed in numerous research papers, where different energy management strategies are proposed and evaluated. For some applications, simple rule-based approaches are sufficient, while more sophisticated strategies, such as optimal control and dynamic programming, are required in others. An overview and more detailed classification of energy management strategies for hydraulic hybrid vehicles is provided in [40]. For hybrid working machines, such as wheel loaders, energy management is particularly challenging due to the presence of multiple power consumers [17]. In addition, the strong influence of the energy management strategy on fuel consumption motivates simultaneous optimisation of energy management and system component sizing. The performance of a simple rule-based controller may then be comparable to that of a more sophisticated approach [19].

In this thesis, the primary focus is on low-level control. This concept refers to what is usually applied in traditional control theory [41], where aspects such as stability, damping and accuracy rather than fuel efficiency are addressed. The low-level control is thus responsible for handling the realisation and dynamic coordination of the power flows demanded by the machine operator and the energy management strategy [39].

\subsubsection{Secondary Control}

A fundamental principle within low-level control of hydraulics hybrids is secondary control, which has been present within fluid power research since the 1980s, see for example [42, 43]. The basic idea is that speed control takes place directly at the load. In the rotational domain, this means that the speed of a hydraulic motor is controlled by the motor's own displacement [25]. This is enabled by subjecting the motor to a constant pressure, see figure 2.4. As shown in equation (2.1), the constant pressure means that the speed is controlled by controlling the unit's torque through the displacement. The system is thus essentially a pure integrator, which requires active speed control for stabilisation [11]. Also, four-quadrant operation and the ability to realise relative displacements within $-1 \leq \varepsilon \leq 1$ are needed to enable braking of the load.

$$
T=\left(p_{\text {sys }}-p_{T}\right) D \varepsilon \propto / \begin{gathered}
\left(p_{\text {sys }}-p_{T}\right)=/ \propto \text { constant }
\end{gathered} / \propto \varepsilon
$$




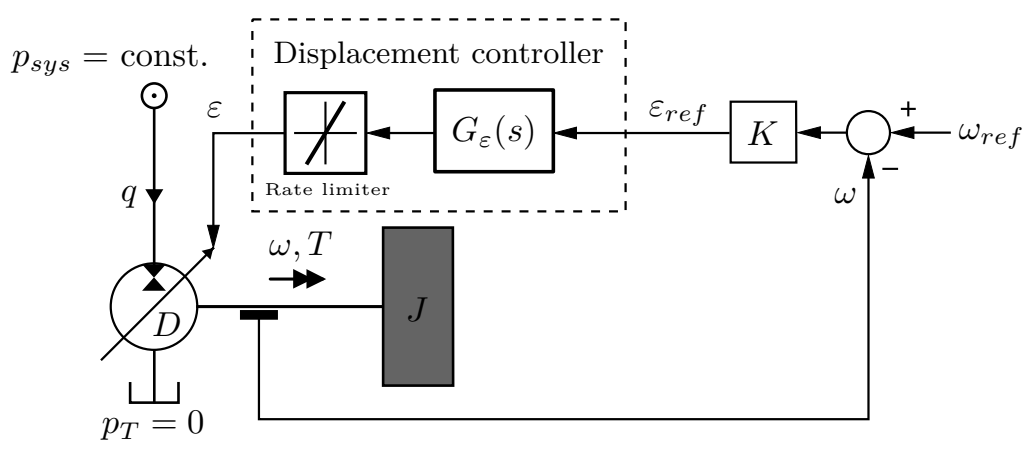

Figure 2.4 Secondary-controlled motor with inertia load and proportional feedback.

Figure 2.5 shows simulated step responses of the system in figure 2.4 without displacement controller dynamics. The speed is a consequence of the torque equilibrium of the flywheel, while the flow is determined by the product of the speed and the displacement according to $q=\omega D \varepsilon$. As the flywheel is braked to rest at 0.5 seconds, the flow changes direction (the unit now acts as a pump) and the kinetic energy stored in the flywheel is sent back into the system, for example to an accumulator.

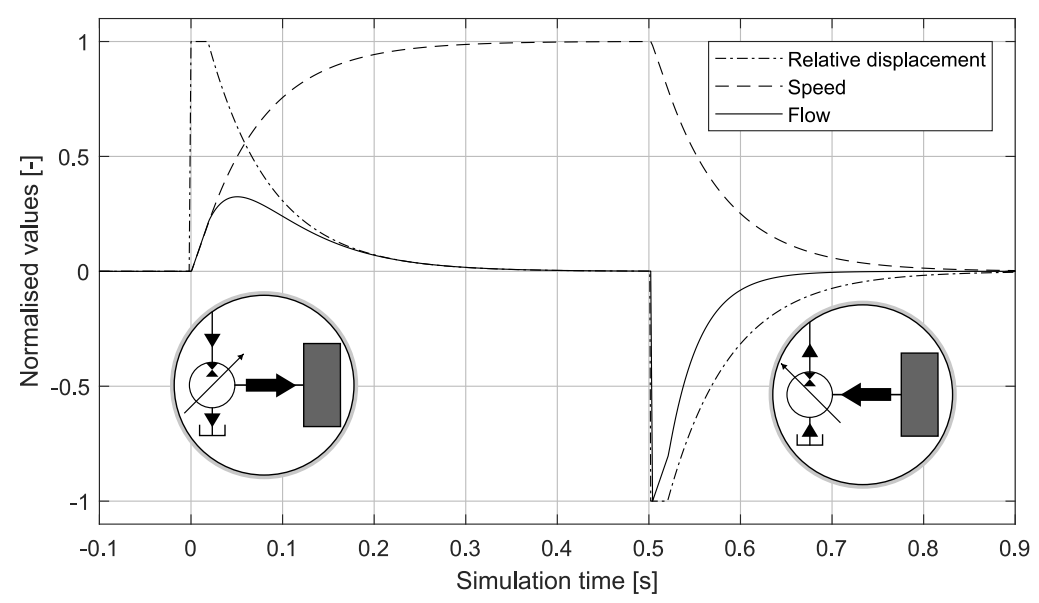

Figure 2.5 Speed step response of the system in figure 2.4, assuming an ideal displacement controller $\left(\varepsilon=\varepsilon_{r e f}\right)$. Simulation parameters are given in table 2.1. 


\subsubsection{Displacement Control}

The displacement controller constitutes the innermost control loop in the secondary control loop and therefore has substantial influence on the dynamic response [44]. In turn, different pump/motor types fulfil the demands on displacement controllers to different degrees. This thesis focuses on swash plate axial-piston units, as they are considered a suitable compromise between efficiency and controllability. In swash plate units, the displacement is varied by changing the swash plate angle. This is usually realised with a hydraulic or electro-hydraulic actuating system with pistons that act on the swash plate [45]. The feedback of the displacement may be carried out internally or externally, which has a fundamental influence on the dynamic response of the displacement controller. Conventional swash plate units use internal feedback with a mechanical linkage from the swash plate to the control valve. This is equivalent to a proportional controller and with a four-way valve solution the closed-loop response may be represented by a first order system [46]:

$$
G_{\varepsilon}(s)=\frac{\varepsilon(s)}{\varepsilon_{r e f}(s)}=\frac{1}{\tau s+1}
$$

with time constant, $\tau$, according to:

$$
\tau=\frac{A_{1} L_{s p}}{2 K_{q} K_{\varepsilon, m}}
$$

where $A_{1}$ is the control piston area, $L_{s p}$ the swash plate radius, $K_{q}$ the valve flow gain and $K_{\varepsilon, m}$ the control linkage gain. Note that the high stiffness of the mechanical linkage means that the valve dynamics may be ignored in the dynamic analysis of the control loop [47].

Apart from the dynamics of the displacement actuator, its speed is limited by the maximum flow of the control valve [48]. Flow saturation does not cause instability in secondary-controlled systems, but gives overshoots and delays the response [25]. This is illustrated in figure 2.6, which shows a step in speed of the system in figure 2.4 if displacement controller dynamics and valve flow saturation are included in the model. The dynamics of the displacement actuator add overshoot in speed, which is amplified if a rate limiter is included to mimic the saturation in valve flow.

Although the mechanical linkage feedback is a robust and stiff solution, it offers little freedom in the control design. By measuring the displacement angle with a sensor, an external feedback loop is created, thereby enabling more sophisticated controllers to be implemented in software [49]. This approach, however, places high demands on the control valve, which then dominates the dynamics. Many of the previous publications on this topic therefore use fast servo valves [48, 44]. Indeed, [48] reports high performance, but servo valves are quite expensive and energy inefficient, and are unlikely to be used in series produced pumps/motors in the short term. A solution with a relatively slow valve thereby relies even more on a sophisticated control strategy for fast response. 


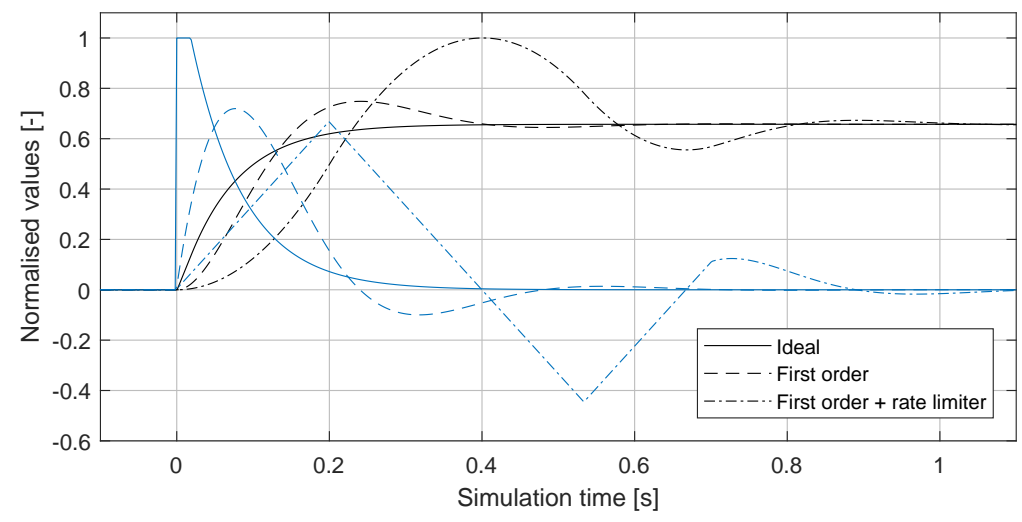

Figure 2.6 Step response in speed (black) of the system in figure 2.4 with different displacement controller dynamics (blue). Simulation parameters are provided in table 2.1 .

Table 2.1 Parameter values used in the simulations in figure 2.5 and 2.6.

\begin{tabular}{lrl}
\hline Parameter & Value & Unit \\
\hline$p_{\text {sys }}$ & 300 & $\mathrm{bar}$ \\
$K$ & 0.12 & $\mathrm{~s} / \mathrm{rad}$ \\
$\omega_{\text {ref }}$ & 100 & $\mathrm{rpm}$ \\
$J$ & 4.0 & $\mathrm{kgm}^{2}$ \\
$D$ & 100 & $\mathrm{~cm}^{3} / \mathrm{rev}$ \\
$\tau$ & 0.06 & seconds \\
$t_{r}($ rate-limiter parameter, & & \\
min time to realise $\varepsilon: 0 \rightarrow \pm 1)$ & 0.3 & seconds \\
\hline
\end{tabular}

\section{Swash-Plate Oscillations}

The mechanical structure of swash plate units gives rise to an oscillating torque that acts on the swash plate. The oscillations occur at a frequency proportional to the shaft speed and are caused by the pistons entering and leaving the highand low-pressure zones of the valve plate [46]. It has been suggested that these oscillations interfere with both the displacement control [50] and in [51], also with efficiency. The oscillating torque has been observed in measurements of the control piston pressure in the axial piston units studied in this thesis (see appendix D). However, no interference with the displacement control has been observed. Swash-plate oscillations due to the oscillating torque are therefore not considered in this work. 


\subsubsection{Mode Shifting}

A mode shift in a multiple-mode HMT is the event in which the mechanical transmission subsystem switches between two single-mode configurations. In practice, this is carried out by disengaging one clutch and engaging another. For high machine productivity and operator comfort, the mode shift should be as smooth as possible. In conventional transmissions with torque converters, jerkfree gear shifts are accomplished with power-shift gear boxes [6]. In multiplemode HMTs with power-split, synchronised mode shifts can be achieved. This means that the transmission modes are chosen so that the shafts of the engaged clutch have equal speeds [52]. In effect, short shifting times with low drop in output torque are possible [53]. Also, synchronised mode shifts can be carried out with low power losses due to the limited slip. In fact, loss-free toothed clutches are proposed in the commonly adapted Jarchow HMT concept [54].

In non-hybrid HMTs, the smoothness of a synchronised mode shift is largely enabled by the ability of the HST to easily adapt its pressure to external loads. As shown in figure 2.7, the power flow through the HST may change direction during a shift, which results in rapid changes in pressure difference and hydrostatic unit torques. This changes the effect of the losses in the HST, which may be handled with efficiency steps in the control of the hydrostatic units $[21,55]$. In the case of hybrid HMTs, the pressure cannot adapt to external loads due to the high accumulator capacitance. Rapid torque changes are instead realised with large steps in displacement [56]. Consequently, the displacement controller dynamics may be expected to have a negative impact on mode shift smoothness.

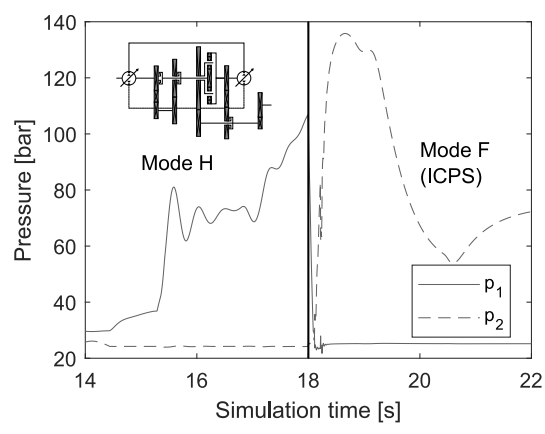

(a) Transmission pressures.

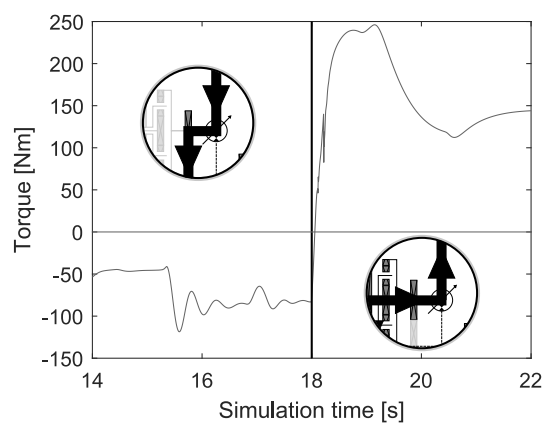

(b) Unit 2 torque.

Figure 2.7 The power flow can change direction in the HST circuit during the mode shift in an HMT. The graphs in this figure show the transmission pressures and the torque on unit 2 when switching from hydrostatic $(H)$ mode to forward (F) ICPS mode (at $T=18$ seconds) in the non-hybrid transmission simulated in $[V I]$, which is hybridised in paper [I]. 


\subsubsection{Powertrain Control}

The impressed system pressure introduces secondary control in a hybrid HMT, and the term is often used to denote the control concept applied in a vehicle, see e.g. [11]. There are, however, some differences between "pure" secondary control as presented in section 2.3.1 and the low-level control of a hybrid vehicle.

Firstly, the pressure is not constant but varies (slowly) with the accumulator's state-of-charge. This means that the output torque and power are limited if the state-of-charge is low, which has to be considered by the energy management strategy [18]. For the low-level controllers, varying pressure also means that secondary control relies on pressure control as the accumulator has minimum and maximum allowed pressure levels.

Secondly, the controller in the secondary control loop is the operator. This means that the operator sets the vehicle output torque to control the vehicle speed, a concept often referred to as torque control [29].

Thirdly, a hybrid vehicle contains an ICE, which requires active speed control to ensure maximum efficiency of operation [57]. In a typical wheel loader of today, the operator uses an accelerator pedal to control the engine speed to, in turn, control output torque via the slip of the torque converter. With a hybrid drivetrain the operator would use the accelerator pedal to control output torque (vehicle speed) directly [2], thereby making the powertrain control responsible for engine speed control.

Compared to pure secondary control, the low-level control of a hybrid HMT is therefore responsible for more than speed control, and needs to consider both the power sources and the driveline. To distinguish a low-level control strategy that considers all these factors, the term powertrain control is used in this thesis.

\section{Engine Speed Control}

For modern heavy working machines, naturally aspirated or turbocharged diesel engines are state-of-the-art. The primary control input is the injected fuel, which, through combustion, translates to a torque on the engine flywheel [58]. A governor adjusts the injected fuel to control the engine shaft speed according to a reference. In the early engines, mechanical fuel injection pumps and governors with centrifugal regulators were used, see e.g. [59, 60], while modern diesel engines usually have common-pressure-rail systems with an electronic governor. Frequently mentioned governor types are droop (proportional control) and isochronous (proportional-integrator control), where droop control is commonly used in vehicle applications [61]. For hybrid HMTs, the governor design is usually not regarded as given, but rather a part of the powertrain control strategy. This approach has a benefit as it allows for easy implementation of disturbance rejection, see e.g. [57,62]. It should be noted, however, that disturbance rejection is possible with a mechanical governor as well, provided that the speed reference value may be adjusted electronically [63]. 
To fulfil stricter regulations on emissions, larger modern diesel engines often require exhaust gas recirculation and variable-geometry turbochargers, which introduce additional engine control inputs [64]. The so-called smoke-limiter function is also used to limit the emissions. Combined with turbo lag, this function causes a delay from desired fuel input to actual output torque during transients [65]. Detailed studies of the transient effects of the smoke-limiter or control inputs other than injected fuel are not within the scope of this thesis but have, for instance, been studied in [66].

\section{Torque Control}

The implementation of torque control is different in hybrid and non-hybrid HMTs. In the non-hybrid case, pressure control may be used [67, 68]. For the hybrid case, torque control is achieved with the principle of secondary control [11]. This solution requires a translation from the hydraulic motor torque to transmission output torque according to the transmission kinematic relationships. For power-split transmissions, different configurations then facilitate torque control implementation to different degrees [29]. For multiple-mode concepts, this aspect poses a challenge when developing a powertrain control strategy. Since each mode may be treated as a unique transmission configuration, a systematic way of realising torque control is required.

\section{Requirements}

In light of the topics discussed in the previous sections, some requirements may be formulated for the powertrain control strategy of a hybrid HMT in a heavy mobile working machine. In summary, this strategy may be expected to:

- be easy to connect to an energy management strategy,

- take displacement controller dynamics into account,

- handle pressure control,

- handle ICE speed control,

- ensure that torque control for the operator is achieved,

- take disturbances from external loads and additional power consumers into account,

- be easy to apply to a multiple-mode power-split transmission configuration.

In this thesis, decoupled control is considered as a suitable strategy to fulfil these requirements. 


\subsubsection{Decoupled Control}

The basic idea of decoupled control is that a MIMO system is converted into a number of Single-Input-Single-Output (SISO) loops that are treated as individual systems. This is done by first implementing a suitable decoupling strategy, usually based on a model of the system in question [69]. In general, a primary motivator of this approach is to cancel out cross-couplings and enable simple implementation and tuning [70]. Another aspect that motivates decoupled control of hybrid HMTs is that one of the controllers may be interpreted as the operator who controls the output speed. This loop is, therefore, out of reach for the control design and should then be as decoupled as possible. In addition, the decoupled strategy may be used to translate the system to one that is independent of the transmission configuration. This feature is highly attractive in a multiple-mode concept, since the configuration changes in between each mode, and the mode shift should be as smooth as possible. The high capacitance of the accumulator also has a decoupling effect, which should facilitate implementation of decoupled control. 


\section{3 \\ Methodology}

To assess the different control aspects, the method illustrated in figure 3.1 was applied during the thesis work. The method is based on the following concepts:

- Modelling

- Simulation

- Experiments

Hardware-in-the-Loop (HWIL) simulation

The method aims at increasing knowledge inductively via the application of established theories on a bounded system which is desired to be controlled. For example, the system boundaries were put around the displacement controller in papers [II, III], while the complete vehicle with engine and transmission was considered in papers $[\mathrm{I}, \mathrm{IV}, \mathrm{V}]$. The different concepts are described in more detail in the following sections.

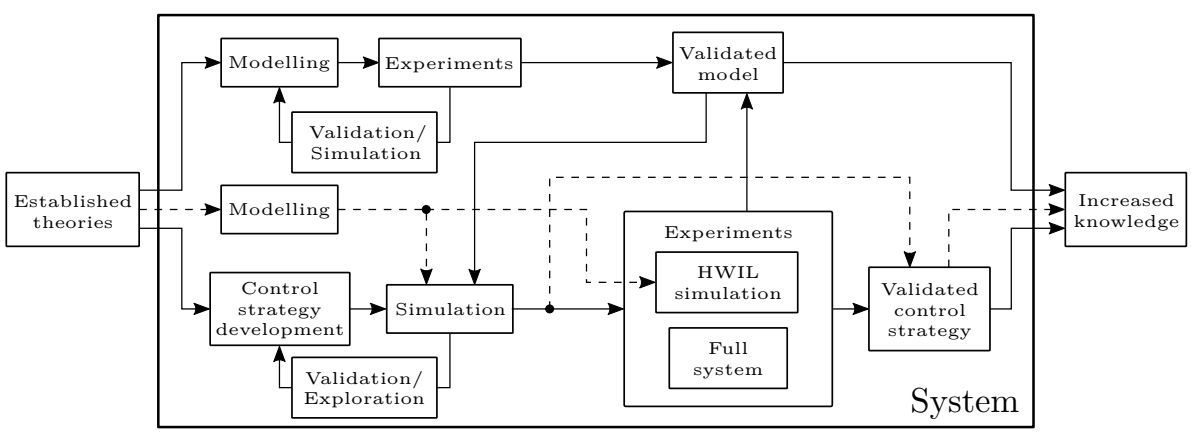

Figure 3.1 Illustration of the method used during the thesis work. Dashed lines imply external experimental validation. 


\subsection{Modelling and Simulation}

To develop an appropriate system control strategy, the system is first modelled. In general, a model may be defined as an abstracted representation of reality. In the scope of this thesis, the definition according to [71] is probably more accurate, where a model of a system is considered as a tool used to answer questions about the system without a need to conduct experiments. The type of models used here are mathematical, where the relationship between the system's physical quantities is represented by mathematical differential equations.

For the development of control strategies of non-linear hydraulic systems, the use of linearised models is well established. Fundamental work was presented by Merritt in 1967 [47], and since then, the concept has been applied to both working hydraulics systems [72, 4], HSTs [73], HMTs [74] and secondary controlled systems [43]. The approximative nature of these models does require support from non-linear models in terms of quantitative fidelity, but provides unique qualitative knowledge [73].

Following the definition of a model, a simulation may be defined as a (virtual) experiment performed on the model [71]. There are several reasons to perform simulations rather than real-life experiments [75]:

- Simulations are cheaper, less time-consuming and safer.

- The full real system may not exist (yet).

- Not all variables are measurable in the real system.

- Models are easier to modify than the real system.

- Simulation allows for suppression of disturbances and effects that are of no or little interest.

For linear models, a big advantage is that they may be conveniently expressed in the frequency domain. Simulations in e.g. bode plots and block diagrams then provide valuable insight into aspects such as stability margins and the causal effects of the system's input signals on its output signals [41]. These simulations may then be complemented with computer-based numerical simulations in the time-domain of both linear and non-linear models with higher quantitative fidelity. In this thesis work, these simulations have been performed with the Transmission Line element Method (TLM). This method is based on the theory of bilateral delay lines which introduces physically motivated time delays to model physical components [76]. This enables the use of distributed equation solvers without introducing numerical errors and consequently, fast, numerically stable simulations with high accuracy may be achieved [77]. For the implementation of TLM, the Hopsan simulation software has been used. 


\subsubsection{Hopsan}

Hopsan is open-source, multi-domain simulation software developed at the division of Fluid and Mechatronic Systems (Flumes) at Linköping University [78]. Since the first version was released in 1977 [79], development has been continuously ongoing. Over the years Hopsan has, for instance, been used for the simulation of HSTs [73] and HMTs [74, VI], and simulation-based optimisation of series hydraulic hybrid vehicles [80]. The current generation, Hopsan $\mathrm{NG}$, is object-oriented, written in $\mathrm{C}++$ and uses a fixed-step solver for TLM implementation [81].

In Hopsan, a simulation model is divided into a number of subcomponents. Each subcomponent then represents a physical component, e.g. a hydraulic pump/motor or a mechanical gear. The components are connected with power ports that correspond to physical interfaces with the flow/effort variables of the specific power domain, as commonly used in bond graph modelling [71]. Due to TLM, the power ports also contain wave variables and characteristic impedance. See $[77,79]$ for further details on the implementation of TLM in Hopsan.

During the work presented in this thesis, Hopsan subcomponent models have been created and enhanced continuously. These have then been combined with components from Hopsan's default library to create different system models depending on the question currently being investigated. An example of the system model used in paper [IV] is shown in figure 3.2. In the appended papers, some of the subcomponents are derived in detail while others are described qualitatively. Component model derivations not provided in the appended papers are therefore included in appendix $\mathrm{A}$ in this thesis.

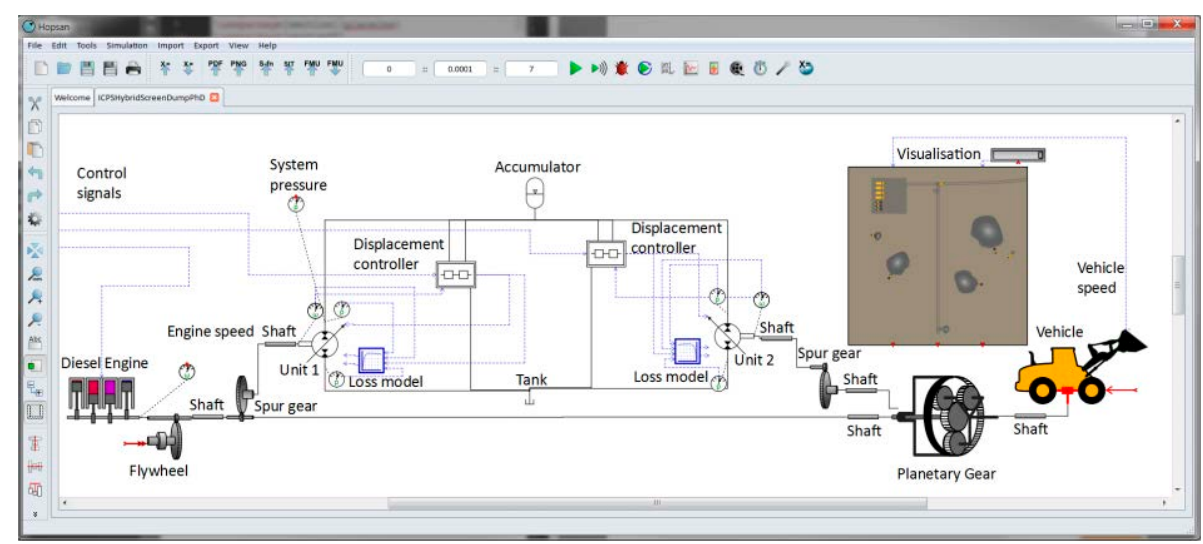

Figure 3.2 Hopsan system model used for offline simulation of the ICPS hybrid in paper [IV]. 


\subsection{Model Validation}

To ensure that the model captures the relevant system behaviour, it is validated against real system experiments. The validation process is iterative and creative, where an experiment is first carried out on the real system and then repeated in simulation. The simulated and measured results are compared, the model parameters and equations are updated, and new experiments are conducted. The validation process is thus a loop in which each model generation is a new hypothesis which is falsified to enhance the model.

As the model fidelity increases, the number of model parameters tends to grow rapidly. This aspect makes it difficult to find the "best" parameter set for a certain model generation. To handle this problem, the built-in optimisation feature in Hopsan was frequently used during the thesis work. Figure 3.3 shows an example of the model used for validation of the displacement controller models derived in paper [II]. The reference displacement setting, system pressure and shaft speed logged during a measurement are sent as input to the model. The optimisation loop then varies the model parameters (e.g. friction, valve break frequency) to minimise the absolute average error between the simulated and measured control piston pressure and resulting relative displacement.

A key aspect during the validation process, is the definition of "relevant system behaviour", which determines both what system behaviour is trying to be captured and, in turn, what experiments are conducted. When the model's purpose is control strategy development, dynamic properties such as time delays, damping and time constants are of high importance, but also non-linearities and static gains.

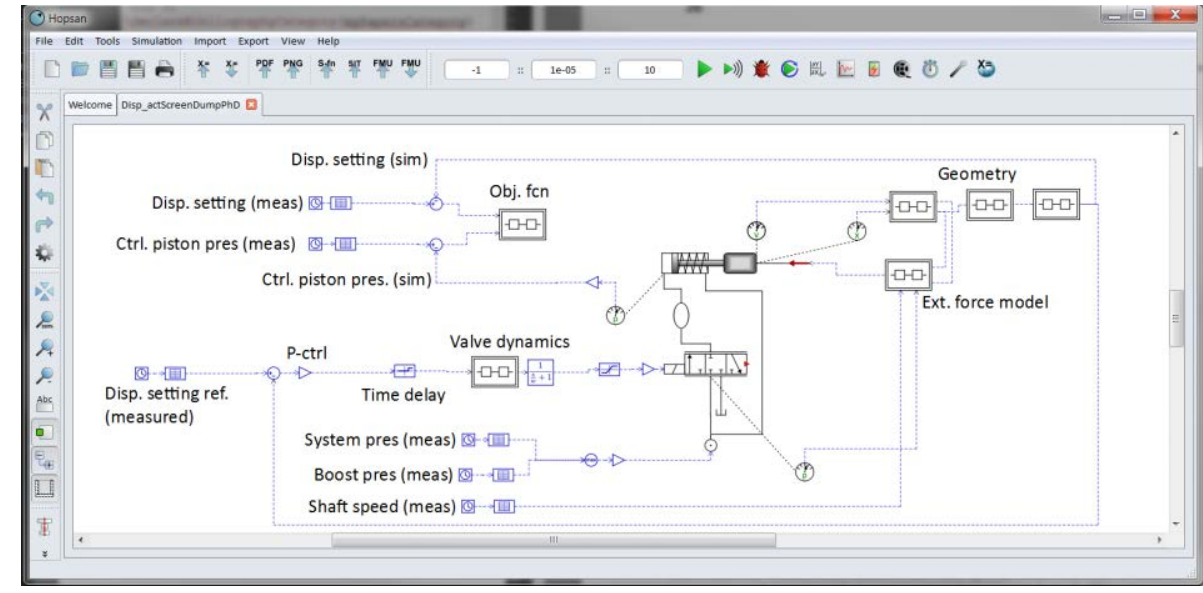

Figure 3.3 Hopsan system model used for validation of the displacement controller model in paper [II]. 


\subsection{Control Strategy Development and Validation}

After the model has been validated it is used for control strategy development. Here, the model is explored, and different control strategy candidates are tested and rejected in simulation. As illustrated in figure 3.1, this process acts as validation of the control strategy, quite similar to the model validation process, with the difference that the falsification is done in simulation. Eventually, one candidate is found suitable for the control of the real system, and is validated in an experiment. Being based on a model, there is always a difference between the strategy's simulated and real performance. However, since the model is validated, this difference should be sufficiently small to either accept, or handle with fine-tuning of the control parameters. If the difference is unacceptably large, it means that the strategy is based on the wrong assumptions. Consequently, this "final" experiment also validates the model which, in turn, may lead to a new control strategy candidate.

Similar to the model validation, a difficulty lies in defining "suitable" when evaluating the control strategy. In turn, this aspect depends on the requirements of the specific application. During the thesis work, the requirements have been obtained from previously published research and discussions with experts in the field.

\subsection{External Experimental Validation}

When large systems with high complexity and multiple components are considered, experimental validation of all components is not always possible. In this case, the control strategy development relies on externally validated models, as indicated with dashed arrows in figure 3.1. This aspect also affects the control strategy validation. When available, the full system may be used in this experiment. When not, the strategy validation can be performed in offline simulation or HWIL simulation.

In the work presented in this thesis, all experiments were carried out in the test rig described in section 3.6. Models for system components not validated in the rig were based on validated models from academic papers and text books.

\subsection{Hardware-in-the-Loop Simulation}

An HWIL simulation may be defined as a time-domain simulation of a model that contains both physical (hardware) and virtual (software) representations of a studied system. In the literature, HWIL simulation commonly refers to Controller-Hardware-in-the-Loop (CHIL) simulation, which is the real-time testing of control code in a physical control unit (the hardware) that interacts with software system models. This interaction takes place in the signal domain with low power levels. In this thesis, HWIL simulation rather refers to 
Power-Hardware-in-the-Loop (PHIL) simulation, which, in contrast to CHIL simulation, has substantial power amplification present in the hardware/software interface [82]. With this feature, HWIL simulation may be interpreted as an extension to pure offline simulation, where any model component may be replaced with its hardware equivalent, for instance a hydraulic pump or an electric motor. This interpretation of HWIL simulation is illustrated in figure 3.4, where the concept is regarded as a middle-way alternative between pure offline simulation and full system experiment when validating a control strategy.

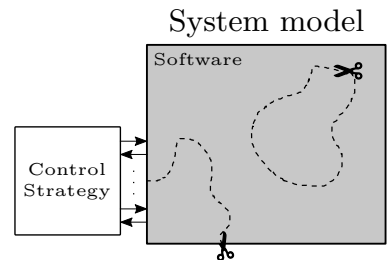

(a) Offline simulation.

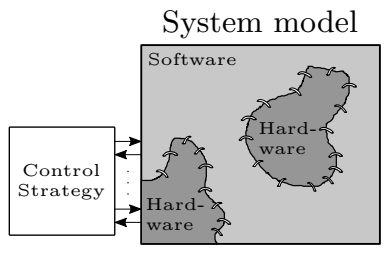

(b) HWIL simulation.

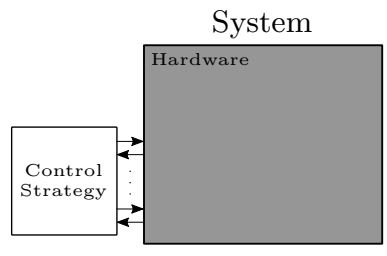

(c) Full system experiment.

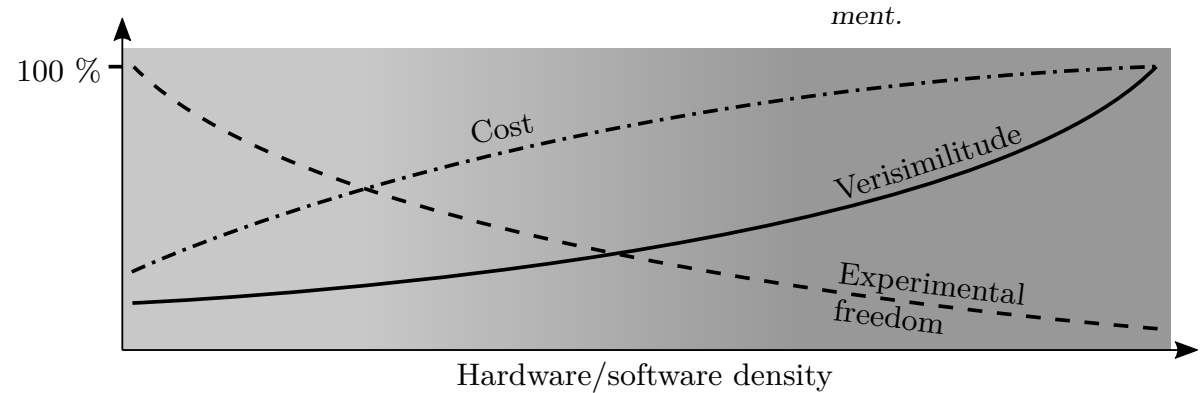

(d) Cost, experimental freedom and verisimilitude.

Figure 3.4 Conceptual illustration of HWIL simulation as a tool for control strategy validation.

The use of HWIL simulation is relatively common within fluid power research in academia. In an early example (1989), Krus and Palmberg [83] used a hydraulic servo valve to simulate a load-sensing system connected to a real lorry crane, in a concept referred to as "hybrid simulations". A load simulator for HSTs was developed by Jansson et. al. in 1993 [84], and used for the testing of control strategies by Lennevi and Palmberg in 1995 [85]. In 1999 [74], Sannelius used HWIL simulations in the testing of control strategies for the two-motor transmission. In 2002, Zhang and Alleyne [86] used a general vehicle powertrain simulator in the development of MIMO control strategies for earthmoving vehicles. Each power consumer in the vehicle (steering, transmission, working hydraulics etc.) was then simulated by a hydraulic motor, while the prime mover was simulated with an induction motor. In 2014, Sprengel 
and Ivantysynova [87] used HWIL simulation for control strategy evaluation of their blended hydraulic hybrid. In the automotive industry, the concept has traditionally been limited to CHIL. According to Fathy et. al [88], however, the development of simulation and testing facilities has transformed HWIL simulation from a control validation tool to a full system integration tool.

The choice of HWIL simulation in favour of any of its two extremes may be motivated by comparing their respective pros and cons, as illustrated in figure $3.4 \mathrm{~d}$. Offline simulations offer low cost and high experimental freedom since, for instance, a model is easy to modify and allows for observation of all the system variables (recall section 3.1). On the other hand, a full system experiment offers high verisimilitude (truthlikeness). That is, the more hardware that is included in the experiment, the closer to reality it is (should be).

\subsubsection{The Hardware-in-the-Loop Interface}

The key to successful HWIL simulation lies in the hardware/software interface, illustrated in figure 3.5. On a conceptual level, the interface may be compared with power ports similar to those used in bond graph modelling [87]. In the HWIL power port, the flow/effort variable is then determined by the software, while the effort/flow variable is determined by the hardware. At the implementation level, this is realised with control [88]:

“...an $H(W) I L$ simulator is in essence a control system whose virtual components command its hardware to 'track' a hypothetical reference 'system."

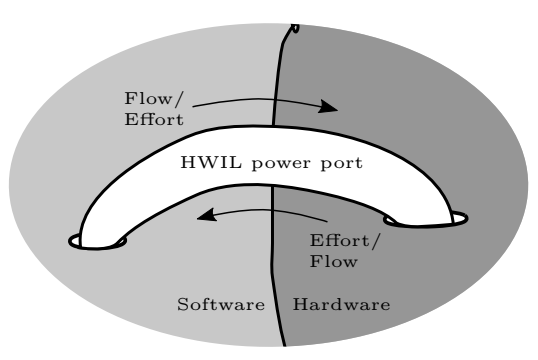

(a) Conceptual (modelling) level.

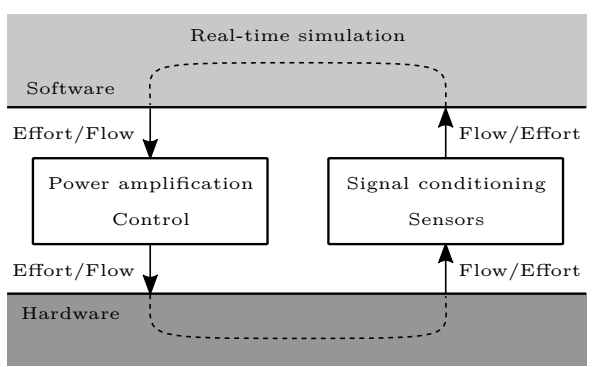

(b) Implementation level, adapted from $[82,88]$.

Figure 3.5 Different levels of the HWIL interface.

The dependence on real-time control introduces a number of key enablers of HWIL simulation, as listed by Fathy et. al. [88]. For instance, high bandwidth and accuracy of the control are required to maximise the reliability of the 
results. Consequently, a strong focus in previous research has been on control aspects of HWIL simulation, e.g. [84, 74, 89]. Another important enabler is the hardware/software integration, which may be divided into partitioning and connection causality.

Partitioning relates to the question of how much, and which parts of the studied system should be represented as hardware or software. The answer to this question is usually a result of the combination of the scope of the investigation and what is feasible (recall figure 3.4d). In the context of transmission development, Sannelius [74] distinguishes between component focus, where a system is simulated around a new (hardware) component, and system focus, where the new component is simulated in an existing (hardware) system. If a specific HMT concept is investigated, it is convenient to represent the engine and vehicle as software and the transmission as hardware [87]. In [84], where an HST is in focus, the engine is represented as a servo valve-controlled pump/motor, while the vehicle is represented as an equivalent inertia (flywheel) with simulated load torque. When aspects such as emissions and fuel efficiency are studied, the engine is usually represented as hardware connected to a dynamometer which emulates a vehicle, then referred to as Engine-in-the-Loop [90]. With so-called rolling road or chassis dynamometers, the complete vehicle is present as hardware, while its surroundings are emulated [91]. The partitioning also determines in which power domain the HWIL interface is inserted, which in turn affects the control implementation. For fluid power systems and HMTs, hydraulic (pressure/flow) or mechanic rotational (torque/angular velocity) interfaces are most often used [74].

Connection causality relates to the question of whether the interface's flow variable (flow/speed) should be determined by the hardware, while the effort variable is determined by the software (pressure/torque), or vice versa. The answer to this question is highly influenced by the behaviour of the hardware and the control performance of the HWIL interface. For instance, the fundamental difference in the dynamic behaviour of hybrid and non-hybrid HSTs (recall section 2.2.1) motivated a switch from torque to speed control of the output shaft during HWIL simulation of the blended hybrid in [87]. Another example of causality-related difficulties is inertia simulation. If the software controls the speed of a transmission output shaft, vehicle inertia simulation can be carried out via integration of the measured shaft torque. On the other hand, if the software controls the shaft torque, inertia simulation is carried out based on angular acceleration, which often needs to be estimated as the speed time derivative [89]. Another alternative is to represent vehicle inertia as a flywheel and add air drag and other losses via torque control. This is often carried out in rolling road dynamometers, where a set of flywheels can be combined to simulate different vehicle sizes [91]. In a combined approach, Jansson et. al. [84] found that the inertia of the flywheel could be increased by around $240 \%$ through estimation of the acceleration, and that higher increases were limited by the stability of the control loop. 
Fixed-step integration is another key enabler of HWIL simulation [88]. In this sense, the use of TLM for software system representation is highly motivated, as it enables the use of numerically robust distributed solvers for efficient real time simulation [92]. It also motivates the use of TLM for offline simulation of the full system, since the same model can be re-used during the HWIL simulation without making reductions in model fidelity [5].

\subsection{Test Rig}

The test rig described in this section has been used for evaluation of control strategies in HMTs in previous research carried out at the division [73, 74, $93,5]$. The rig was modified for the work carried out in this thesis and has been used for all experiments presented. More specifically, it was used for HWIL simulation for powertrain control strategy validation in paper [V], and for model validation and full system control strategy validation of displacement controllers in papers [II] and [III], respectively.

\subsubsection{Hardware-in-the-Loop Implementation}

The test rig is shown in figure 3.8. The basic idea of the setup is to enable HWIL simulation of the generic hybrid HMT shown in figure 1.1. In relation to the previously discussed topics, the following implementations are made:

Partitioning: The hardware part of the simulation is the hydraulic circuit, while engine, transmission subsystem and vehicle are represented as software. This partitioning facilitates testing of different transmission concepts by altering the software model. The hydraulic circuit contains two Bosch A11VO four-quadrant in-line axial piston units with $110 \mathrm{~cm}^{3} / \mathrm{rev}$ displacement. These are equipped with electro-hydraulic displacement actuators that are controlled with external feedback, see section 4.2 and papers [II, III]. They are connected in open circuit with two 20-L piston accumulators connected in parallel on the high-pressure side. A servo-valve is connected to the high-pressure side to simulate the effect of flow disturbances.

Connection causality: The shaft torques of the hydraulic units are measured in the test rig and sent to the model, which calculates the corresponding shaft speeds. These values are sent to the rig controller, which controls the actual shaft speeds in closed loop with a servo valve-controlled pump/motor connected to each hydrostatic transmission unit. See Appendix B for details concerning the rig controller. This causality (measure torque $\rightarrow$ control speed) is motivated by the fact that the hydrostatic units act as torque sources due to the impressed system pressure [87]. No flywheels are used on the shafts, since all vehicle and engine inertial effects are present in the model. 
Real-time and fixed-step integration: The software model is implemented as a Hopsan model executed on a National Instruments PXI computer that runs in real time with a sampling frequency of $1 \mathrm{kHz}$. This computer also handles the control of the HWIL interface. The full Hopsan offline simulation model is re-used by replacing the hydrostatic circuit with torque sources and adding communication ports, compare figures 3.2 and 3.6. Communication with the PXI computer for software model/controller updates and during HWIL simulation in real time is carried out on a LabVIEW-based Graphical User Interface (GUI) called Viking [94], see figure 3.7. See [95] for details on the implementation of the real-time Hopsan simulation and paper [II] for further details on the data acquisition system hardware.

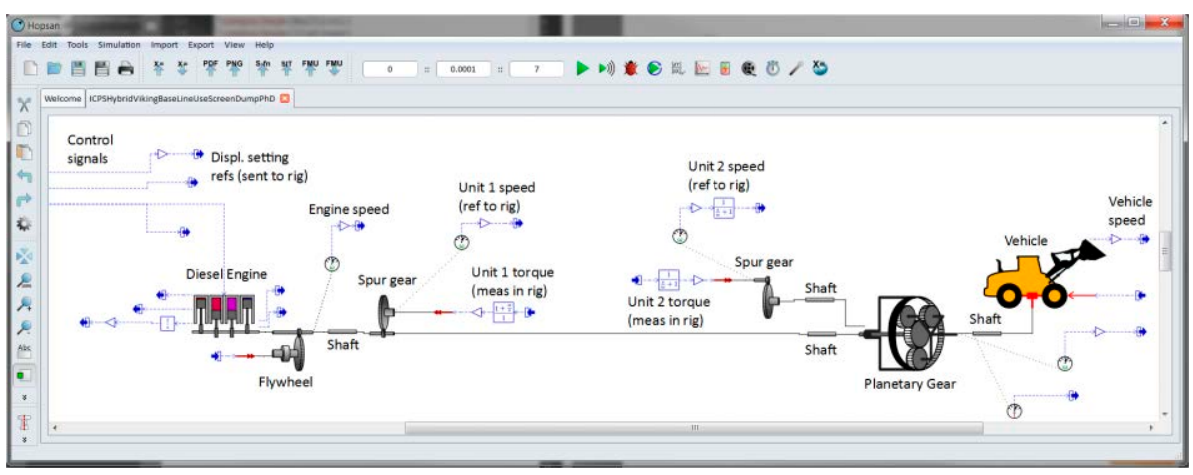

Figure 3.6 Hopsan system model used for HWIL simulation of the ICPS hybrid in paper $[V]$. Note that input/output interface components and signal noise filters have been added compared to the model in figure 3.2.

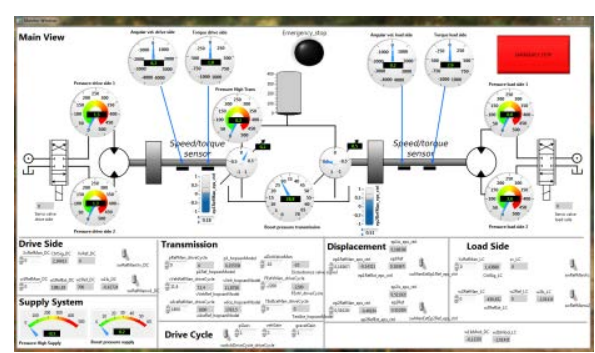

(a) Main view panel.

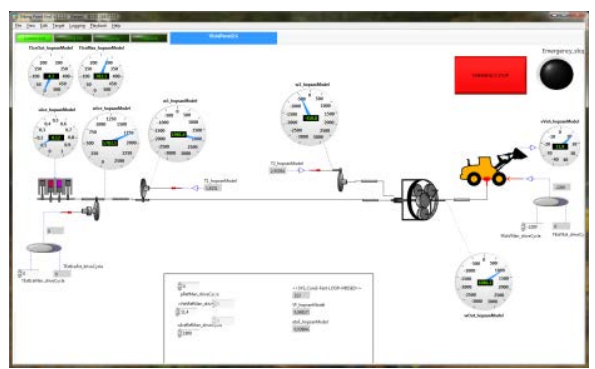

(b) Hopsan model panel.

Figure 3.7 View panels from the Viking GUI. 


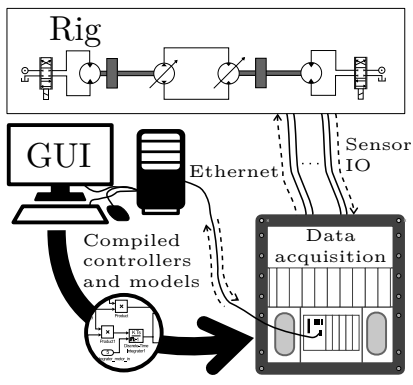

(a) Communication.

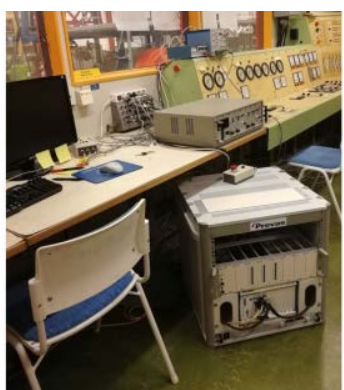

(b) Control room.

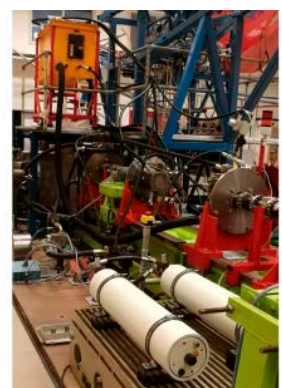

(c) Tank and accs.

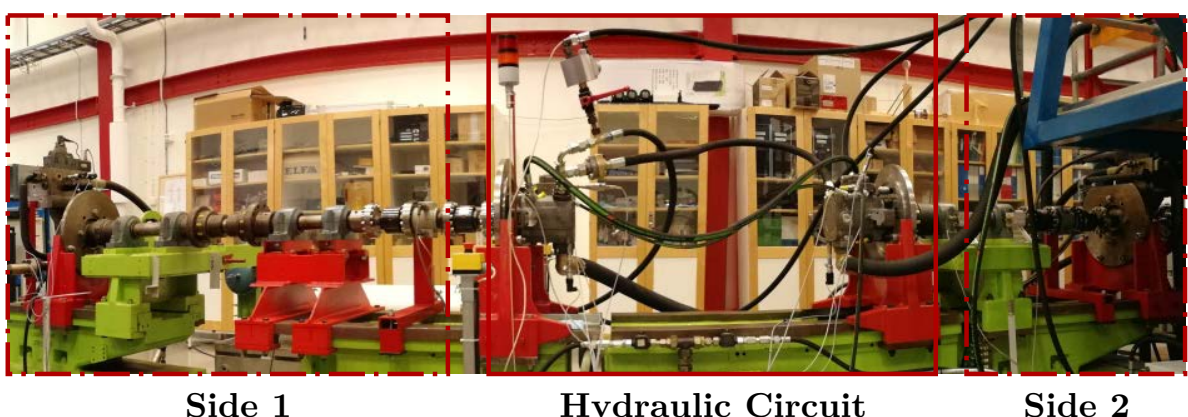

(d) Rig main view.

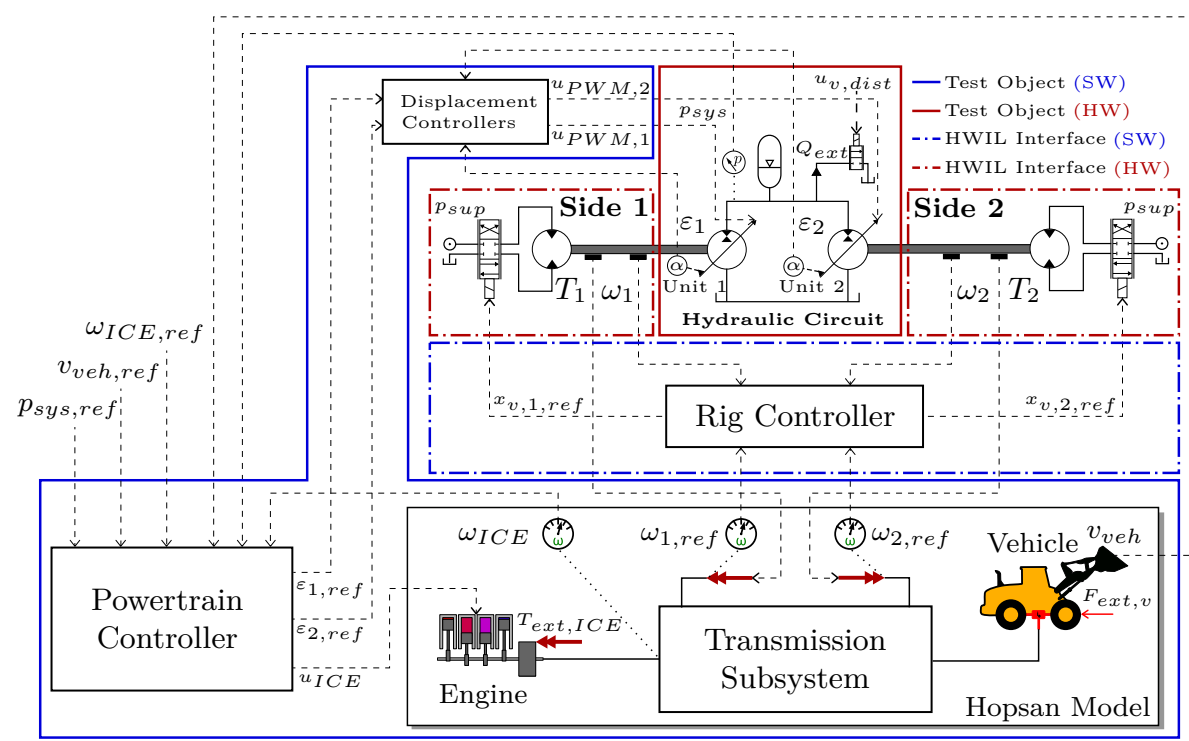

(e) HWIL operation principle. Note that, compared to the system in figure 1.1, the operator is included in the powertrain controller. $S W=$ Software, $H W=$ Hardware.

Figure 3.8 Overview of the HWIL simulation test rig used in the thesis work. 


\section{4 \\ Contributions}

The control aspects highlighted in chapter 2 and in figure 1.1 have been investigated in the appended papers. This chapter summarises the primary findings.

\subsection{Mode Shifting}

On a powertrain control level, the mode shift is often simplified to a discrete event in which the transmission subsystem switches instantaneously from one single-mode configuration to another. In paper [I], continuous aspects of mode shifting in hybrid HMTs are explored. The approach to this exploration is that a non-hybrid HMT is hybridised by adding an accumulator to the hydraulic circuit. As previously discussed, this action changes the dynamic behaviour of the pressure in the circuit. Instead of being a consequence of the load, it is rather determined by the accumulator's state-of-charge, and the hydraulic unit torques are determined by their displacements.

During a mode shift, one clutch is engaged, and another one is disengaged. After the new clutch has been engaged, the kinematic relationships of the transmission subsystem have changed. For a smooth mode shift, the hydraulic circuit needs to adapt to this change within the mode shifting event. As discussed in section 2.3.3, this adaptation is neatly handled in non-hybrid HMTs with synchronised mode shifts. The variator speeds are then equal in the two modes, but the variator power flow and torques change direction during the shift. This change is handled automatically in the non-hybrid variator, as the pressure adapts to the load. In the hybrid case, however, rapid changes in torque are realised by rapid changes in displacement, and too slow a displacement controller response would affect the mode shift negatively.

To study the severity of this effect, a transmission concept with synchronised modes shifts, shown in figure 4.1, was studied in simulation in paper [I]. The concept has a pure hydrostatic mode near zero vehicle speed (clutch $S_{h}$ is engaged) and an ICPS mode in forward (clutch $S_{f w d}$ ) and reverse (clutch $S_{\text {rev }}$ ). 


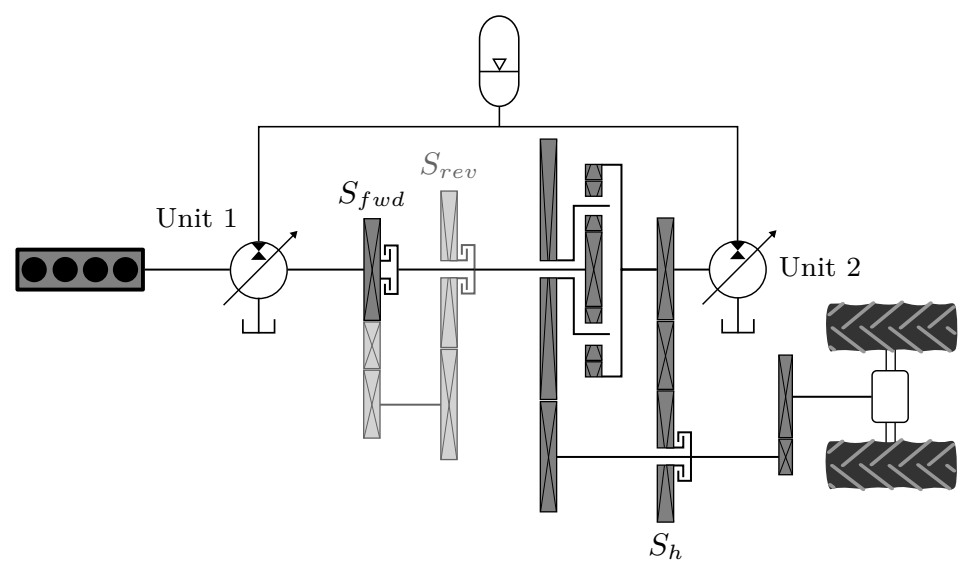

Figure 4.1 Hybrid multiple-mode HMT studied in paper [I]. The clutch $S_{\text {rev }}$ was not used in the investigation.

Figures $4.2 \mathrm{a}$ and $4.2 \mathrm{~b}$ show results of a simulation of the hybrid HMT in figure 4.1 during a shift from pure hydrostatic to ICPS mode (clutches: $S_{h} \rightarrow S_{f w d}$ ) at constant acceleration. Unit 2 determines the output torque in both modes and controls the vehicle speed. As seen in figure $4.2 \mathrm{~b}$, the mode shift implies a step in Unit 2's relative displacement from approximately 0.2 to -0.3 . Due to the dynamics of the displacement controller, this does not happen instantaneously, which results in a disturbance in vehicle speed.

\section{The Effect of the Displacement Controller Response}

Figure 4.2c shows the relative drop in vehicle speed for different rise times of unit 2. There is a clear trend in terms of more severe disturbance for a slower displacement controller. It may also be observed that the severity of the disturbance is related to the load, as larger output torques require larger relative displacement and therefore larger steps in relative displacement during the mode shift. Another noteworthy phenomenon is that the drop increases if the displacement actuators are too fast. This is explained by the fact that there are also some dynamics in the clutches, and if the displacement controllers are too fast they will affect the output torque before the clutches have changed the kinematic relationships. In turn, this stresses the importance of synchronising the clutches with the displacement controllers. 


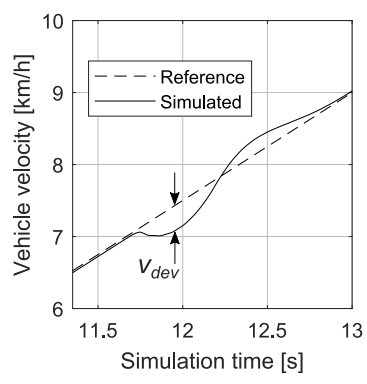

(a) Vehicle speed.

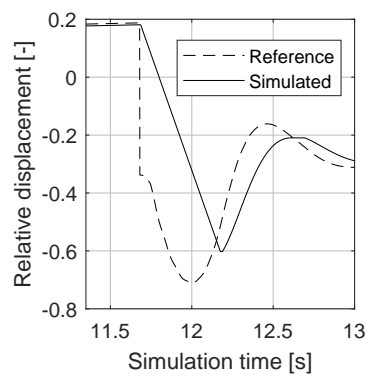

(b) Unit 2's relative displacement.

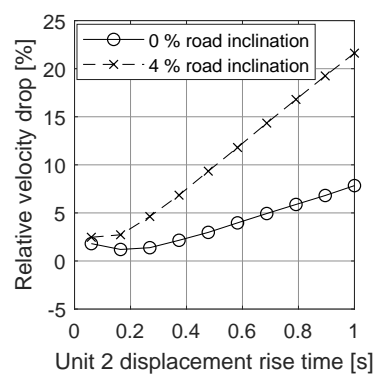

(c) Relative drop in vehicle speed due to mode shift for different responses of unit 2 .

Figure 4.2 (a) and (b): Simulation of a mode shift from hydrostatic to ICPS mode in the hybrid multi-mode HMT in figure 4.1. (c) shows how the velocity drop shown in (a) varies for different loads and displacement controller responses. Displacement rise time is defined as the time it takes to realise $\varepsilon: 0 \rightarrow 1$. The relative velocity drop is calculated as the maximum relative velocity deviation after the shift $\left(v_{\text {dev }}=\frac{v_{v e h, r e f}-v_{v e h}}{v_{v e h, r e f}}\right)$.

\subsection{Displacement Control}

To understand the dynamic behaviour of displacement controllers, models of the axial piston units used in the test rig (see section 3.6) were derived and validated in paper [II]. Displacement control strategies were developed in paper [III]. This section summarises the primary findings of papers [II, III].

The displacement of the studied unit is varied by an electrohydraulic actuator mechanism, shown schematically in figure 4.3. The control problem is equivalent to a three-way valve controlled piston position servo, where the controller, $F_{\varepsilon}(s)$, sets the Pulse-Width-Modulated (PWM) signal, $u_{P W M}$, of a proportional spool valve to vary the swash plate angle, $\alpha . \alpha$ is, in turn, measured with a Hall effect sensor, which enables external closed-loop control of the displacement setting, $\varepsilon$. 


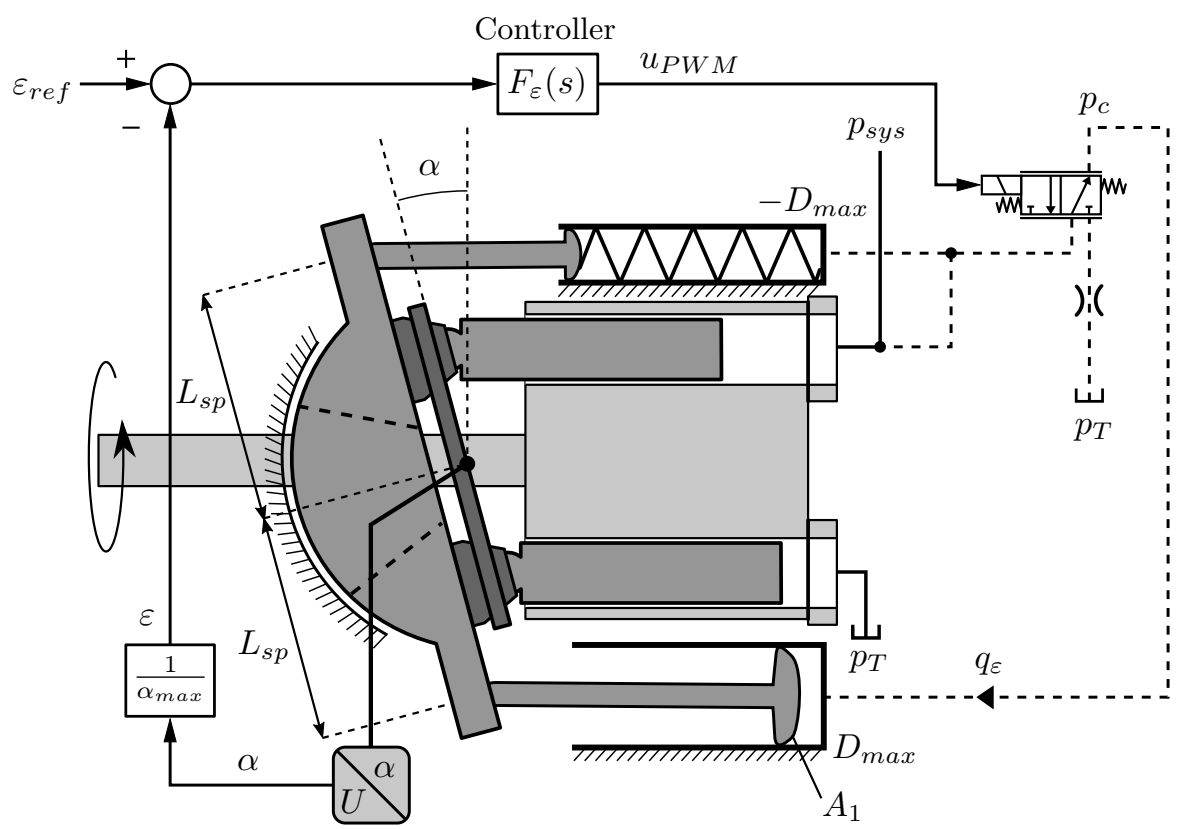

Figure 4.3 Displacement actuator mechanism in the axial piston unit used in the test rig.

\subsubsection{Linearised Model}

In the derivation of this model, an important assumption is that $p_{\text {sys }}$ is impressed. Also, the hydraulic eigenfrequency, as defined in [47], is assumed to be very high and dominated by the valve dynamics. This assumption is motivated by the small piston chamber volume and low inertia of the moving masses [48]. For the studied unit, it was found that a first order system with lumped valve and solenoid dynamics agreed closely with the experiments [II]. The open-loop transfer function from valve input signal, $u_{P W M}$, to relative displacement, $\varepsilon$, may then be written as:

$$
G_{O, \varepsilon}(s)=\frac{\varepsilon}{u_{P W M}}=\frac{K_{s}}{s\left(\frac{s}{\omega_{v}}+1\right)}
$$

where $K_{s}$ is the lumped static loop gain:

$$
K_{s}=\frac{K_{P W M} K_{q}}{A_{1} L_{s p} \alpha_{\max }}
$$


The valve flow gain, $K_{q}$, is determined according to:

$$
K_{q}=-\frac{\partial q_{\varepsilon}}{\partial x_{v}}=\left\{\begin{array}{l}
C_{q} d \pi \sqrt{\frac{2}{\rho_{\text {oil }}}\left(p_{c, 0}-p_{T}\right)}, \quad x_{v} \geq 0 \\
C_{q} d \pi \sqrt{\frac{2}{\rho_{\text {oil }}}\left(p_{\text {sys }, 0}-p_{c, 0}\right)}, \quad x_{v}<0
\end{array}\right.
$$

where $p_{s y s, 0}$ and $p_{c, 0}$ are linearisation points of the system and control piston pressures. $p_{s y s, 0}$ varies slowly with the accumulator's state-of-charge, while $p_{c, 0}$ is a consequence of the control piston force equilibrium and the area ratio between the two pistons [II].

\subsubsection{Control}

The pure integrator in $G_{O, \varepsilon}$ requires a feedback loop for stabilisation. Two candidates for $F_{\varepsilon}$ were studied in paper [III]. The first, a standard Proportional controller (P-controller):

$$
F_{\varepsilon}=K_{\varepsilon}
$$

The second, a Proportional controller with lead compensator (P-leadcontroller):

$$
F_{\varepsilon}(s)=K_{\varepsilon} \frac{\frac{s}{\omega_{F, 1}}+1}{\frac{s}{\omega_{F, 2}}+1}
$$

Neither candidate contains purely integrating elements. This is motivated partly by the existence of a pure integrator in $G_{O, \varepsilon}$ and partly by a desire to avoid problems caused by integrator wind-up when the controller is used as an inner loop in a full system.

\subsubsection{Parametrisation: Pole Placement}

Both controller candidates are parametrised by placing the poles of the closedloop system:

$$
G_{\varepsilon}(s)=\frac{F_{\varepsilon} G_{O, \varepsilon}}{1+F_{\varepsilon} G_{O, \varepsilon}}=\frac{1}{\frac{s^{2}}{\omega_{a}^{2}}+\frac{2 \delta_{a}}{\omega_{a}} s+1}
$$

where the desired closed-loop resonance frequency, $\omega_{a}$, and relative damping, $\delta_{a}$, are given as input.

\section{P-controller}

Equations (4.1) and (4.4) with identification of $\omega_{a}$ and $\delta_{a}$ in equation (4.6) yield that the controller gain, $K_{\varepsilon}$, in the P-controller may be chosen with either $\omega_{a}$ (equation (4.7)) or $\delta_{a}$ (equation (4.8)) as input. 


$$
\begin{aligned}
& K_{\varepsilon}=\frac{1}{\omega_{v} K_{s}} \omega_{a}^{2} \\
& K_{\varepsilon}=\frac{\omega_{v}}{4 K_{s}} \frac{1}{\delta_{a}^{2}}
\end{aligned}
$$

Equations (4.7) and (4.8) yield the following relationship between $\delta_{a}$ and $\omega_{a}$ :

$$
\omega_{a} \delta_{a}=\frac{\omega_{v}}{2}
$$

With a $\mathrm{P}$-controller there is thus a compromise between damping and resonance (i.e. response), and to increase both of them simultaneously a faster valve is required.

\section{P-lead-controller}

Equations (4.1) and (4.5) with identification of $\omega_{a}$ and $\delta_{a}$ in equation (4.6) yield that $\omega_{F, 1}$ and $\omega_{F, 2}$ in the P-lead-controller may be chosen according to equations (4.10) and (4.11), respectively.

$$
\begin{gathered}
\omega_{F, 1}=\omega_{v} \\
\omega_{F, 2}=2 \omega_{a} \delta_{a}
\end{gathered}
$$

The controller gain, $K_{\varepsilon}$, may be chosen according to:

$$
K_{\varepsilon}=\frac{\omega_{a}}{2 K_{s} \delta_{a}}
$$

With the P-lead-controller, the damping and resonance are decoupled and may therefore be chosen independently of each other. Equation (4.10) means that there is a pole cancellation of the valve dynamics. With a $\omega_{F, 2}$ significantly higher than $\omega_{v}$, a significantly faster response with maintained damping is therefore possible with the P-lead-controller compared to the P-controller.

\subsubsection{Simulations and Measurements}

Figure 4.4 shows measured and simulated step responses for the P-controller and the P-lead-controller for different values of $\omega_{a}$ and $\delta_{a}$. The P-controller was designed with a desired $\omega_{a}$ as input according to equation (4.7). For both controllers, $\omega_{v}=26.6 \mathrm{rad} / \mathrm{s}$ and $K_{s}=0.76$ were used. These values correspond to a shaft speed of $1000 \mathrm{rpm}$ and a system pressure of $100 \mathrm{bar}$. The compromise with the $\mathrm{P}$-controller is well illustrated in figure 4.4, as a faster response leads to decreased damping. In contrast, the response time of the P-lead-controller may be improved with a constant relative damping. The P-lead-controller manages responses with $\omega_{a}=90 \mathrm{rad} / \mathrm{s}$ with a relative damping of $\delta_{a}=0.8$, while the $\mathrm{P}$-controller is limited to $\omega_{a}=20 \mathrm{rad} / \mathrm{s}$ for approximately the same damping. 


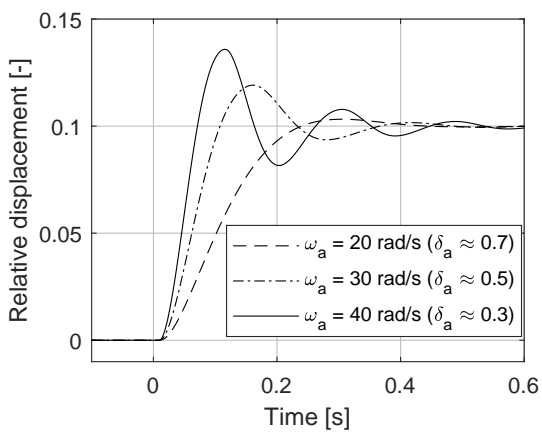

(a) P-controller, simulated.

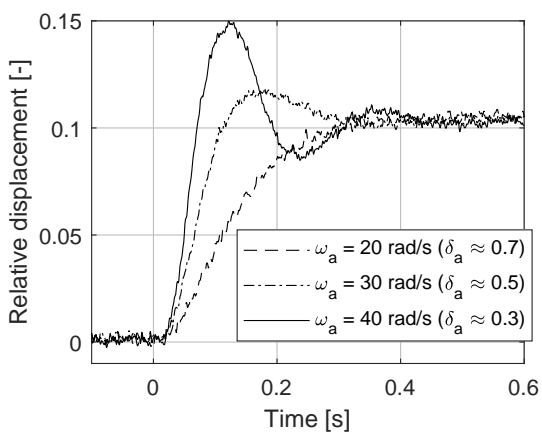

(c) P-controller, measured.

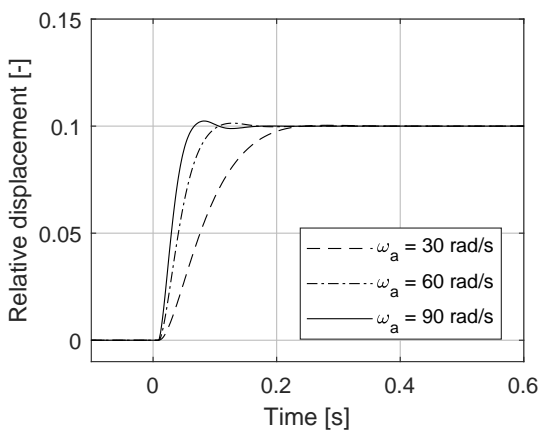

(b) P-lead-controller with $\delta_{a}=0.8$, simulated.

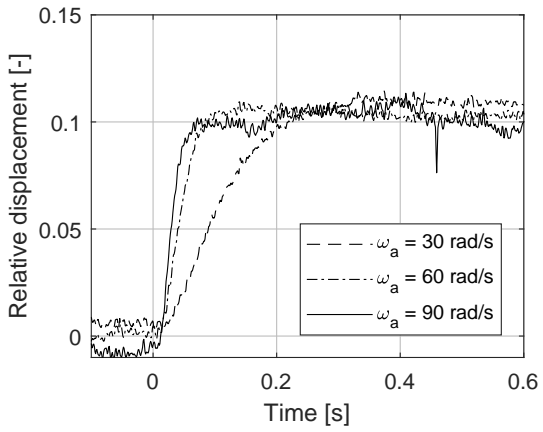

(d) P-lead-controller with $\delta_{a}=0.8$, measured.

Figure 4.4 Simulated (top) and measured (bottom) step responses with different values of $\omega_{a}$ with P-controller (left) and P-lead-controller (right). The simulations were made with the model derived in paper [II]. The results were obtained for a shaft speed of $1000 \mathrm{rpm}$ and system pressure of $100 \mathrm{bar}$.

For larger step magnitudes, see figure 4.5, non-linearities affect the control performance. Primarily, these are saturation in valve flow and limitation in valve input signal. The saturated valve flow may be observed as constant velocity in the beginning of the steps, while the limited valve input signal causes an over-damped behaviour in the end of the larger steps.

Figure 4.6 shows measured time constants for different step sizes and system pressures. The displacement controller becomes slower as the step size increases, which is due to the limitations in voltage and valve stroke. For step sizes below 0.3, the pressure has little effect on the response. For larger steps, increased pressure decreases the time constant primarily because of the maximum deliverable flow of the valve that increases with the pressure. 


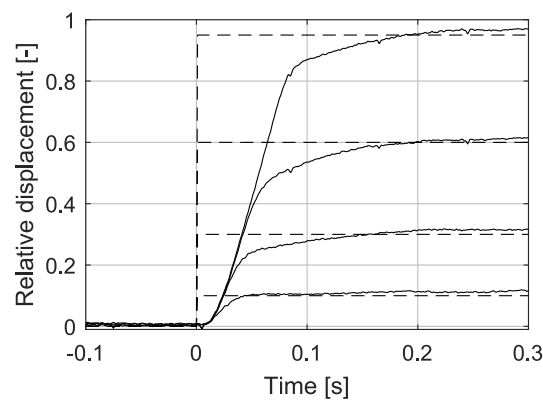

(a) Rig measurements.

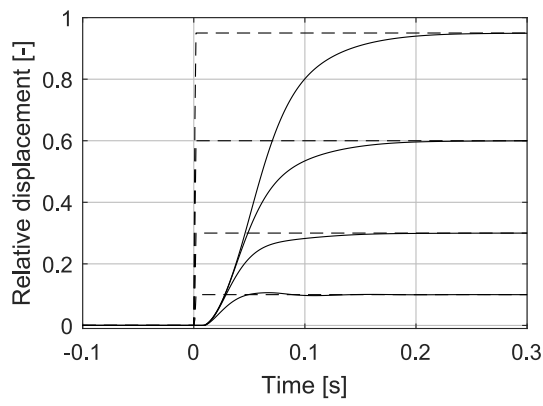

(b) Hopsan simulations.

Figure 4.5 Measured (a) and simulated (b) step responses at $1000 \mathrm{rpm}$ and $200 \mathrm{bar}$ with $\omega_{a}=90 \mathrm{rad} / \mathrm{s}$, and $\delta_{a}=0.9$ with a $P$-lead-controller. The simulations were made with the model derived in paper [II].

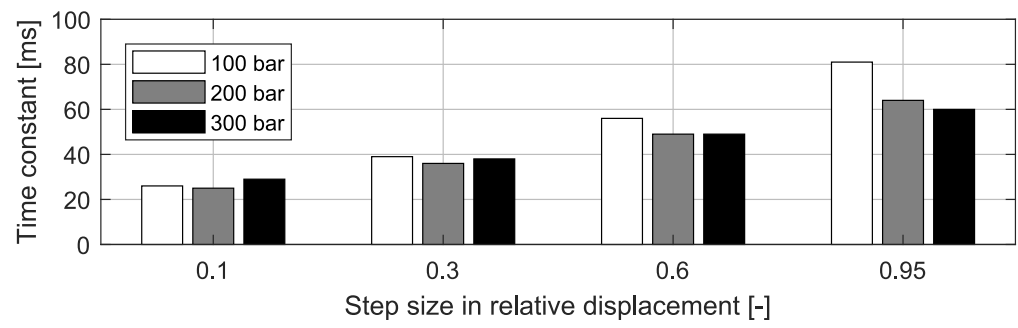

Figure 4.6 Measured time constants $(0 \rightarrow 63 \%)$ for different relative step sizes and pressures. The same controller as the one used for the results in figure 4.5 was used in all cases. All tests were carried out at a shaft speed of $1000 \mathrm{rpm}$.

\subsubsection{Summary}

A key component that limits the response of the displacement controllers is the control valve. The valve's bandwidth dominates the dynamics for small variations in displacement, while saturation in flow and input signal limits the response for larger variations. The P-lead-controller may be used to significantly reduce the influence of the valve dynamics, but valve flow saturation may only be solved with a bigger valve. With knowledge of the valve dynamics and the static loop gain, pole placement may be used to parametrise the P-lead-controller in a convenient manner. Instead of trimming the specific control gains and frequencies manually, the resonance $\omega_{a}$, and damping, $\delta_{a}$, of the closed-loop response can be used as direct input from a control designer. The appropriate choice of $\omega_{a}$ and $\delta_{a}$ depends on the outer loop. This is studied in more detail in the following section. 


\subsection{Powertrain Control}

A decoupled MIMO control approach for powertrain control was proposed and tested in simulation in paper [IV]. In paper $[\mathrm{V}]$, this approach was tested in HWIL simulations and compared to a baseline approach based on proportional SISO control. This section summarises the primary findings of papers [IV, V].

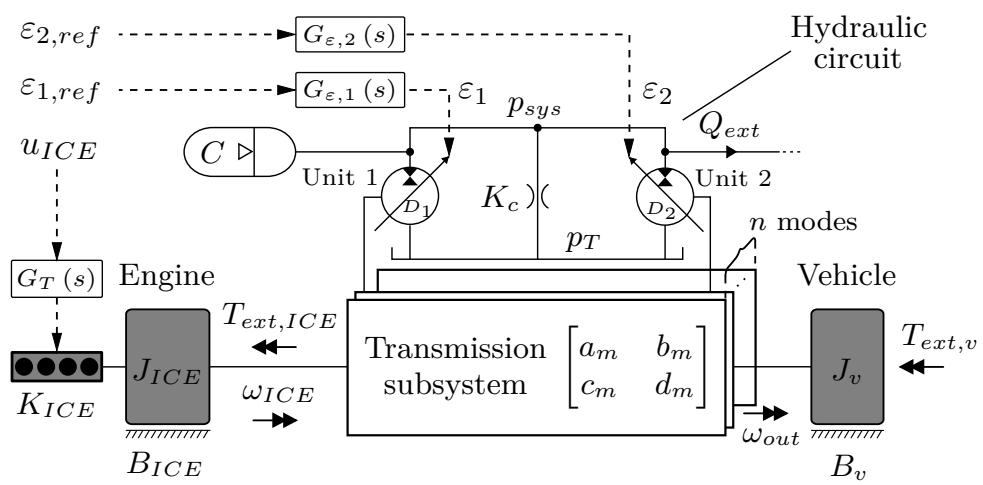

Figure 4.7 Linear lumped-parameter model of the general multiple-mode hybrid hydromechanical transmission shown in figure 1.1, with vehicle expressed in the rotational domain.

\subsubsection{Linearised Model}

To understand the powertrain dynamics and derive the decoupling strategy used in the decoupled MIMO control approach, a linearised model of the general vehicle shown in figure 1.1 was derived in paper [IV]. This model, illustrated in figure 4.7, relies on a number of assumptions:

- The tank pressure, $p_{T} \approx 0$, is constant.

- Both hydraulic units may realize four-quadrant operation, i.e. $\varepsilon_{1 / 2} \in$ $[-1,1]$.

- The hydraulic circuit capacitance is dominated by that of the accumulator, $C$, and is high.

- The accumulator operates within minimum and maximum pressure levels (i.e. it is never empty).

- All mechanical inertia is concentrated at the engine $\left(J_{I C E}\right)$ and the vehicle $\left(J_{v}\right)$.

- The engine operates at idling speed or above at all times.

- The transmission subsystem is lossless, and each mode, $m$, is constituted by one of the single-mode configurations mentioned in section 2.2.2. 
To achieve a general powertrain description, which is not limited to one transmission configuration, a matrix description according to [20] is used to model the transmission subsystem:

$$
\begin{aligned}
& {\left[\begin{array}{c}
\omega_{1} \\
\omega_{2}
\end{array}\right]=I_{\omega}\left[\begin{array}{c}
\omega_{I C E} \\
\omega_{\text {out }}
\end{array}\right]=\left[\begin{array}{ll}
a_{m} & b_{m} \\
c_{m} & d_{m}
\end{array}\right]\left[\begin{array}{c}
\omega_{I C E} \\
\omega_{\text {out }}
\end{array}\right],} \\
& {\left[\begin{array}{c}
T_{I C E} \\
T_{\text {out }}
\end{array}\right]=-I_{\omega}^{t}\left[\begin{array}{l}
T_{1} \\
T_{2}
\end{array}\right]=\left[\begin{array}{ll}
-a_{m} & -c_{m} \\
-b_{m} & -d_{m}
\end{array}\right]\left[\begin{array}{l}
T_{1} \\
T_{2}
\end{array}\right]}
\end{aligned}
$$

where $\omega_{1 / 2}$ and $T_{1 / 2}$ are the shaft speeds and torques of the hydraulic units. The matrix elements $\left(a_{m}, b_{m}, c_{m}, d_{m}\right)$ are lumped representations of the gear ratios and planetary gear constants active in mode $m$. Their numerical values therefore depend on the exact mode configuration. However, the single-mode configurations presented in section 2.2.2 may be identified by setting some of the elements equal to zero [29], as illustrated in table 4.1.

Table 4.1 Speed kinematics matrix for different transmission subsystems.

\begin{tabular}{c|c|c|c|c}
\hline \multirow{2}{*}{ Configuration } & Series & ICPS & OCPS & Compound \\
\hline$I_{\omega}$ & $-\left[\begin{array}{cc}a_{m} & 0 \\
0 & d_{m}\end{array}\right]$ & {$\left[\begin{array}{cc}a_{m} & 0 \\
c_{m} & d_{m}\end{array}\right]$} & {$\left[\begin{array}{cc}a_{m} & b_{m} \\
0 & d_{m}\end{array}\right]$} & {$\left[\begin{array}{ll}a_{m} & b_{m} \\
c_{m} & d_{m}\end{array}\right]$} \\
\hline $\begin{array}{c}\text { Hydraulic } \\
\text { circuit }\end{array}$
\end{tabular}

In the frequency domain, the linearised model is described as:

$$
\left[\begin{array}{c}
p_{\text {sys }} \\
\omega_{\text {out }} \\
\omega_{I C E}
\end{array}\right]=G_{O}(s)\left[\begin{array}{c}
\varepsilon_{\text {ref }, 1} \\
\varepsilon_{\text {ref }, 2} \\
u_{I C E}
\end{array}\right]-\left[\begin{array}{ccc}
\frac{1}{C s+K_{C}} & 0 & 0 \\
0 & \frac{1}{J_{v} s+B_{v}} & 0 \\
0 & 0 & \frac{1}{J_{I C E}+B_{I C E}}
\end{array}\right]\left[\begin{array}{c}
Q_{\text {ext }} \\
T_{\text {ext }, v} \\
T_{\text {ext }, I C E}
\end{array}\right]
$$

where $G_{O}(s)$ is the open-loop transfer function matrix:

$G_{O}(s)=$

$$
\left[\begin{array}{ccc}
\frac{D_{1}\left(a_{m} \omega_{I C E, 0}+b_{m} \omega_{o u t, 0}\right) G_{\varepsilon, 1}(s)}{C s+K_{C}} & \frac{D_{2}\left(c_{m} \omega_{I C E, 0}+d_{m} \omega_{o u t, 0}\right) G_{\varepsilon, 2}(s)}{C s+K_{C}} & 0 \\
-\frac{b_{m} D_{1} p_{s y, 0} G_{\varepsilon, 1}(s)}{J_{v} s+B_{v}} & -\frac{d_{m} D_{2} p_{s y s, 0} G_{\varepsilon, 2}(s)}{J_{v} s+B_{v}} & 0 \\
-\frac{a_{m} D_{1} p_{s y s, 0} G_{\varepsilon, 1}(s)}{J_{I C E} s+B_{I C E}} & -\frac{c_{m} D_{2} p_{s y s, 0} G_{\varepsilon, 2}(s)}{J_{I C E} s+B_{I C E}} & \frac{K_{I C E} G_{T}(s)}{J_{I C E} s+B_{I C E}}
\end{array}\right]
$$


$G_{O}(s)$ may be factorised according to:

$$
G_{O}(s)=G_{\text {sys }}(s) G_{t s, m}(s)
$$

where $G_{\text {sys }}(s)$ is a diagonal matrix that contains the governing dynamics of each state:

$$
G_{s y s}(s)=\left[\begin{array}{ccc}
\frac{1}{C s+K_{C}} & 0 & 0 \\
0 & \frac{1}{J_{v} s+B_{v}} & 0 \\
0 & 0 & \frac{1}{J_{I C E} s+B_{I C E}}
\end{array}\right]
$$

and $G_{t s, m}(s)$ contains transmission kinematics and actuator dynamics:

$$
\begin{aligned}
& G_{t s, m}(s)= \\
& {\left[\begin{array}{ccc}
D_{1}\left(a_{m} \omega_{I C E, 0}+b_{m} \omega_{\text {out }, 0}\right) G_{\varepsilon, 1}(s) & D_{2}\left(c_{m} \omega_{I C E, 0}+d_{m} \omega_{\text {out }, 0}\right) G_{\varepsilon, 2}(s) & 0 \\
-b_{m} D_{1} p_{s y s, 0} G_{\varepsilon, 1}(s) & -d_{m} D_{2} p_{s y s, 0} G_{\varepsilon, 2}(s) & 0 \\
-a_{m} D_{1} p_{s y s, 0} G_{\varepsilon, 1}(s) & -c_{m} D_{2} p_{s y s, 0} G_{\varepsilon, 2}(s) & K_{I C E} G_{T}(s)
\end{array}\right]}
\end{aligned}
$$

The turbo dynamics are modelled according to [96]:

$$
G_{T}(s)=\frac{\tau_{T} s+1}{\frac{\tau_{T}}{K_{\tau}} s+1}
$$

A block-diagram representation of the model in figure 4.7 is shown in figure 4.8. The transmission subsystem causes cross-couplings between the pressure and output speed loops, while the engine speed loop is subject to disturbances from the other loops.

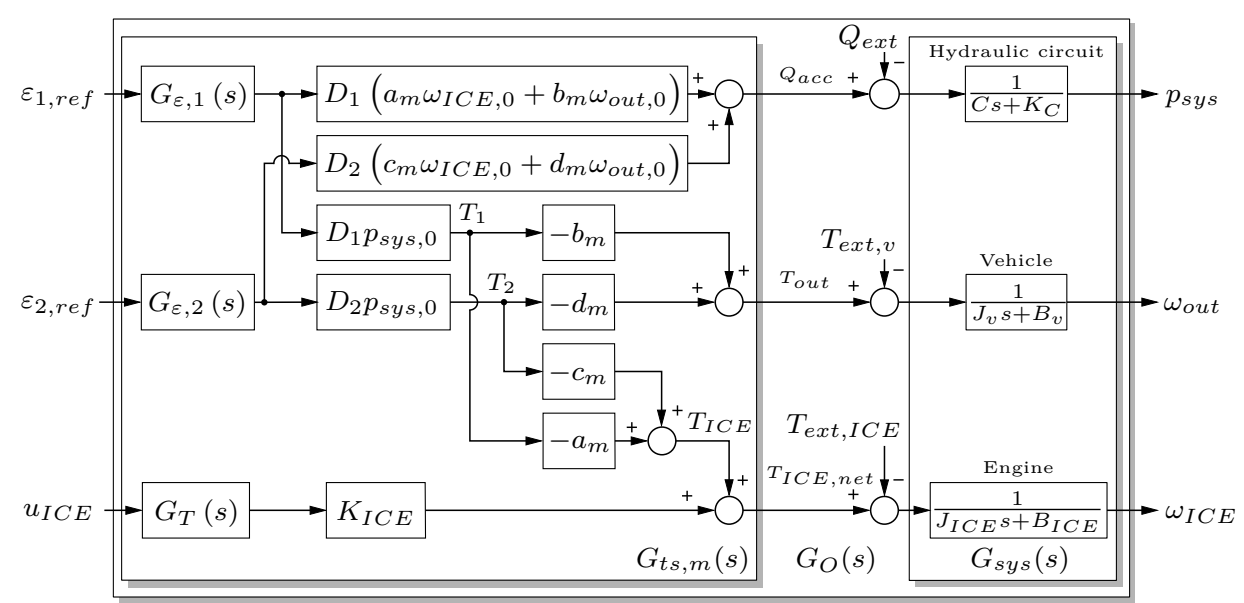

Figure 4.8 Block diagram of the linear model in figure 4.7 linearised at $\left(p_{\text {sys }, 0}, \omega_{\text {out }, 0}, \omega_{I C E, 0}\right)$. 


\subsubsection{Control}

The decoupled control strategy proposed in papers $[\mathrm{IV}, \mathrm{V}]$ is illustrated in figure 4.9. The basic idea is that a decoupling matrix, $W_{m}$, is defined for each mode, $m$, so that the control problem is simplified to three decoupled SISO loops with one controller each. At this level, a mode shift thus implies a switch from one $W_{m}$ to another. Although dynamic decoupling is possible [70], static decoupling is considered enough here. $W_{m}$ is calculated to let the SISO controllers control the inputs of $G_{\text {sys }}$ :

$$
\begin{aligned}
W_{m}= & G_{t s, m}^{-1}(0)= \\
& {\left[\begin{array}{ccc}
\frac{d_{m}}{\left(a_{m} d_{m}-b_{m} c_{m}\right) D_{1} \omega_{I C E, 0}} & \frac{c_{m} \omega_{I C E, 0}+d_{m} \omega_{\text {out }, 0}}{\left(a_{m} d_{m}-b_{m} c_{m}\right) D_{1} p_{s y s} \omega_{I C E, 0}} & 0 \\
\frac{b_{m}}{\left(b_{m} c_{m}-a_{m} d_{m}\right) D_{2} \omega_{I C E, 0}} & \frac{a_{m} \omega_{I C E, 0}+b_{m} \omega_{o u t, 0}}{\left(b_{m} c_{m}-a_{m} d_{m}\right) D_{2} p_{s y s, 0} \omega_{I C E, 0}} & 0 \\
\frac{p_{s y s, 0}}{K_{I C E} \omega_{I C E, 0}} & \frac{\omega_{\text {out }, 0}}{K_{I C E} \omega_{I C E, 0}} & \frac{1}{K_{I C E}}
\end{array}\right] }
\end{aligned}
$$

In paper [IV], it was found that the decoupling is facilitated if the displacement controllers have equal response. This condition is not self-evidently fulfilled since the two units may be of different types and sizes. It is, however, possible with the P-lead-controller strategy proposed in section 4.2. The displacement controllers are then modelled according to:

$$
G_{\varepsilon, 1}(s)=G_{\varepsilon, 2}(s)=G_{\varepsilon}(s)=\frac{1}{\frac{s^{2}}{\omega_{a}^{2}}+2 \frac{\delta_{a}}{\omega_{a}} s+1}
$$

This results in the following decoupled open-loop transfer function, $\tilde{G}_{O}(s)$ :

$$
\begin{aligned}
\tilde{G}_{O}(s)= & G_{O}(s) W_{m}= \\
& {\left[\begin{array}{ccc}
G_{\varepsilon}(s) & 0 \\
C s+K_{C} & 0 & 0 \\
0 & \frac{G_{\varepsilon}(s)}{J_{v} s+B_{v}} & 0 \\
\frac{p_{s y s, 0}\left(G_{T}(s)-G_{\varepsilon}(s)\right)}{\omega_{I C E, 0}\left(J_{I C E} s+B_{I C E}\right)} & \frac{w_{\text {out }, 0}\left(G_{T}(s)-G_{\varepsilon}(s)\right)}{\omega_{I C E, 0}\left(J_{I C E} s+B_{I C E}\right)} & \frac{G_{T}(s)}{J_{I C E} s+B_{I C E}}
\end{array}\right] }
\end{aligned}
$$

The following can be noted concerning $W_{m}$ and $\tilde{G}_{O}$ :

- $W_{m}$ contains linearisation points of pressure and shaft speeds. Consequently, gain scheduling is required to ensure that $\tilde{G}_{O}(s)$ according to equation (4.22) is achieved.

- $\tilde{G}_{O}(s)$ is independent of mode $m$.

- Since $W_{m}$ is static, the difference between the displacement controller dynamics and turbo dynamics causes dynamic disturbances in the engine control loop. 


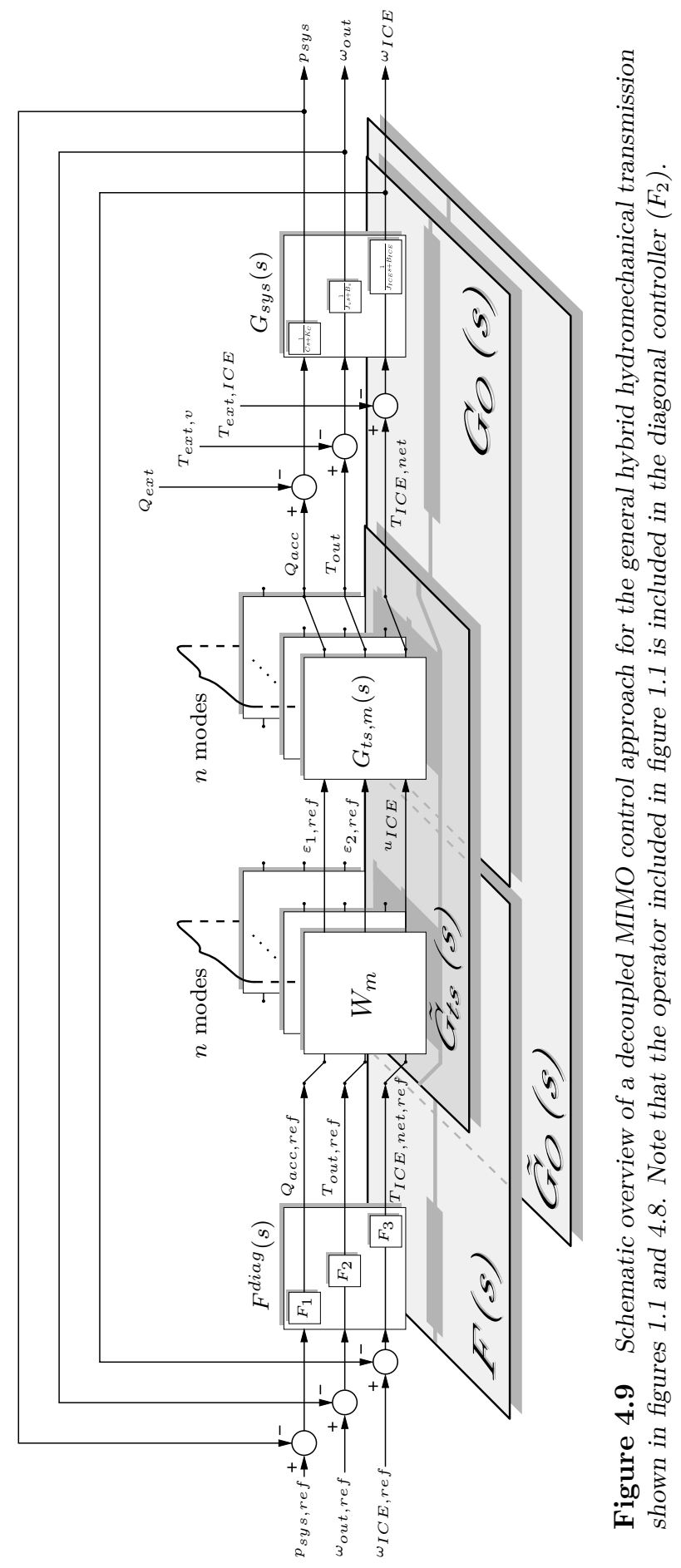


The diagonal controller, $F^{\text {diag }}(s)$, is chosen based on the diagonal elements of $\tilde{G}_{O}(s)$. Proportional control is considered to illustrate the distinguishing features of the decoupled control:

$$
F^{\text {diag }}(s)=\left[\begin{array}{ccc}
F_{1}(s) & 0 & 0 \\
0 & F_{2}(s) & 0 \\
0 & 0 & F_{3}(s)
\end{array}\right]=\left[\begin{array}{ccc}
K_{1} & 0 & 0 \\
0 & K_{2} & 0 \\
0 & 0 & K_{3}
\end{array}\right]
$$

The decoupled open-loop transfer function matrix in equation (4.22) may be interpreted as three individual SISO loops controlled by the diagonal elements of $F^{\operatorname{diag}}(s)$, as illustrated in figure 4.10.

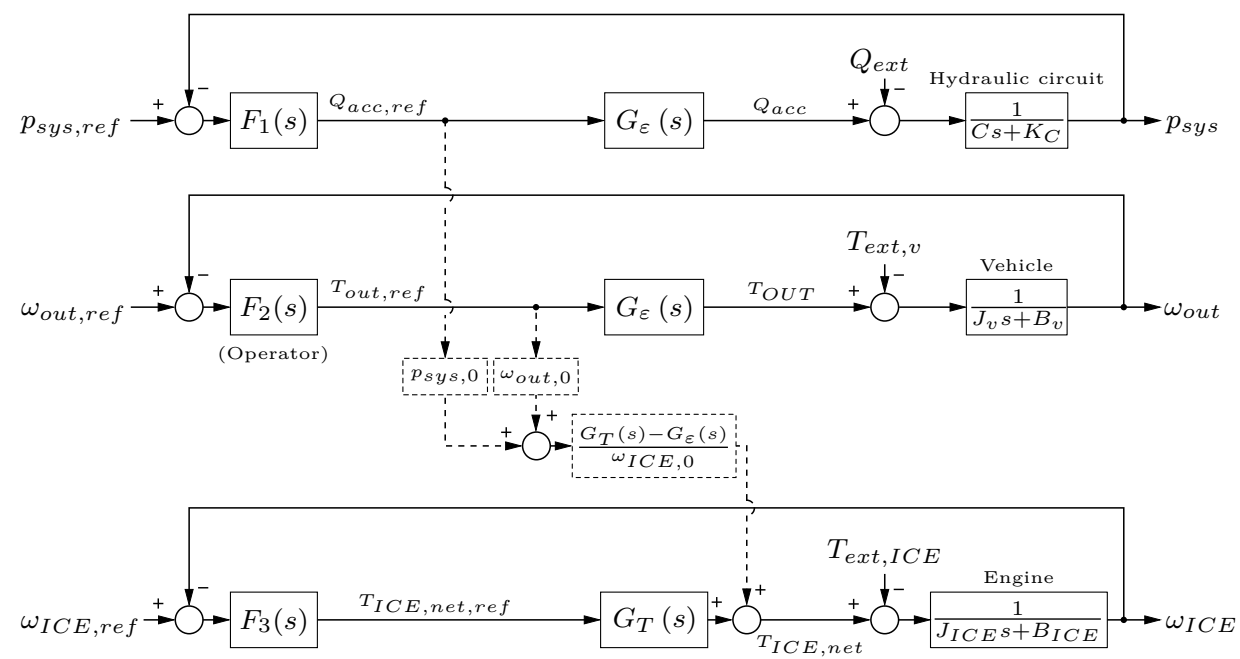

Figure 4.10 Block diagram of the decoupled system with SISO controllers.

The dashed lines indicate that the signal is zero in the steady-state.

The frequency response of the pressure and output speed SISO open loops with proportional control is shown in figure 4.11. These loops are of the same order and are very similar to the pure secondary control loop shown in section 2.3.1. Since the displacement controller dynamics are of the second order, the phase shift is more than -180 degrees, and instability may occur. Under the assumption that $\frac{K_{C}}{C} \ll \omega_{a}$ and $\frac{B_{v}}{J_{v}} \ll \omega_{a}$, the following conditions may be formulated on $K_{1}$ and $K_{2}$ for stability:

$$
\left\{\begin{array}{l}
K_{1}<2 C \delta_{a} \omega_{a} \\
K_{2}<2 J_{v} \delta_{a} \omega_{a}
\end{array}\right.
$$

As shown in equation (4.24), the stability of the pressure and output speed loops relies on displacement controllers with high bandwidth and damping. 
In addition, the stability margins vary with the vehicle inertia $\left(J_{v}\right)$ and the accumulator capacitance $(C)$. This effect is also illustrated in figure 4.11. As shown in appendix A.5, the capacitance varies with the system pressure. Varying dynamics in the pressure loop depending on operation point may therefore be expected, as discussed further in section 4.3.3.

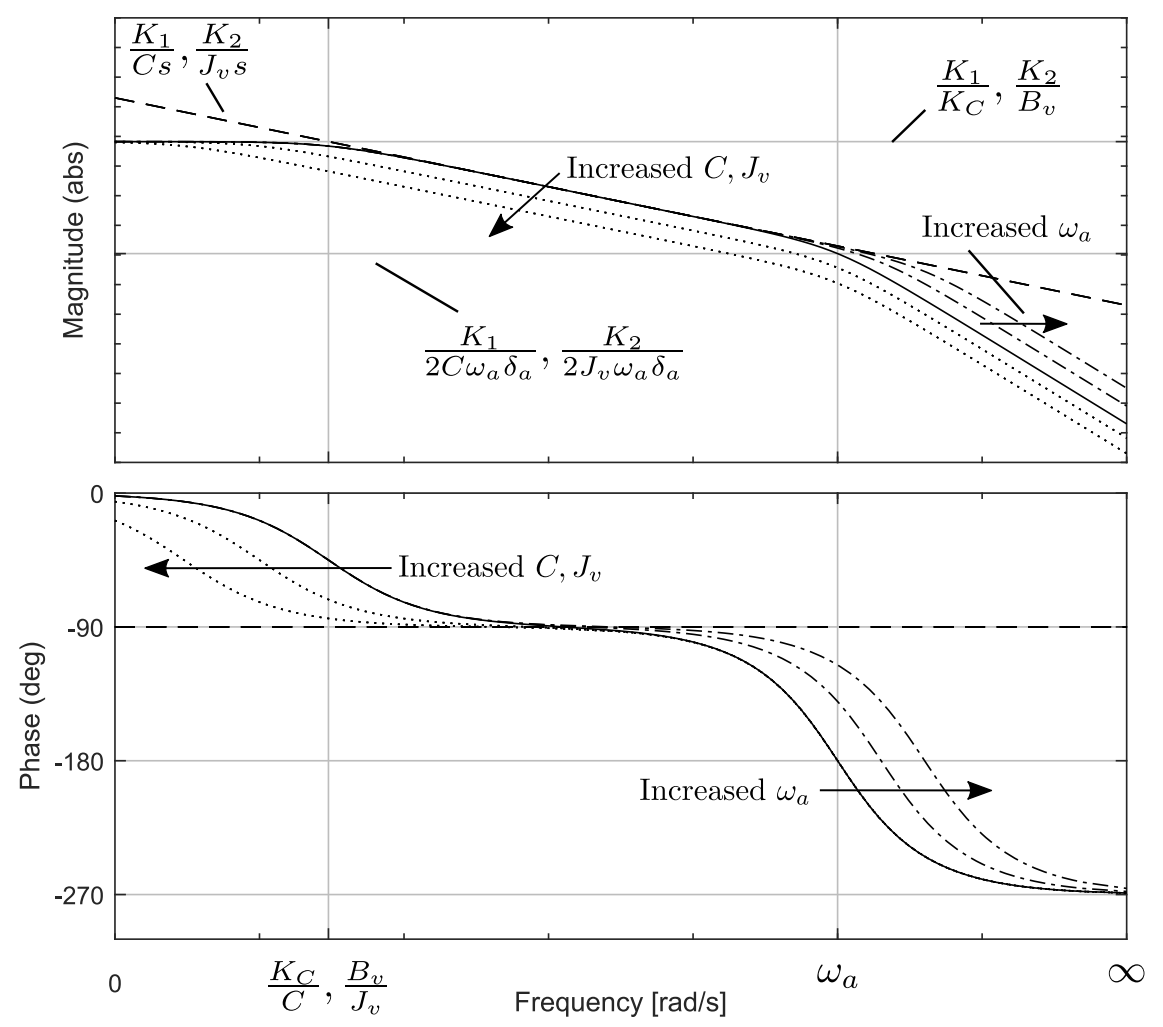

Figure 4.11 Bode diagram of the pressure $\left(\frac{K_{1} G_{\varepsilon}(s)}{C s+K_{C}}\right)$ and output speed $\left(\frac{K_{2} G_{\varepsilon}(s)}{J_{v} s+B_{v}}\right)$ SISO loops. 


\section{Choosing Control Parameters}

The choice of the controller gains depends on the requirements of the closed loops. Since the displacement controllers are parametrised with pole placement, $\omega_{a}$ and $\delta_{a}$ may also be considered as parts of the parameter sets of the closedloop controllers. Assuming $K_{C} \approx 0$, a convenient closed loop with well-damped response and sufficient stability margins in relation to equation (4.24) may be achieved for the pressure loop according to:

$$
\tilde{G}_{p, C}(s)=\frac{p_{\text {sys }}}{p_{\text {sys,ref }}}=\frac{K_{1} \frac{G_{\varepsilon}(s)}{C s}}{1+K_{1} \frac{G_{\varepsilon}(s)}{C s}}=\frac{1}{\left(\frac{s}{\omega_{p}}+1\right)^{3}}
$$

where $\omega_{p}$ is the desired bandwidth of the closed loop. $K_{1}, \omega_{a}$ and $\delta_{a}$ may then be identified as:

$$
\left\{\begin{array}{l}
K_{1}=\frac{1}{3} C \omega_{p} \\
\omega_{a}=\sqrt{3} \omega_{p} \\
\delta_{a}=\frac{\sqrt{3}}{2} \approx 0.9
\end{array}\right.
$$

Assuming $B_{v} \approx 0$, similar expressions may be formulated for the output speed loop by replacing $K_{1}$ with $K_{2}$ and $C$ with $J_{v}$. In theory, the values in equation (4.24) enables exact mapping and predictable response of the closed loop. In practice, however, this was found to be difficult due to non-linearities and uncertainties in the model parameters required for exact pole placement. The design criteria in equation (4.26) should therefore be interpreted as indicative rather than definitive. A non-linearity that was found to have high influence on the results was the limitation in valve flow of the displacement controller. Primarily, this aspect limits the achievable value of $\omega_{a}$ for large changes in displacement. A relaxed design criterion was then found to be (i.e. maximise $\omega_{a}$ ):

$$
\left\{\begin{array}{l}
K_{1}=\frac{1}{3} C \omega_{p} \\
\omega_{a} \geq \sqrt{3} \omega_{p} \\
\delta_{a}=\frac{\sqrt{3}}{2} \approx 0.9
\end{array}\right.
$$

For the engine speed loop, low phase shift implies little risk of instability. $K_{3}$ may then be chosen to achieve a fast and well-damped response, while minimising negative influences of non-linearities, such as varying turbo dynamics and limited torque. 


\section{Baseline}

To study the influences of the system's cross-couplings, and how they are handled by the decoupled control approach, a comparison with a baseline strategy was carried out in paper $[\mathrm{V}]$. The baseline strategy is to apply a diagonal controller based solely on the diagonal elements of $G_{O}(s)$, thereby ignoring the cross-couplings. To make the responses of the two controllers comparable, this diagonal controller is chosen as the diagonal elements of the full controller, $F(s)$, used in the decoupled strategy:

$$
F_{B L}=\left[\begin{array}{ccc}
K_{1} \frac{d_{m}}{\left(a_{m} d_{m}-b_{m} c_{m}\right) D_{1} \omega_{I C E, 0}} & 0 & 0 \\
0 & K_{2} \frac{a_{m} \omega_{I C E, 0}+b_{m} \omega_{\text {out }, 0}}{\left(b_{m} c_{m}-a_{m} d_{m}\right) D_{2} p_{s y s, 0} \omega_{I C E, 0}} & 0 \\
0 & 0 & K_{3} \frac{1}{K_{I C E}}
\end{array}\right]
$$

where the same controller gains $K_{1 / 2 / 3}$ and gain-scheduling of pressure and shaft speeds as in the decoupled strategy are used.

\subsubsection{Simulations and Measurements}

The decoupled control approach was applied to a reference vehicle equipped with an ICPS and tested in offline simulations in paper [IV] and in HWIL simulations in paper [V]. For the ICPS, shown in figure $4.12 \mathrm{a}$, the transmission subsystem constants may be identified according to:

$$
\left[\begin{array}{ll}
a_{m} & b_{m} \\
c_{m} & d_{m}
\end{array}\right]=\left[\begin{array}{cc}
i_{1} & 0 \\
\frac{1}{i_{2} R} & \frac{R-1}{i_{2} R}
\end{array}\right]
$$

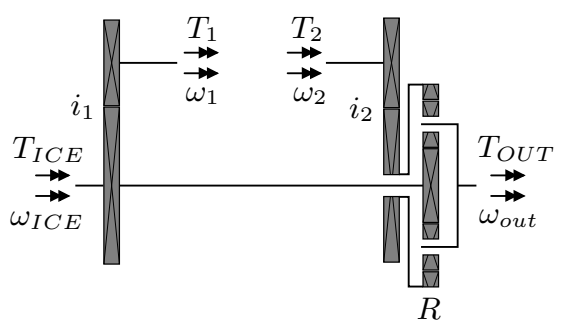

(a) ICPS Transmission subsystem.

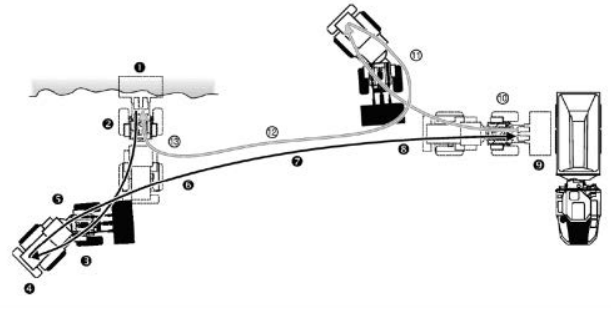

(b) Load-and-carry cycle [3].

Figure 4.12 Reference vehicle transmission and drive cycle. 


\section{Controller Performance}

Figure 4.13 shows HWIL simulations of the reference vehicle with the decoupled and baseline control strategies for a load-and-carry cycle [3]. In this cycle, illustrated in figure $4.12 \mathrm{~b}$, the machine enters a gravel pile to fill the bucket in low velocity, reverses, and then travels with higher velocity to a load receiver to empty the bucket.

The basic idea of the decoupled control strategy is that each state is controlled by a decoupled control signal. This is illustrated in figure 4.13. The system pressure is controlled by the desired accumulator flow, $Q_{a c c, r e f}$, which primarily reacts to changes in reference pressure. Similarly, the desired output torque, $T_{\text {out }, \text { ref }}$, is altered to follow the speed reference. The gravel pile model gives a peak in torque and drop in vehicle speed at 10-12 seconds.

In contrast to the decoupled strategy, the baseline approach is limited to handle the cross-couplings using its state feedbacks and gain-scheduling. Consequently, steady-state error is present in the pressure loop. This is a result of the fact that both hydrostatic units affect the net flow into the accumulator (see figure 4.8), but in the baseline strategy $\varepsilon_{1}$ is dedicated to pressure control while $\varepsilon_{2}$ is dedicated to output speed control. The vehicle speed tracking is very similar for both strategies. This is because the output torque of an ICPS is determined by the torque of unit 2 alone $\left(b_{m}=0\right)$, thereby making the vehicle speed loop naturally decoupled.

Figures 4.14 and 4.15 show a series of step responses in reference and disturbance signals for the decoupled and baseline strategy, respectively. 

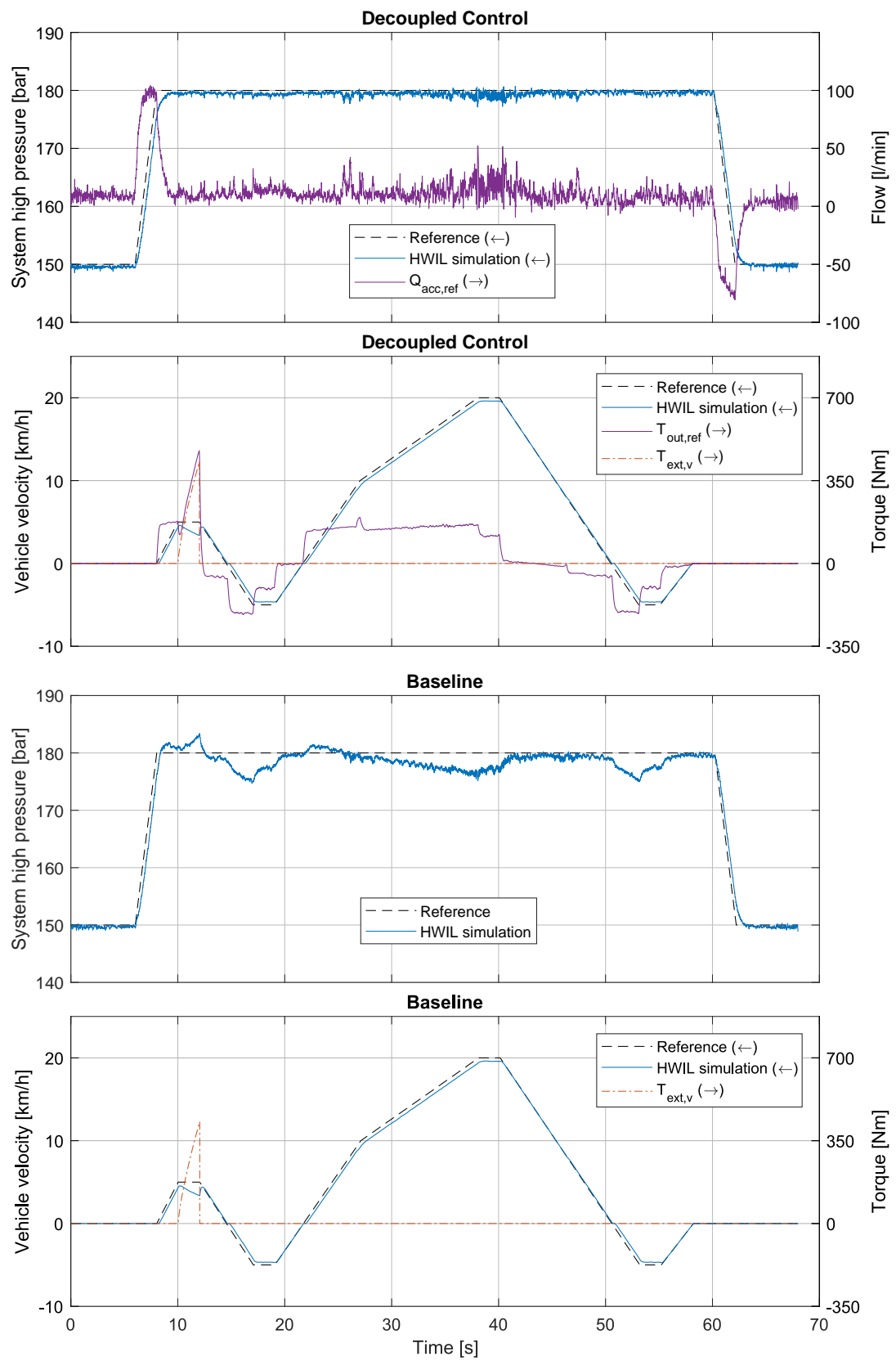

Figure 4.13 HWIL simulation results of the load-and-carry cycle for decoupled control (top) and baseline control (bottom). $Q_{\text {ext }}$ and $T_{\text {ext,ICE }}$ are zero for this cycle and are therefore not included in the graphs. The output shaft speed has been scaled to vehicle velocity via the wheel radius and final gear ratio $\left(\omega_{\text {out }}=\frac{v_{v e h}}{i_{0} r_{w}}\right)$. The engine speed measurements are provided in paper [V]. 

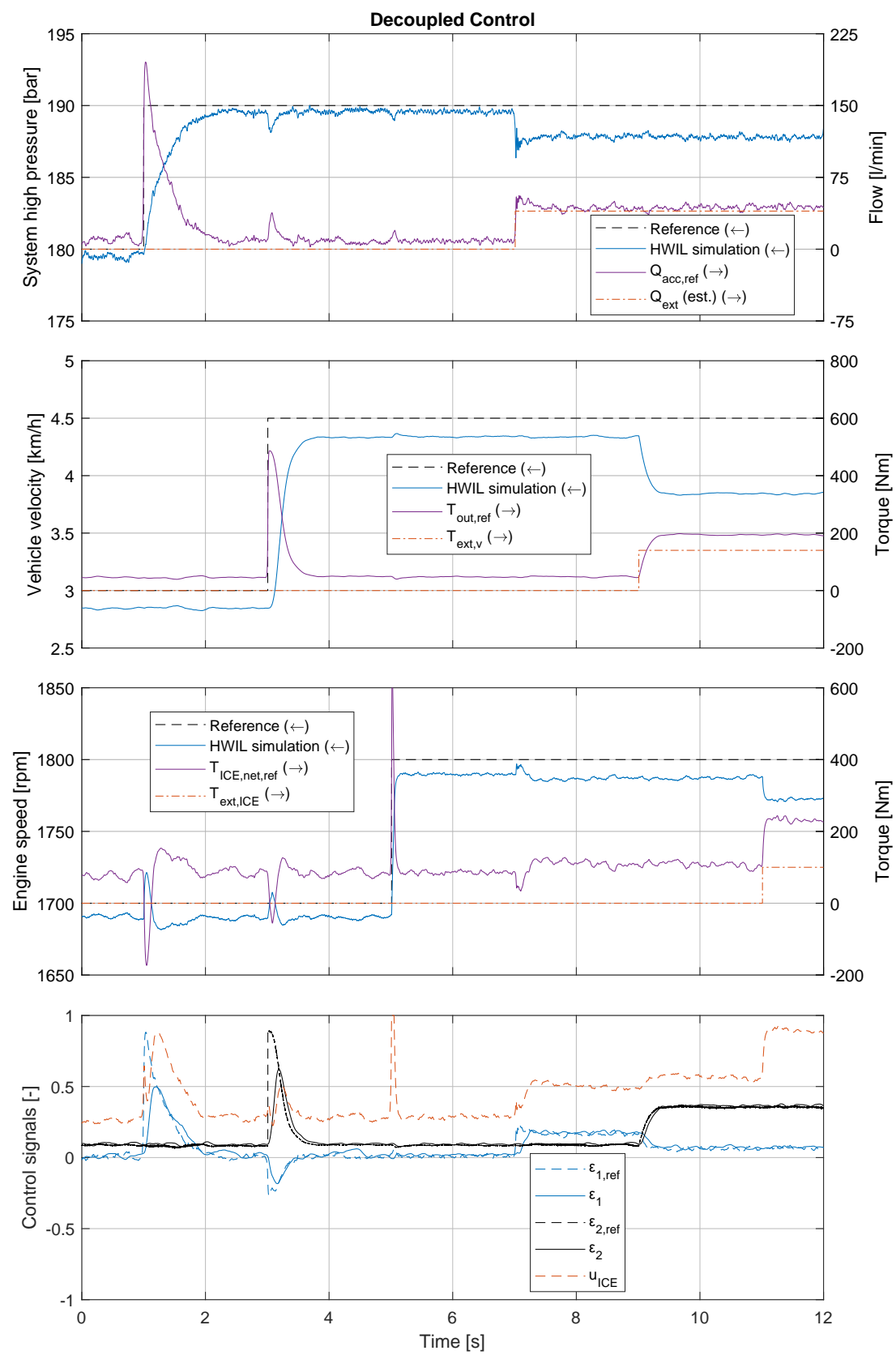

Figure 4.14 HWIL simulation results of the step-series cycle with decoupled control. The output shaft speed has been scaled to vehicle velocity via the wheel radius and final gear ratio $\left(\omega_{\text {out }}=\frac{v_{v e h}}{i_{0} r_{w}}\right)$. Q Q ext was estimated according to $Q_{\text {ext }}=u_{v, \text { dist }} \cdot 1.35 \sqrt{p_{\text {sys }} \cdot 10^{-5}}$, where a step of $2.15 \mathrm{~V}$ was made in $u_{v, \text { dist }}$. 

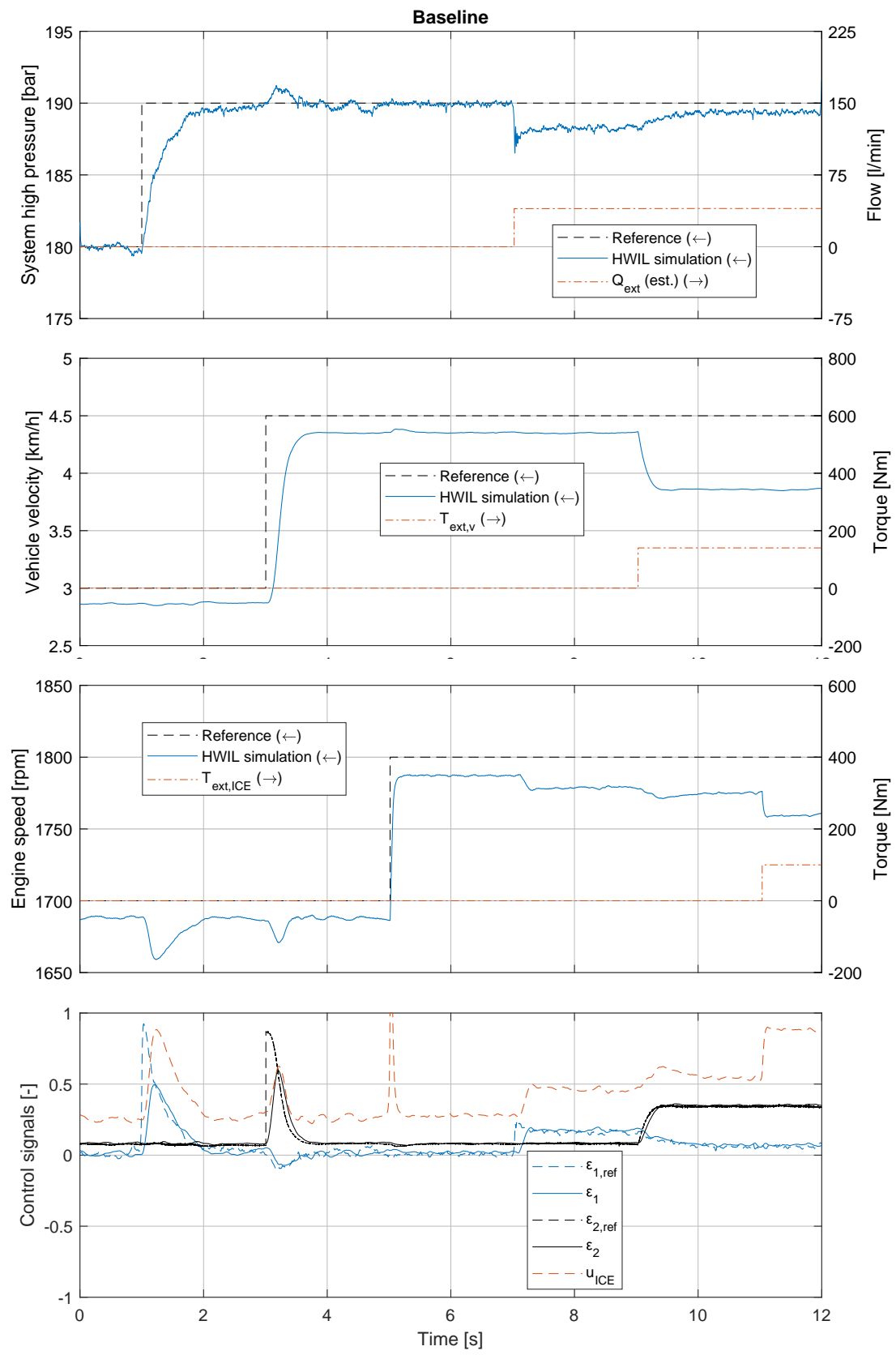

Figure 4.15 HWIL simulation results of the step-series cycle with baseline control. The output shaft speed has been scaled to vehicle velocity via the wheel radius and final gear ratio $\left(\omega_{o u t}=\frac{v_{v e h}}{i_{0} r_{w}}\right)$. Qext was estimated according to $Q_{\text {ext }}=u_{v, \text { dist }} \cdot 1.35 \sqrt{p_{\text {sys }} \cdot 10^{-5}}$, where a step of $2.15 \mathrm{~V}$ was made in $u_{v, \text { dist }}$. 
For the decoupled strategy, the presence of dynamic disturbances in the engine speed loop may be observed at 1 and 3 seconds as steps are made in pressure and vehicle speed. In the pressure loop, a similar disturbance occurs at 3 seconds, when a step is made in vehicle velocity. This behaviour is not predicted by the linear model and is explained by the displacement actuators not being equally fast in reality, primarily due to flow saturation in the actuators for larger step magnitudes. As shown in paper [IV], and explained further in appendix $\mathrm{C}$, non-equal response of the displacement controllers introduces dynamic off-diagonal terms in $\tilde{G}_{O}(s)$. The external disturbances cause steadystate errors in all loops, since these are not known by the decoupling strategy. In the engine speed loop, a small disturbance may also be observed at 7 seconds as the pressure loop compensates for its flow disturbance.

The differences between the baseline and decoupled strategies are confirmed further in the step-series cycle. The engine is subject to more severe disturbances caused by the other states, and also suffers from additional static error as the disturbances are introduced in the other states. One phenomenon that may be observed in the pressure loop, is that the steady-state error is lowered as the torque disturbance is introduced in the vehicle speed loop. This is because the increased displacement of unit 2 causes an extra flow into the circuit, which compensates for the external disturbance flow.

\section{Hardware-in-the-Loop Performance}

The reliability of the HWIL simulation depends on the performance of the interface controller. As mentioned in section 3.6, the rig controller in the used setup controls the unit shaft speeds according to reference values determined by the Hopsan model. This control error may then be used as an indicator of the trustworthiness of the measurements. Figure 4.16 shows the control error of the load-and-carry and step-series cycles for decoupled control. During steady-state conditions, the error is small. For the load-and-carry cycle, the part where the machine enters the gravel pile is difficult to simulate, since the reference speed and the displacement setting of unit 2 change simultaneously. Larger errors are also observable where the shaft speed of unit 2 crosses zero. This is because of poor resolution at low speeds of the encoders used for speed measurement. The transients of the step-series cycle are also challenging to simulate. The step in vehicle speed is particularly difficult, since this step results in simultaneous steps in displacement setting and shaft speed of unit 2. Consequently, a relatively large error occurs at this part of the cycle. For the HWIL simulation, this aspect results in limitations in both testable drive cycles and control strategies. For instance, increased controller gains $\left(K_{1 / 2 / 3}\right)$ would result in faster dynamics and thus larger control errors. 


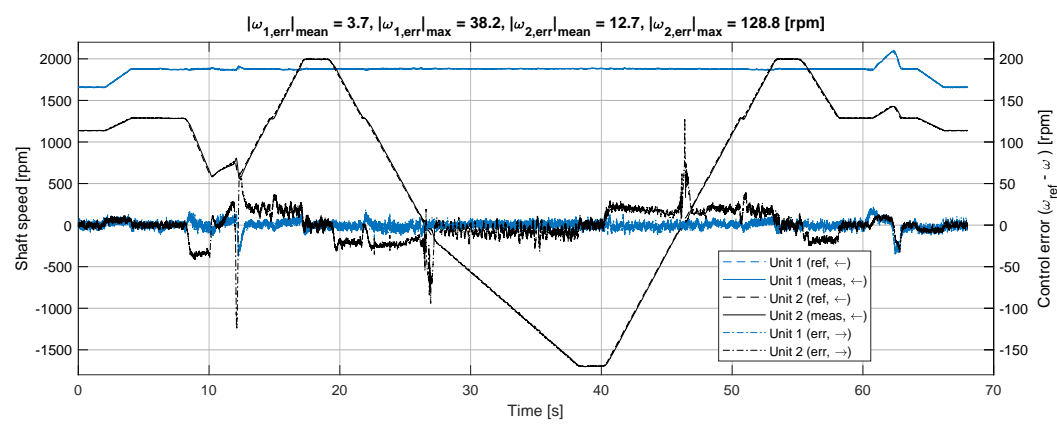

(a) Load-and-carry (figure 4.13).

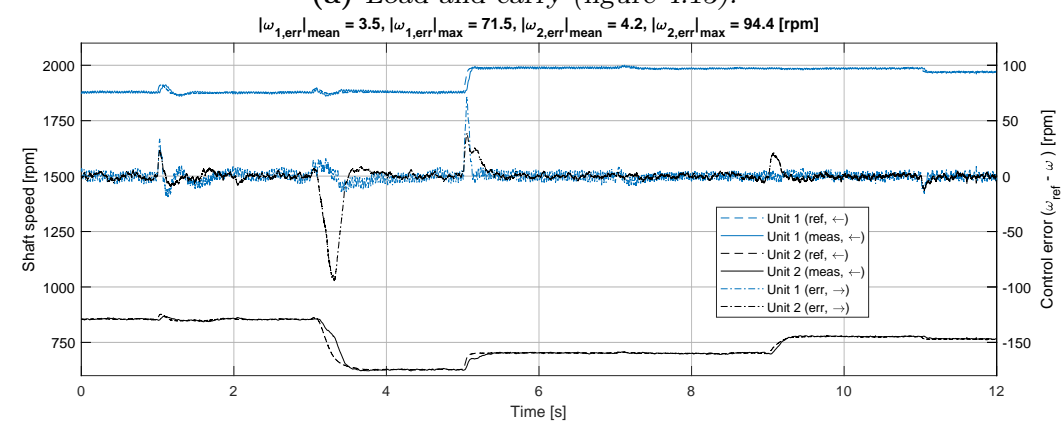

(b) Step series (figure 4.14).

Figure 4.16 Performance of the HWIL simulations shown in figures 4.13 and 4.14 (decoupled control).

\section{Sensitivity Analysis}

To study the effect of variations of the variables of the decoupled system (figure 4.10) on the system dynamics, a sensitivity analysis was carried out in HWIL simulation and offline simulation. Note that the results presented in this section are not included in any of the appended papers. The sensitivity analysis was carried out by repeating the step-series cycle in figure 4.14 for different variable values. One parameter that was found to vary significantly in offline simulations was the accumulator capacitance (see figure A.9). This was confirmed in the HWIL simulations. As shown in figure 4.17a, the capacitance decreases for increased system pressures. As shown in equation (4.24), this lowers the stability margins, with resulting faster dynamics of the pressure control loop. The capacitance also changes with the accumulator volume. This was tested by disconnecting one of the accumulators in the test rig to halve the total accumulator volume. As illustrated in figure $4.17 \mathrm{~b}$, this action also decreases the capacitance. 


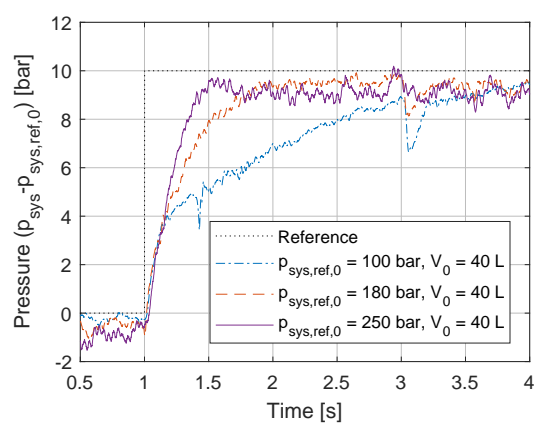

(a) HWIL simulation.

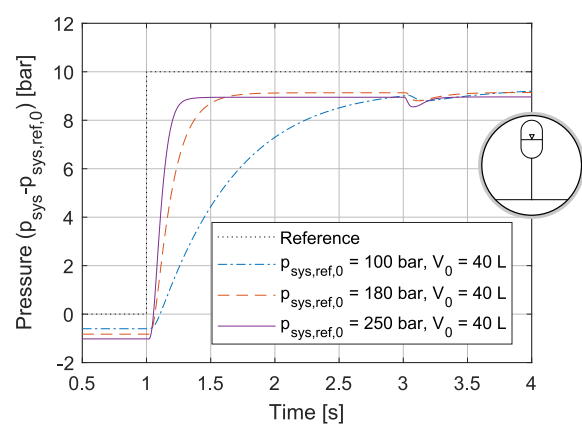

(c) Offline simulation.

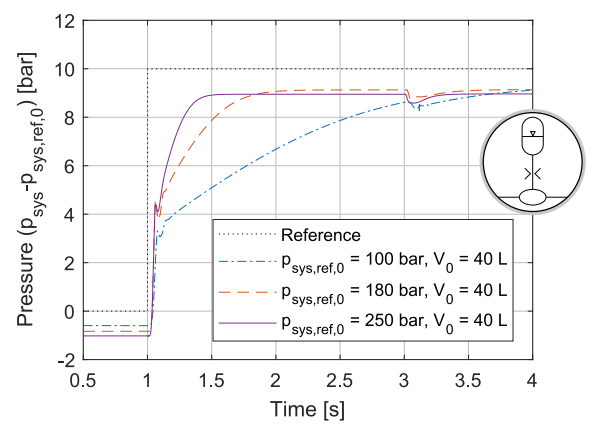

(e) Offline simulation (with volume and orifice).

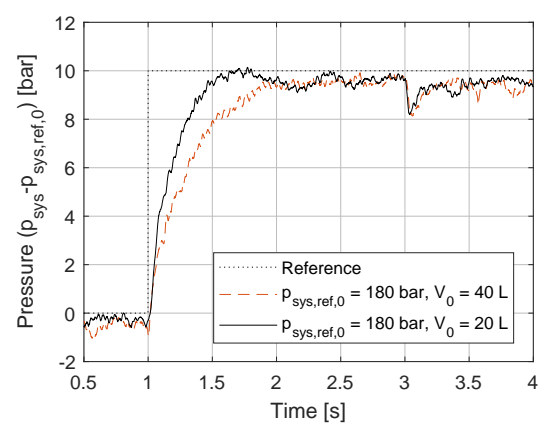

(b) HWIL simulation.

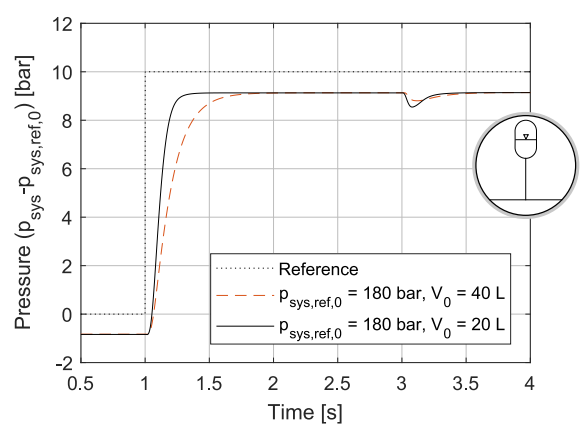

(d) Offline simulation.

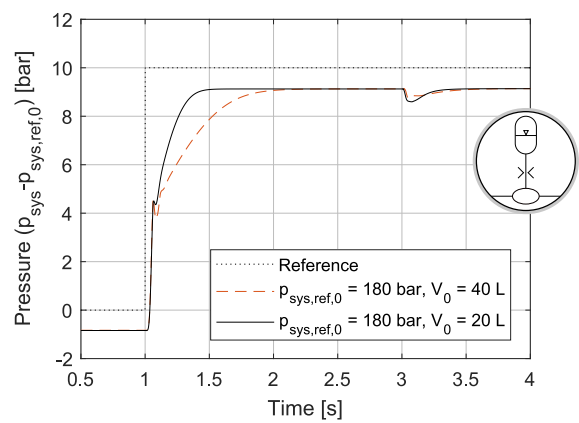

(f) Offline simulation (with volume and orifice).

Figure 4.17 First part of the pressure curve of the step-series cycle in figure 4.14 (decoupled control) for different pressures (left) and accumulator sizes (right). 
Figure 4.17 also illustrates how HWIL simulation may be used for model validation. In the offline simulations in figures $4.17 \mathrm{c}$ and $4.17 \mathrm{~d}$, it is assumed that the accumulator is connected directly to the hydrostatic units. In the rig, however, the accumulators are connected with hoses and couplings that cause a pressure drop at high flows. In figures $4.17 \mathrm{e}$ and $4.17 \mathrm{f}$, this effect is captured with a turbulent orifice $(d=10 \mathrm{~mm})$ and a volume $(V=1 \mathrm{~L})$ added between the hydrostatic units and the accumulator in the offline simulation model. Note that, as mentioned in section 3.3 and indicated in figure 3.1, this effect may be important enough to update the control strategy.

Figure 4.18a shows the effect of varying response of the displacement controllers on the output speed control loop. This variation was achieved by changing the desired resonance, $\omega_{a}$, in the pole placement of the P-leadcontroller (recall section 4.2.3). As shown in equation (4.24), the stability margins decrease for lowered $\omega_{a}$. This may be observed as lowered damping of the response in figure 4.18a.

Figure 4.18b shows the dynamic disturbance in the engine speed loop caused by steps of 10 bar from different system pressures. As shown in figure 4.10, the disturbance is amplified with $p_{s y s, 0}$, which is observable as an increase in amplitude of the disturbance for different values of $p_{\text {sys,ref, } 0}$.

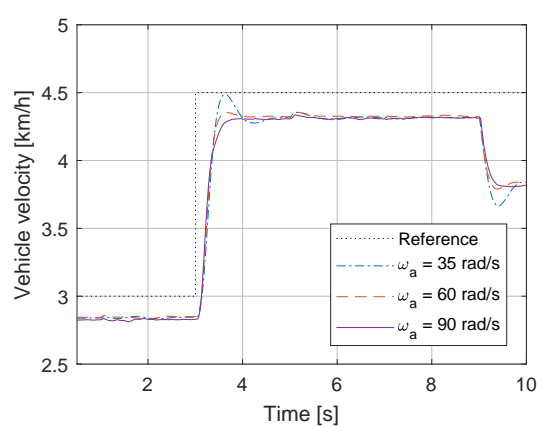

(a) Vehicle speed. $p_{\text {ref }, 0}=180$ bar has been used in all cases.

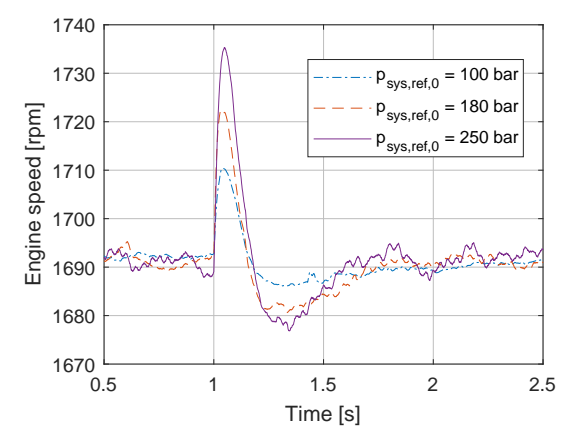

(b) Engine speed disturbance, $\omega_{a}=90$ $\mathrm{rad} / \mathrm{s}$ has been used in all cases. A step of 10 bar has been carried out for each pressure.

Figure 4.18 Selected parts of the HWIL simulations of the step-series cycle in figure 4.14, with varying displacement controller response (a) and system pressures (b). $V_{0}=40 \mathrm{~L}$ has been used in all cases. 


\section{5 \\ Discussion}

The decoupled control approach proposed in this thesis has several benefits. It allows for the operator and energy management strategy to operate in parallel with little interference. Being based on a generic transmission model, it is also easy to implement on different transmission architectures, which motivates its use in multiple-mode concepts. It should be noted, however, that decoupled control in itself does not guarantee fuel-optimal operation. An energy management strategy is required to choose proper system pressure level and engine speed [17]. Also, the output torque control needs to be blended with friction brakes, since energy recuperation is not always possible [39].

A key feature of decoupled control is that it cancels out cross-couplings. In this thesis, the effect of these was studied in the comparison with the baseline approach. For more detailed examination of the cross-couplings and their effect on system stability, different methods of quantifying cross-couplings could be considered, see e.g. [69, 97, 61].

The severity of the cross-couplings and how they are handled by the decoupling strategy may also change depending on the considered transmission architecture. The reference transmission was of the input-coupled power-split type. But, for instance, the output-coupled power-split architecture results in cross-couplings between the output speed and system pressure loop, which may interfere with the output torque control [29]. In addition, the losses in the pump/motor units could influence the control in some configurations, and may then need to be considered in the control strategy [98].

The presence of multiple power-consumers is often stressed as an important factor that affects both the design and energy management of hybrid working machines [19]. In this thesis, these have been considered as external disturbances. A natural extension would be to include the work functions as additional states and control signals. This could be done either as a conventional working hydraulics system connected to the engine, or as a secondary controlled system connected to the hydraulic circuit, see e.g. [18]. On the same topic, an interesting aspect is that there are interactions between the work functions 
and the transmission via the load, e.g. during bucket-filling in a gravel pile [3]. Cross-couplings between the work functions and the transmission may therefore be expected.

Displacement controllers are key low-level actuators in hybrid hydromechanical transmissions. This concerns both stability aspects of the powertrain control loops and their decoupling, and the smoothness of mode shifts. For swash plate units, the idea of using external control offers high freedom in control design, but also places higher demands on the control valve used in the actuator. A slow valve can be compensated for to some extent with a sophisticated control strategy. For large variations in displacement, however, flow saturation may only be solved with a bigger valve. This approach requires higher power for actuation, which thus poses a potential conflict with the system's overall purpose, which is increased energy efficiency. New pump/motor designs could then be motivated, both for increased efficiency of the unit itself and for alternative methods of displacement variation, see e.g. [99, 100].

A key aspect that has affected all the proposed control strategies in this thesis, is the high capacitance of the hydraulic accumulator. For the powertrain control, the decoupling is very much facilitated by the slow pressure dynamics. In addition to those shown in the simulations and experiments, other crosscouplings are present in a hydromechanical transmission. These are suppressed by the slow pressure dynamics of the accumulator [IV], but may become important for small accumulator sizes. For instance, the stiff nature of hydrostatic transmissions results in a different control problem than its hybrid equivalent, see for instance [73]. For the displacement control, the accumulator suppresses the feedback loop present if the actuator is supplied with the system pressure, which otherwise could lead to oscillations [101].

The control strategies presented in this thesis are to a large extent based on linear models. There are, however, several non-linearities that affect the dynamic behaviour of the real system. Primarily, these are saturation in control signals, such as limitations in displacement setting, displacement actuator velocity and engine torque. The limitation in displacement actuator velocity causes the displacement controllers of the two hydrostatic units to be unequally fast for different step magnitudes, which resulted in dynamic cross-couplings in the experiments. The effect of limited displacement and engine torque is not within the scope of this thesis, but could have an effect on the performance of the proposed powertrain control strategy.

Another important non-linear effect, is that some system parameter values change with operation point. For instance, the decoupling strategy contains linearisation points of pressure and shaft speeds, which was handled with gainscheduling in the experiments. It was also found that the accumulator capacitance varied significantly with system pressure. Since the capacitance is directly related to the stability of the pressure loop, this effect should be taken into consideration when choosing controller gains. This could be done either by tuning the controller for maximum pressure, or by implementing gain-scheduling to 
increase the response at lower pressures.

In the testing of control strategies for hybrid hydromechanical transmissions, hardware-in-the-loop simulation is a powerful tool. By including hardware in the simulation, it is closer to reality and should therefore be more reliable. It should be noted, however, that this reliability depends on accurate control in the hardware/software interface. In the setup used in this thesis, the greatest challenge was found to be the reproduction of highly dynamic events. This, in turn, limited what cases could be tested. Enhancement of the rig controllers and the measurement system could therefore be necessary to enable testing of other cases and transmission designs.

Another interesting question concerning hardware-in-the-loop simulations is the choice of hardware/software density of the model. The idea that the reliability of the results increases with the proportion of hardware present in the simulation is often implied in the literature. It could be argued, however, that the increased amount of hardware also increases uncertainty, since the software model represents the current state-of-knowledge of the system. From a strictly academic viewpoint, on the other hand, this increased uncertainty is also what is required to enable model validation. That is, the more reality that is included in the setup, the higher the chance of falsifying the model. The next problem is then to know what falsified it. This problem becomes more difficult the larger the step that is taken in hardware/software density, and the key is then to find an optimal step size.

In this thesis, the step from offline simulation to hardware-in-the-loop simulation was taken by replacing the hydraulic circuit with hardware. As a result, it was found that the line between the accumulators may cause a sufficiently high pressure drop to change the pressure dynamics. This new knowledge motivated an update of the model, which could lead to a new control strategy. For the given application, however, this is probably not necessary.

The next step in hardware/software density should be motivated by the scope of the investigation and the parts of the model that have low fidelity. In the setup used in this thesis, a natural next step could be to address fuel efficiency aspects and energy management strategies. This would then require more accurate prediction of engine fuel consumption than is possible with the current engine model. More specifically, a model with higher accuracy that considers intake pressure dynamics and the effect of the smoke-limiter in more detail is required. This model may, in turn, be represented as either software or hardware. 


\section{6 \\ Conclusions}

The overall aim of this thesis is to increase the knowledge of low-level control aspects that are important to consider to ensure the functionality of a complex hybrid hydromechanical transmission. Referring to the research questions listed in section 1.1, the following conclusions may be drawn:

RQ1: How is the mode shifting event in complex hybrid HMTs affected by the dynamic performance of the displacement controllers?

In hybrid systems, the impressed system pressure means that fast displacement controllers are needed to achieve fast torque control. Since mode shifts imply instantaneous changes in unit torques, displacement controllers that are too slow would cause disturbances in vehicle speed during the shift.

RQ2: What are the dominating dynamic characteristics in displacement controllers that use sensor-based feedback?

The dynamic response of displacement controllers that use a sensor for external displacement feedback is limited by the dynamics and the maximum flow of the control valve. By using software-based controllers, more sophisticated algorithms may be used to improve the response of the displacement controller.

RQ3: What is a suitable strategy for displacement control in hybrid HMTs?

For the hydrostatic units studied in this thesis, proportional-lead control showed significantly better performance and allowed more than four times higher resonance for the same relative damping compared to standard proportional control. If the valve dynamics are known, pole placement may be used to parametrise the controller using desired relative damping and resonance of the closed-loop system as input. The controller may thereby be trimmed in a simple, intuitive way. 
RQ4: What is required of the dynamic response of displacement controllers used in hybrid HMTs?

High bandwidth and well-damped displacement controllers are required in hybrid multiple-mode hydromechanical transmissions to ensure closed-loop stability, and to minimise disturbances during the mode shifting event. In addition, equal response of the two hydrostatic units facilitates a decoupled powertrain control approach. This criterion may, for instance, be fulfilled with the displacement control strategies proposed in this thesis.

RQ5: What is a suitable strategy for powertrain control in hybrid HMTs? Decoupled control is suitable in complex hybrid hydromechanical transmissions, since these systems contain cross-couplings between several states (pressure, engine speed and vehicle speed) that are desired to control individually. Also, it facilitates the implementation of output torque control for the operator.

If based on a general model of the transmission kinematics, a decoupled control approach may be applied to a high number of transmission configurations in a convenient manner. In addition, this approach cancels out the steady-state errors caused by the system cross-couplings without an introduction of integrating elements, which should facilitate mode shifts in multiple-mode transmissions. 


\section{7 \\ Review of Papers}

\section{Paper I}

\section{Mode Shifting in Hybrid Hydromechanical Transmissions}

In this paper, the problem of shifting modes in hybrid hydromechanical transmissions is identified. The problem is linked to the hydraulic accumulator's influence on the pressure in the hydrostatic circuit. A black box model approach is used to identify mode shift categories and how the mode shift affects the torques on the hydrostatic transmission for the different categories. Two hydrostatic transmission circuit configurations are presented, one of which includes a high-speed switching valve. The transmission concept studied in paper [VI] is hybridised and the two hydrostatic transmission configurations are evaluated in simulations. The benefits of the high-speed switching valve and the significance of fast displacement actuators on the hydraulic units are shown.

\section{Paper II}

\section{Modelling of the Swash Plate Control Actuator in an Axial Piston Pump for a Hardware-in-the-Loop Simulation Test Rig}

Here, a model of a swash plate control actuator for a prototype pump of axial piston, in-line design is derived. The model is implemented in Hopsan and validated with rig measurements. A sensitivity analysis is conducted to identify the parameters of highest significance in the dynamic behaviour of the control actuator. The major limiting factors of the displacement response are identified as the maximum control valve opening area and the break frequency of the control valve spool. 


\section{Paper III}

\section{Displacement Control Strategies of an In-Line Axial-Piston Unit}

In this paper, two controller architectures (proportional and proportional-lead) for displacement control of the prototype pump modelled in paper [II] are proposed. The controllers are parametrised using a pole placement approach, in which the desired relative damping and resonance of the closed-loop system are used as input. In simulations and hardware tests, the proportional-lead controller's performance is found to be superior to that of the proportional controller in terms of fast response with maintained damping. The response of the displacement controller is found to ultimately be limited by the maximum flow of the control valve, especially if the controller reference signal is a step with high amplitude.

\section{Paper IV}

\section{A General Approach to Low-level Control of Heavy Complex Hybrid Hydromechanical Transmissions}

In this paper, a decoupled Multiple-Input-Multiple-Output (MIMO) control strategy for powertrain control of complex hybrid Hydromechanical Transmissions (HMTs) is proposed. A linear model of a general hybrid HMT is derived and used to determine a decoupling strategy for the control approach. The strategy is tested on a reference vehicle in non-linear simulations and stability criteria for the decoupled loops are derived. It is found that the resulting output speed and system pressure loops rely on fast displacement control for stability. It is also found that the decoupling is facilitated if the displacement controllers of the two hydraulic units are equally fast. Suitable values for the resonance and damping used as input for the displacement control strategy proposed in paper [III] are derived based on pole placement of the closed decoupled output speed and pressure loops. The effects of non-linearities, such as limitation in displacement actuator flow and pressure-dependant hydraulic capacitance, on system response and dynamics are shown. 


\section{Paper V}

\section{Low-level Control of Hybrid Hydromechanical Transmissions for Heavy Mobile Working Machines}

In this paper, the decoupled control strategy proposed in paper [IV] is refined and focussed on multiple-mode hybrid HMTs. The strategy is combined with the proportional-lead displacement control strategy proposed in paper [III] and tested on a reference vehicle in hardware-in-the-loop simulations for two drive cycles. The benefit of the decoupled control strategy is shown via a comparison with a baseline approach which ignores the system's cross-couplings. In the context of multiple-mode hybrid HMTs, it is found that an important benefit of the proposed control strategy is that it minimises the steady-state errors caused by the cross-couplings without introducing integrating elements. In addition, the strategy implements torque control for the operator in a convenient manner. 


\section{A \\ Hopsan Component Models}

This chapter provides derivations of the Hopsan component models that were developed during the work presented in this thesis, but that are not provided in the appended papers. It should be pointed out that this chapter focuses on the individual components. See chapter 3 for examples of full system models that were used in the papers. Linearised representations of the vehicle, engine and accumulator that are used in the linearised transmission model in chapter 4 are provided as well.

The implementation of TLM in Hopsan distinguishes between C- and Q-type components $[102,79,77]$. During each simulation time step, a C-component determines and updates the characteristic impedance, $Z_{c}$, and the wave variable, $c$. Based on these values, a connected Q-component then updates the effort (torque, $T$ /pressure, $p$ ) and flow variables (angular velocity, $\omega /$ flow, $q$ ). The sign convention of these variables in C- and Q-components is different from what is commonly assumed when modelling mechanical components in the rotational domain. Translation of the states to TLM is therefore needed for some of the components described here. Throughout this chapter, states with signs according to TLM are labelled as $\left(\left[T_{i}, \omega_{i}\right],\left[p_{i}, q_{i}\right]\right)$, where $i \in[1,2,3 \ldots]$ denotes a component connection port. These states should be regarded as internal for each component and are provided in this chapter alone, to show the full Hopsan implementation according to TLM. 


\section{A.1 Mechanical Sub-Components}

The mechanical subsystem of a hydromechanical transmission is an assembly of gears, shafts and clutches. In Hopsan, the shafts are modelled as transmission line elements (C-components) in the rotational domain, while the gears are modelled as Q-components. The clutch components are modelled as shafts with limited transmittable torque, and are described in paper [I].

\section{A.1.1 Shaft}

Figure A.1 shows a rotating shaft represented as a transmission line element in the mechanical rotational domain. According to TLM [77], the relationship between the torques and the speeds of the two ends of the shaft may be expressed as:

$$
\begin{aligned}
& T_{1}(t)=Z_{c}\left[\omega_{1}(t)+\omega_{2}\left(t-T_{s}\right)\right]+T_{2}\left(t-T_{s}\right) \\
& T_{2}(t)=Z_{c}\left[\omega_{2}(t)+\omega_{1}\left(t-T_{s}\right)\right]+T_{1}\left(t-T_{s}\right)
\end{aligned}
$$

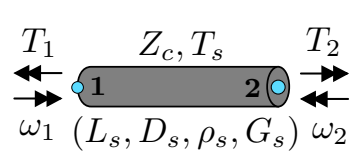

(a) Transmission line element representation, with characteristic impedance $Z_{c}$, time delay $T_{s}$, length $L_{s}$, diameter $D_{s}$, density $\rho_{s}$ and shear modulus $G_{s}$.

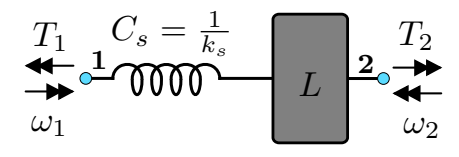

(b) Lumped parameter representation, with capacitance $C_{s}$, spring coefficient $k_{s}$ and inductance (inertia) L.

Figure A.1 Mechanical rotating shaft with torques $T_{1}$ and $T_{2}$ and angular velocities $\omega_{1}$ and $\omega_{2}$, modelled as a $C$-component with the corresponding sign conventions of torques and speeds. The bold numbers denote connection port indices.

The wave variables, $c_{1}$ and $c_{2}$, are introduced according to:

$$
\begin{aligned}
& c_{1}(t)=Z_{c} \omega_{2}\left(t-T_{s}\right)+T_{2}\left(t-T_{s}\right) \\
& c_{2}(t)=Z_{c} \omega_{1}\left(t-T_{s}\right)+T_{1}\left(t-T_{s}\right)
\end{aligned}
$$

By combining equations (A.1) and (A.2) the torques may be expressed as:

$$
\begin{aligned}
& T_{1}(t)=c_{1}(t)+Z_{c} \omega_{1}(t) \\
& T_{2}(t)=c_{2}(t)+Z_{c} \omega_{2}(t)
\end{aligned}
$$


A shift of equations (A.3) an interval $T_{s}$ back in time combined with equations (A.2) yields how the wave variables are updated for each time step in the simulation according to:

$$
\begin{aligned}
& c_{1}(t)=2 Z_{c} \omega_{2}\left(t-T_{s}\right)+c_{2}\left(t-T_{s}\right) \\
& c_{2}(t)=2 Z_{c} \omega_{1}\left(t-T_{s}\right)+c_{1}\left(t-T_{s}\right)
\end{aligned}
$$

The wave variables are then filtered with a numerical damping factor $\alpha_{f} \in$ [0...0.5] according to equations (A.5), to dampen high-frequency oscillations otherwise present in a pure, lossless transmission line:

$$
\begin{aligned}
& c_{1 f}(t)=\alpha_{f} c_{1 f}\left(t-T_{s}\right)+\left(1-\alpha_{f}\right) c_{1}(t) \\
& c_{2 f}(t)=\alpha_{f} c_{2 f}\left(t-T_{s}\right)+\left(1-\alpha_{f}\right) c_{2}(t)
\end{aligned}
$$

The implementation of $\alpha_{f}$ may physically be interpreted as an introduction of viscoelastic material properties; although high-frequency oscillations are damped, no losses are present at steady state [102].

In the low frequency range the transmission line shaft component may be represented by the model shown in figure A.1b. In this representation, the shaft is a lumped capacitance, $C_{s}=1 / k_{s}$, and inductance (inertia), $L$. For a real shaft, $T_{s}$ is a consequence of $C_{s}$ and $L$. In a Hopsan simulation model, however, $T_{s}$ is the same as the simulation time step and equal for all shafts. Therefore, desired values of both $L$ and $C_{s}$ may not be achieved at the same time. This aspect of TLM is commonly handled by choosing $Z_{c}$ based on the dominating effect (capacitance/inductance), and making sure the resulting parasitic inductance/capacitance is sufficiently small to be ignored or compensated for in the adjacent components [77]. For correct capacitance, $Z_{c}$ may be chosen according to equation (A.6a) [102], thereby resulting in a parasitic inductance, $L_{p}$, according to:

$$
\begin{aligned}
Z_{c} & =\frac{1}{1-\alpha_{f}} \frac{T_{s}}{C_{s}}=\frac{1}{1-\alpha_{f}} k_{s} T_{s} \\
L_{p} & =\frac{1}{C_{s}}\left(\frac{T_{s}}{1-\alpha_{f}}\right)^{2}=k_{s}\left(\frac{T_{s}}{1-\alpha_{f}}\right)^{2}
\end{aligned}
$$

Alternatively, $Z_{c}$ may be chosen according to (A.7a) for correct inductance, thereby resulting in a parasitic capacitance, $C_{p}$, according to:

$$
\begin{aligned}
Z_{c} & =\left(1-\alpha_{f}\right) \frac{L}{T_{s}} \\
C_{p} & =\frac{1}{k_{s}}=\frac{1}{L}\left(\frac{T_{s}}{1-\alpha_{f}}\right)^{2}
\end{aligned}
$$


Note that in both approaches, the parasitic property is significantly reduced by a smaller time step. For the models used in this thesis work, the approach in equations (A.6) is used, but $T_{s}, k_{s}$ and $\alpha_{f}$ are chosen so that $L_{p}$ may represent the lumped inertia of the shaft/gear combination. This lowers the modelling complexity, as the spur gears and planetary gears may be modelled as static components.

The stiffness, $k_{s}$, and inertia, $L$, of the shaft in figure A.1a may also be calculated from its physical properties according to:

$$
\begin{aligned}
& k_{s}=\frac{1}{C_{s}}=\frac{\pi D_{s}^{4}}{32 L_{s}} G_{s} \\
& L=\frac{1}{32} \pi D^{4} L_{s} \rho_{s}
\end{aligned}
$$

Combined with equations (A.6), equations (A.8) may be used to give a hint of proper values of $k_{s}, \alpha_{f}$ and $T_{s}$ according to:

$$
\begin{aligned}
L_{s} & =\frac{1}{1-\alpha_{f}} T_{s} \sqrt{\frac{G_{s}}{\rho_{s}}} \\
D_{s} & =\sqrt[4]{\frac{32}{\pi\left(1-\alpha_{f}\right)} k_{s} T_{s} \sqrt{\frac{1}{\rho_{s} G_{s}}}}
\end{aligned}
$$

For instance, the parameter values used in the simulations presented in this thesis were $\alpha_{f}=0.3, T_{s}=0.0001 \mathrm{~s}$ and $k_{s}=100000 \mathrm{Nm} / \mathrm{rad}$. Assuming steel shafts $\left(\rho_{s} \approx 7800 \mathrm{~kg} / \mathrm{m}^{3}, G_{s} \approx 80 \mathrm{GPa}\right)$, this results in $D_{s} \approx 0.05 \mathrm{~m}$, $L_{s} \approx 0.46 \mathrm{~m}$ and $L \approx 0.002 \mathrm{kgm}^{2}$. It should be noted, that if $T_{s} \rightarrow 0, L_{p} \rightarrow 0$ as well, and no inertia is present in the transmission. This approach may then be difficult to use in a general offline simulation as the simulation time step is used as a model parameter. In this thesis, the approach is, however, motivated by the application of HWIL simulations since a larger time step lowers the computational effort during the real-time simulations.

\section{A.1.2 Gears}

The gears are modelled as stiff and massless as shown in Figure A.2.

\section{Spur Gear}

The governing equations for the spur gear are determined by:

$$
\begin{aligned}
& \omega_{s g, \text { out }}=i_{s g} \omega_{s g, \text { in }} \\
& T_{s g, \text { out }}=-\frac{T_{s g, \text { in }}}{i_{s g}} \eta_{s g}^{j_{s g}}
\end{aligned}
$$




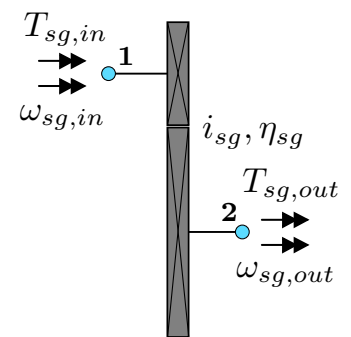

(a) Spur gear with speed ratio $i_{s g}$, torques $T_{s g, \text { in }}$ and $T_{s g, o u t}$, shaft speeds $\omega_{s g, i n}$ and $\omega_{s g, o u t}$ and efficiency $\eta_{s g}$.

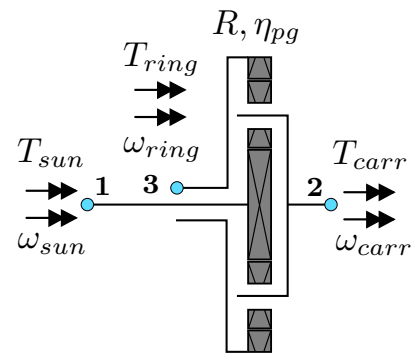

(b) Planetary gear with standing gear ratio $R$, ring torque $T_{\text {ring }}$, carrier torque $T_{\text {carr }}$, sun torque $T_{\text {sun }}$, ring speed $\omega_{\text {sun }}$, carrier speed $\omega_{\text {carr }}$, sun speed $\omega_{\text {sun }}$ and efficiency $\eta_{p g}$.

Figure A.2 Mechanical gears for the mechanical subsystem (Q-components). The bold numbers denote connection port indices.

where $i_{s g}<0$ indicate an external gear. $j_{s g}$ is defined as:

$$
j_{s g}= \begin{cases}1 & , T_{s g, i n} \omega_{s g, i n}>0 \\ -1 & , T_{s g, i n} \omega_{s g, i n} \leq 0\end{cases}
$$

The torque and shaft speeds are translated to those of a Q-component (index according to figure A.2a):

$$
\left\{\begin{array}{l}
\omega_{1}=-\omega_{s g, \text { in }} \\
\omega_{2}=\omega_{\text {sg, out }}
\end{array},\left\{\begin{array}{l}
T_{1}=T_{\text {sg }, \text { in }} \\
T_{2}=-T_{\text {sg,out }}
\end{array}\right.\right.
$$

In Hopsan, the Q-type gear components update the speed and torque at each connection port according to equation (A.3). For the spur gear, the shaft speeds are then updated according to ${ }^{1}$ :

$$
\left\{\begin{array}{l}
\omega_{1}=\frac{-c_{1} \eta_{s g}^{j_{s g}}+c_{2} i_{s g}}{\eta_{s g}^{j_{s g}} Z_{c 1}+i_{s g}^{2} Z_{c 2}} \\
\omega_{2}=-i \omega_{1}
\end{array}\right.
$$

where the shaft torques have been rewritten as:

$$
\left\{\begin{array}{l}
T_{1}=c_{1}+Z_{c 1} \omega_{1} \\
T_{2}=c_{2}+Z_{c 2} \omega_{2}
\end{array}\right.
$$

After the speeds have been updated according to equation (A.13), equations (A.14) may be used to update the torques.

\footnotetext{
${ }^{1}$ Note that the implementation of equations (A.13) implies that $\omega_{1}$ is calculated before $\omega_{2}$.
} 


\section{Planetary Gear}

The governing equations for the planetary gear are given by [103]:

$$
\begin{aligned}
& R=\frac{\omega_{\text {sun }}-\omega_{\text {carr }}}{\omega_{\text {ring }}-\omega_{\text {carr }}} \\
& T_{\text {sun }}+T_{\text {carr }}+T_{\text {ring }}=0 \\
& T_{\text {ring }}=-T_{\text {sun }} R \eta_{\text {pg }}^{j_{\text {pg }}}
\end{aligned}
$$

where $j_{p g}$ is defined as:

$$
j_{p g}= \begin{cases}1 & , T_{\text {sun }}\left(\omega_{\text {sun }}-\omega_{\text {carr }}\right) \geq 0 \\ -1 & , T_{\text {sun }}\left(\omega_{\text {sun }}-\omega_{\text {carr }}\right)<0\end{cases}
$$

The torque and shaft speeds are translated to those of a Q-component (index according to figure A.2b):

$$
\left\{\begin{array}{l}
\omega_{1}=-\omega_{\text {sun }} \\
\omega_{2}=\omega_{\text {carr }} \\
\omega_{3}=-\omega_{\text {ring }}
\end{array},\left\{\begin{array}{l}
T_{1}=T_{\text {sun }} \\
T_{2}=-T_{\text {carr }} \\
T_{3}=T_{\text {ring }}
\end{array}\right.\right.
$$

In a similar way to the spur gears, the shaft speeds may be updated during each simulation time step in Hopsan according to ${ }^{2}$ :

$$
\left\{\begin{array}{l}
\omega_{1}=\frac{c_{3} R Z_{c 2}+\left(c_{2}-c_{1}\right)(R-1) Z_{c 3}+c_{1} \eta_{p g}^{j_{p g}} R\left[R\left(Z_{c 2}+Z_{c 3}\right)-Z_{c 3}\right]}{\left(R Z_{c 1}-Z_{c 1}-Z_{c 2}\right) Z_{c 3}+\eta_{p g}^{j_{p g}} R Z_{c 1}\left[Z_{c 3}-R\left(Z_{c 2}+Z_{c 3}\right)\right]} \\
\omega_{2}=\frac{\left(\eta_{p g}^{j p g} R-1\right)\left(c_{3} R Z_{c 1}-c_{1} Z_{c 3}\right)-c_{2}\left(\eta_{p g}^{j p g} R^{2} Z_{c 1}+Z_{c 3}\right)}{\left[(1-R) Z_{c 1}+Z_{c 2}\right] Z_{c 3}+\eta_{p g}^{j_{p g}} R Z_{c 1}\left[R\left(Z_{c 2}+Z_{c 3}\right)-Z_{c 3}\right]} \\
\omega_{3}=\frac{1}{R} \omega_{1}+\left(\frac{1}{R}-1\right) \omega_{2}
\end{array}\right.
$$

where the torques have been rewritten as:

$$
\left\{\begin{array}{l}
T_{1}=c_{1}+Z_{c 1} \omega_{1} \\
T_{2}=c_{2}+Z_{c 2} \omega_{2} \\
T_{3}=c_{3}+Z_{c 3} \omega_{3}
\end{array}\right.
$$

After the speeds have been updated according to equation (A.18), equations (A.19) may be used to update the torques.

\footnotetext{
${ }^{2}$ Note that the implementation of equations (A.18) implies that $\omega_{1}$ and $\omega_{3}$ are calculated before $\omega_{2}$.
} 


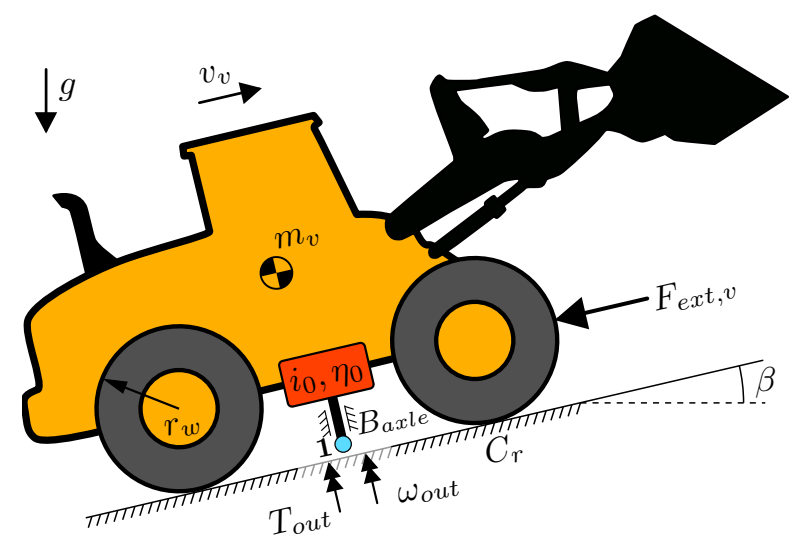

Figure A.3 $1-D$ vehicle ( $Q$-component) with mass $m_{v}$, vehicle velocity $v_{v}$, wheel radius $r_{w}$, axle losses $B_{a x l e}$, rolling resistance coefficient $C_{r}$, final gear ratio $i_{0}$ and final gear efficiency $\eta_{0}$. $T_{\text {out }}$ is the torque from transmission and $F_{\text {ext,v }}$ is an external force. $\omega_{\text {out }}$ is the transmission output shaft angular velocity and $\beta$ the road slope. The bold number indicates the connection port index.

\section{A.2 Vehicle}

The vehicle is modelled as a Q-component as shown in figure A.3. It is represented as a one-dimensional mass, ignoring aerodynamic forces and tyre slip. The governing equations for the model may be derived using Newton's second law of motion (Laplace-transformed):

$$
\begin{aligned}
& \frac{T_{\text {out }}}{i_{0} r_{w}} \eta_{0}^{j_{f g}}-B_{a x l e} v_{v}-m_{v} g \cos (\beta) C_{r} \cdot j_{c r}-m_{v} g \sin (\beta)-F_{e x t, v}=m_{v} v_{v} \cdot s \\
& j_{f g} \text { is determined by: }
\end{aligned}
$$

$$
j_{f g}= \begin{cases}1 & , T_{\text {out }} \omega_{\text {out }} \geq 0 \\ -1 & , T_{\text {out }} \omega_{\text {out }}<0\end{cases}
$$

and $j_{c r}$ is calculated as:

$$
j_{c r}= \begin{cases}1 & , v_{v}>0 \\ -1 & , v_{v} \leq 0\end{cases}
$$

The vehicle velocity may be translated to angular velocity at the transmission output shaft via the final gear ratio and the wheel radius:

$$
\omega_{\text {out }}=\frac{v_{v}}{i_{0} r_{w}}
$$


The shaft torque and speed are translated to those of a Q-component (index according to figure A.3):

$$
\left\{\begin{array}{l}
\omega_{1}=-\omega_{\text {out }} \\
T_{1}=T_{\text {out }}
\end{array}\right.
$$

As with the gears in section A.1.2, the output shaft speed may be updated during each simulation time step in Hopsan according to:

$$
\omega_{1}=\frac{-c_{1} \eta_{0}^{j_{f g}}+F_{e x t, v} i_{0} r_{w}+C_{r} j_{c r} m_{v} g r_{w} i_{0}}{B_{a x l e} i_{0}^{2} r_{w}^{2}+\eta_{0}^{j_{f g}} Z_{c 1}+m_{v} i_{0}^{2} r_{w}^{2} \cdot s}
$$

where the shaft torque has been rewritten as:

$$
T_{1}=c_{1}+Z_{c 1} \omega_{1}
$$

Note that, unlike the gear components in section A.1.2, equation (A.25) contains time derivatives. In Hopsan, the required integration of equation (A.25) is done with filters based on bilinear transform [78]. After $\omega_{1}$ has been updated, $T_{1}$ may be updated according to equation (A.26). $\omega_{\text {out }}$ and $v_{v}$ may then be updated with equations (A.24) and (A.23), respectively.

\section{A.2.1 Linearised representation}

In the linearised model presented in chapter 4 , the vehicle is represented in the rotational domain (Laplace-transformed):

$$
\omega_{\text {out }}=\frac{1}{J_{v} s+B_{v}}\left(T_{\text {out }}-T_{\text {ext }, v}\right)
$$

where $J_{v}$ is the equivalent rotational inertia:

$$
J_{v}=m_{v}\left(i_{0} r_{w}\right)^{2}
$$

and $B_{v}$ is the rotational viscous friction, calculated by transforming the axle losses to the rotational domain:

$$
B_{v}=B_{a x l e}\left(i_{0} r_{w}\right)^{2}
$$

$T_{e x t, v}$ is the translated external force:

$$
T_{e x t, v}=F_{e x t, v} r_{w} i_{0}
$$




\section{A.3 The Efficiency Flip}

In the gears and the vehicle models presented above, constant efficiencies and rolling resistance are used. Since the losses change direction depending on the power flow direction, sign functions are used (equations (A.11), (A.16), (A.21), (A.22)) to flip the efficiencies with the variables $j_{s g}, j_{p g}, j_{f g}$ and change the sign of the rolling resistance force with the variable $j_{c r}$. Due to the constant simulation time step used in Hopsan, pure sign functions tend to lead to oscillations near zero power flows, see figure A.4b. To lower this effect, the sign functions are implemented with a sigmoid function:

$$
j=\frac{2}{1+e^{-\frac{x}{x_{0}}}}-1
$$

where $x$ is the parameter that determines if $j$ should change sign (e.g. $x=$ $T_{s g, i n} \omega_{s g, i n}$ determines the sign of $j=j_{s g}$ in equation (A.21)), and $x_{0}$ is a tuning parameter. As shown in figure A.4a, the sigmoid function approaches a pure sign function for $x_{0} \rightarrow 0$.

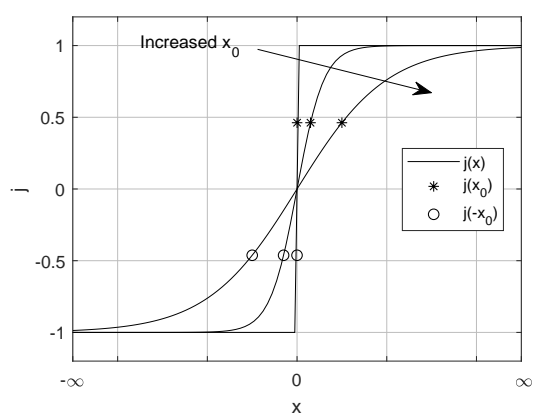

(a) Sigmoid function

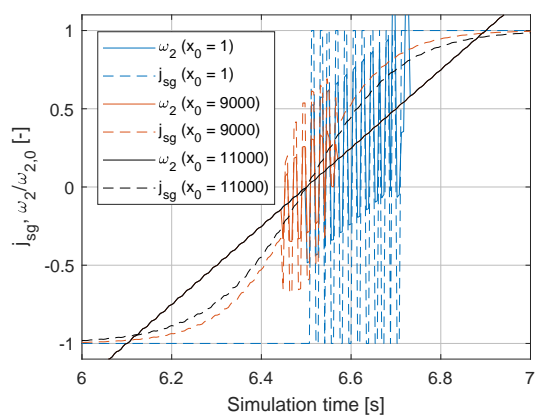

(b) Example simulation of the spur gear model when changing speed direction under constant torque $T_{2}=1000 \mathrm{Nm}$. $\eta_{s g}=$ $0.98, i_{s g}=-1, \omega_{2,0}=400 \mathrm{rpm}$.

Figure A.4 Effect of the sigmoid function according to equation (A.31).

\section{A.4 Diesel Engine}

This section describes the diesel engine model used in papers $[\mathrm{IV}, \mathrm{V}]^{3}$. It is modelled based on the Mean Value Engine Modelling (MVEM) principle and assumed to operate under optimal ignition and lean fuel mixture, which is a

\footnotetext{
${ }^{3}$ In paper [I], a simpler model, described in [55], was used.
} 
common assumption for a diesel engine [58]. In Hopsan, it is modelled as a C-type torque source component. The structure of the component is shown as a block diagram in figure A.5.

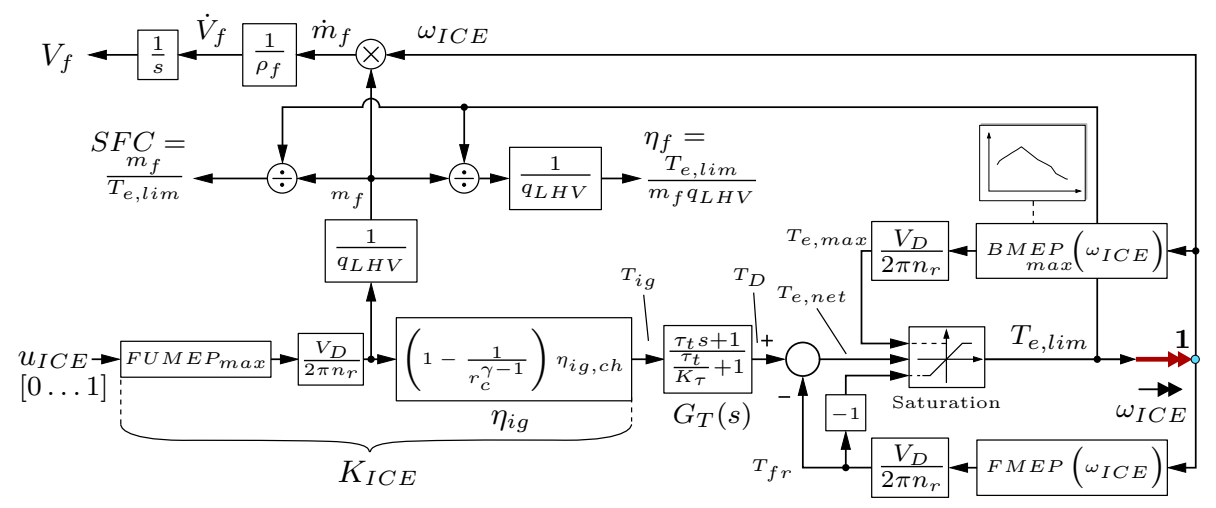

Figure A.5 Block diagram of a diesel engine modelled as a C-type torque source component. The bold number denotes the connection port index.

The engine control input is a normalised injected fuel, $u_{I C E} \in[0 \ldots 1]$ :

$$
u_{I C E}=\frac{m_{f}}{m_{f, \max }}
$$

which translates to an indicated gross torque, $T_{i g}$, according to:

$$
T_{i g}=u_{I C E} K_{I C E}
$$

$K_{I C E}$ is the static engine gain which is a lumped parameter, defined as:

$$
K_{I C E}=\frac{F U M E P_{\max } \eta_{i g} V_{D}}{2 \pi n_{r}}
$$

where $F U M E P_{\max }$ is the maximum Fuel Mean Effective Pressure (FUMEP) [39], which was approximated for the engine in [104] (FUMEP $\max \approx 51$ bar), and is regarded as independent of engine size $\left(m_{f, \max }\right.$ is assumed to scale with $\left.V_{D}\right)$ :

$$
F U M E P_{\max }=\frac{q_{L H V} m_{f, \max }}{V_{D}}
$$

where $q_{L H V}$ is the fuel lower heating value (for diesel: $q_{L H V} \approx 43 \mathrm{MJ} / \mathrm{kg}$ $[58]) . \eta_{i g}$ is the indicated gross efficiency, calculated according to:

$$
\eta_{i g}=\left(1-\frac{1}{r_{c}^{\gamma-1}}\right) \eta_{i g, c h}
$$


where $r_{c}$ is the compression ratio, $\gamma=\frac{c_{p}}{c_{v}}$ is the ratio of specific heats for air, and $\eta_{i g, c h}$ represents the combustion chamber losses (assumed constant). The indicated gross torque is delayed according to:

$$
T_{D}=G_{T}(s) T_{i g}
$$

where $G_{T}(s)$ is the turbo dynamics, which are modelled according to Lennevi et al. [96]:

$$
G_{T}(s)=\frac{\tau_{T} s+1}{\frac{\tau_{T}}{K_{\tau}} s+1}
$$

where $\tau_{T}$ is the turbo time constant and $K_{\tau}$ is the turbo gain. The net engine torque, $T_{e, n e t}$, is determined by subtracting the friction torque, $T_{f r}$, according to:

$$
T_{e, n e t}=T_{D}-T_{f r}
$$

where $T_{f r}$ is determined by the Friction Mean Effective Pressure (FMEP):

$$
T_{f r}=\frac{V_{D}}{2 \pi n_{r}} F M E P\left(\omega_{I C E}\right)
$$

The FMEP is modelled as a polynomial function of engine speed $[58]^{4}$ :

$$
\begin{gathered}
F M E P\left(\omega_{I C E}\right)=c_{f r 1} \omega_{I C E}^{2}+c_{f r 2} \omega_{I C E}+c_{f r 3} \\
c_{f r 1}=6.5620 \mathrm{~Pa} \cdot \mathrm{s}^{2} / \mathrm{rad}^{2} \quad c_{f r 2}=-135.0271 \mathrm{~Pa} \cdot \mathrm{s} / \mathrm{rad} \quad c_{f r 3}=35900 \mathrm{~Pa}
\end{gathered}
$$

The FMEP according to equation (A.41) is plotted as a function of engine speed in figure A.7. Finally, a saturation is implemented on $T_{e, n e t}$ due to the maximum torque characteristics of the engine:

$$
T_{e, l i m}= \begin{cases}T_{e, \max }\left(\omega_{I C E}\right) & , T_{e, n e t}>T_{e, \max }\left(\omega_{e}\right) \\ T_{e, n e t} & ,-T_{f r}\left(\omega_{I C E}\right)<T_{e, n e t} \leq T_{e, \max }\left(\omega_{I C E}\right) \\ -T_{f r}\left(\omega_{I C E}\right) & , T_{e, n e t} \leq-T_{f r}\left(\omega_{I C E}\right)\end{cases}
$$

These maximum torque characteristics are implemented as:

$$
T_{e, \max }\left(\omega_{I C E}\right)=\frac{V_{D}}{2 \pi n_{r}} B M E P_{\max }\left(\omega_{I C E}\right)
$$

where $B M E P_{\max }\left(\omega_{I C E}\right)$ is the maximum Break Mean Effective Pressure (BMEP), which was obtained from the maximum torque curve of the engine in [104] and is shown in figure A.7.

\footnotetext{
${ }^{4}$ The numerical values for the friction parameters were extracted from the model derived in [64].
} 
As shown in the block diagram in figure A.5, the input signal may be used to calculate the consumed mass fuel during the simulation:

$$
m_{f}=\frac{V_{D} F U M E P_{\max }}{2 \pi n_{r} q_{L H V}} u_{I C E}
$$

With the engine speed, $m_{f}$ may in turn be used to determine the mass fuel rate, $\dot{m}_{f}$, and the volumetric fuel consumption:

$$
\left\{\begin{array}{l}
\dot{V}_{f}=\frac{\dot{m}_{f}}{\rho_{f}}=\frac{m_{f}}{\rho_{f}} \omega_{I C E} \\
V_{f}=\int \dot{V}_{f} d t
\end{array}\right.
$$

where $\rho_{f}$ is the fuel density, (for diesel: $\rho_{f} \approx 820 \mathrm{~kg} / \mathrm{m}^{3}$ [58]). The Specific Fuel Consumption (SFC), and the fuel efficiency, $\eta_{f}$, may also be determined from $m_{f}$ :

$$
\begin{aligned}
& S F C=\frac{m_{f}}{T_{e, l i m}} \\
& \eta_{f}=\frac{T_{e, l i m}}{m_{f} q_{L H V}}
\end{aligned}
$$

The shaft torque and speed are translated to those of a C-component (index according to figure A.5):

$$
\left\{\begin{array}{l}
\omega_{1}=-\omega_{I C E} \\
T_{1}=T_{e, l i m}
\end{array}\right.
$$

The engine is modelled as a C-type torque source:

$$
\left\{\begin{array}{l}
c_{1}=T_{e, l i m} \\
Z_{c 1}=0 \\
\left(T_{1}=c_{1}+Z_{c 1} \omega_{1}\right)
\end{array}\right.
$$

During simulation, the wave variable is thus continuously updated via $u_{I C E}$, while $\omega_{1}=-\omega_{I C E}$ and $T_{e, l i m}=T_{1}$ are updated by the engine flywheel component.

\section{A.4.1 Engine Flywheel}

The engine flywheel is implemented with the Q-component for a rotational inertia in the Hopsan standard library, and its implementation according to TLM is therefore not included here. The fundamental equations are, however, repeated to show their relation to the rest of the engine and transmission model. A free body diagram of the engine flywheel is shown in figure A.6. The governing equations are determined by the law of motion in the rotational domain:

$$
T_{e, l i m}-T_{I C E}-T_{e x t, I C E}=J_{I C E} \dot{\omega}_{I C E}
$$


where $T_{I C E}$ is the torque from the transmission and $T_{\text {ext,ICE }}$ is an external torque acting on the engine, for instance from a working hydraulics pump.

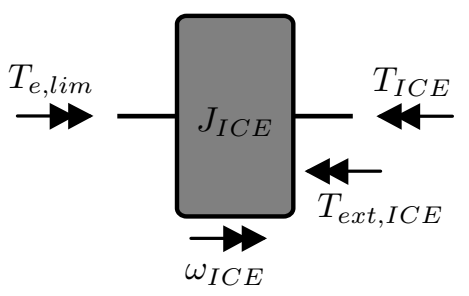

Figure A.6 Free body diagram of the engine flywheel with rotational inertia $J_{I C E}(Q$-component).

\section{A.4.2 Linearised Representation}

In the linearised model presented in chapter 4, the governing dynamics are determined according to:

$$
\omega_{I C E}=\frac{1}{J_{I C E} s+B_{I C E}}\left(G_{T}(s) K_{I C E} u_{I C E}-T_{e x t, I C E}-T_{I C E}\right)
$$

where $B_{I C E}$ is the engine viscous friction:

$$
\begin{aligned}
B_{I C E} & =\left(\frac{\mathrm{d} T_{f r}}{\mathrm{~d} \omega_{I C E}}\right)_{\omega_{I C E}=\omega_{I C E, 0}}=\frac{V_{D}}{2 \pi n_{r}}\left(\frac{\mathrm{d} F M E P}{\mathrm{~d} \omega_{I C E}}\right)_{\omega_{I C E}=\omega_{I C E, 0}} \\
& =\frac{V_{D}}{2 \pi n_{r}}\left(2 c_{f r 1} \omega_{I C E, 0}+c_{f r 2}\right)
\end{aligned}
$$

As seen in equation (A.52), $B_{I C E}$ varies with $\omega_{I C E, 0}$. With friction parameters according to [64], it was found that $\omega_{I C E, 0} \approx 1745 \mathrm{rpm}$ gave a good average value, see figure A.7.

\section{A.4.3 Static Characteristics}

To give an idea of the model's general properties, its static characteristics are plotted in figure A.7. The viscous friction model is represented as FMEP. $\eta_{f}$ and $S F C$ have been calculated as functions of the BMEP:

$$
B M E P=u_{I C E} F U M E P_{\max } \eta_{i g}-F M E P
$$




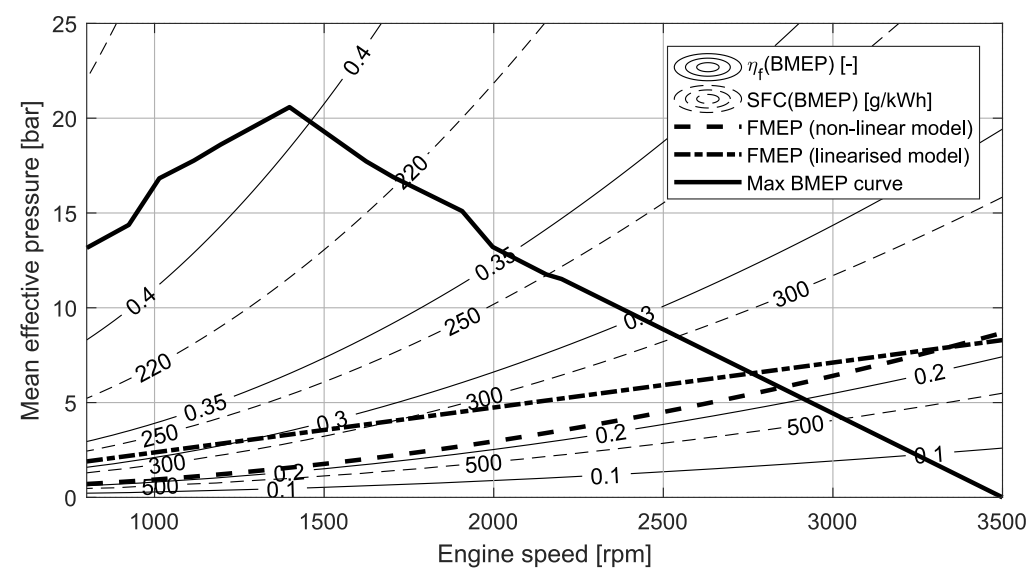

Figure A.7 Static characteristics of the engine model.

\section{A.5 Accumulator}

In this thesis, a piston-type accumulator is modelled. It is assumed that the gas pressure is equal to the oil pressure, and the compressibility of the oil is ignored in comparison to that of the nitrogen. A schematic of the accumulator model and its parameters is shown in Figure A.8a.

To properly model the heat transfer between the gas and the surroundings, the gas temperature needs to be modelled. As derived by Rydberg [24], $T_{g}$ may be determined by the differential equation:

$$
\frac{\mathrm{d} T_{g}}{\mathrm{~d} t}=\frac{1}{\tau_{w}}\left(T_{\infty}-T_{g}\right)+\frac{T_{g}}{c_{v}}\left(\frac{\partial p_{s y s}}{\partial T_{g}}\right)_{v} \frac{q_{a c c}(t)}{m_{g}}
$$

where the thermal time constant, $\tau_{w}$, may be determined according to ${ }^{5}$ :

$$
\tau_{w}=\frac{m_{g} c_{v}}{\alpha_{w} A_{w}}
$$

where $\alpha_{w}$ is the wall heat transfer coefficient and $A_{w}$ is the accumulator surface area. The input flow, $q_{a c c}$, is regarded as an input signal, and may be translated to the rate of change of $V_{g}$ :

$$
\frac{\mathrm{d} V_{g}}{\mathrm{~d} t}=-q_{a c c}
$$

\footnotetext{
${ }^{5}$ In Rydberg's model [24], $c_{v}$ varies slightly with $p_{s y s}$ and $T_{g}$, and equation (A.55) then contains the mean value of $c_{v}$. In this thesis, $c_{v}$ is regarded as constant, with the sacrifice of less accurate prediction for pressures higher than 250 bar.
} 


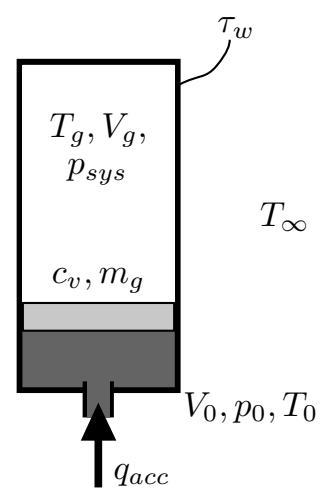

(a) Non-linear representation, with gas temperature $T_{g}$, gas pressure $p_{s y s}$ and gas volume $V_{g} . m_{g}$ is the gas mass, $c_{v}$ is the gas specific heat capacity, $T_{\infty}$ is the ambient temperature and $\tau_{w}$ is the thermal time constant. $V_{0}$ is the total accumulator volume, $p_{0}$ is the accumulator pre-charge pressure and $T_{0}$ is the temperature at precharge conditions $\left(V_{0}, T_{0}\right)$.

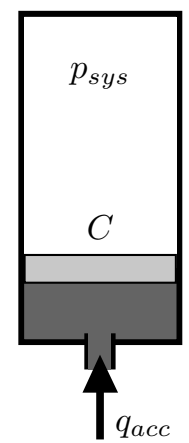

(b) Linear representation with gas pressure $p_{\text {sys }}$ and capacitance $C$.

Figure A.8 Accumulator models with input flow $q_{a c c}$.

The partial derivative, $\left(\frac{\partial p_{s y s}}{\partial T_{g}}\right)_{v}$, is calculated from an equation of state that describes the relationship between $p_{s y s}, T_{g}$ and $V_{g}$. Different equations of state with varying accuracy are commonly found in the literature, such as the ideal gas equation, the van der Waal equation or the Benedict-Webb-Rubin equation [105]. In this thesis, the Beattie-Bridgeman equation for nitrogen according to [24] is used:

$$
p_{\text {sys }}=\frac{R_{g} T_{g}}{v^{2}}\left(1-\frac{C_{0}}{v T_{g}^{3}}\right)\left[v+B_{0}\left(1-\frac{b_{0}}{v}\right)\right]-\frac{A_{0}}{v^{2}}\left(1-\frac{a_{0}}{v}\right)
$$

$$
\begin{array}{lll}
R_{g}=296.8 \mathrm{~J} /(\mathrm{kg} \cdot \mathrm{K}) & A_{0}=174.1 \mathrm{Jm}^{3} / \mathrm{kg}^{2} & B_{0}=1.801 \cdot 10^{-3} \mathrm{~m}^{3} / \mathrm{kg} \\
a_{0}=9.338 \cdot 10^{-4} \mathrm{~m}^{3} / \mathrm{kg} & b_{0}=-2.474 \cdot 10^{-4} \mathrm{~m}^{3} / \mathrm{kg} & C_{0}=5.095 \cdot 10^{-8} \mathrm{~m}^{3} \mathrm{~K}^{3} / \mathrm{kg}
\end{array}
$$

where $v=\frac{V_{g}}{m_{g}}$ is the specific gas volume. The partial derivative in equation (A.54) may then be determined according to:

$$
\left(\frac{\partial p_{\text {sys }}}{\partial T_{g}}\right)_{v}=\frac{R_{g}}{v^{2}}\left(1+\frac{2 C_{0}}{v T_{g}^{3}}\right)\left[v+B_{0}\left(1-\frac{b_{0}}{v}\right)\right]
$$




\section{A.5.1 Linearised Representation}

In the linear model presented in chapter 4 , the accumulator is modelled as a pure capacitance, $C$. Using the nomenclature in figure A.8b, hydraulic capacitance is defined as:

$$
\frac{\mathrm{d} p_{s y s}}{\mathrm{~d} t}=\frac{q_{a c c}}{C}
$$

$\frac{\mathrm{d} p_{\text {sys }}}{\mathrm{d} t}$ may be determined as the time derivative of the Beattie-Bridgeman equation (A.57) according to:

$$
\frac{\mathrm{d} p_{\text {sys }}}{\mathrm{d} t}=\left(\frac{\partial p_{\text {sys }}}{\partial v}\right)_{T_{g}} \frac{\mathrm{d} v}{\mathrm{~d} t}+\left(\frac{\partial p_{\text {sys }}}{\partial T_{g}}\right)_{v} \frac{\mathrm{d} T_{g}}{\mathrm{~d} t}
$$

Assuming $m_{g}$ is constant, $\frac{\mathrm{d} v}{\mathrm{~d} t}$ may be calculated according to:

$$
\frac{\mathrm{d} v}{\mathrm{~d} t}=\frac{1}{m_{g}} \frac{\mathrm{d} V_{g}}{\mathrm{~d} t}=-\frac{1}{m_{g}} q_{a c c}
$$

Equations (A.54) and (A.61) in equation (A.60) yield a new expression for $\frac{\mathrm{d} p_{\text {sys }}}{\mathrm{d} t}$ according to:

$$
\frac{\mathrm{d} p_{\text {sys }}}{\mathrm{d} t}=\left[-\left(\frac{\partial p_{\text {sys }}}{\partial v}\right)_{T_{g}}+\frac{T_{g}}{c_{v}}\left(\frac{\partial p_{\text {sys }}}{\partial T_{g}}\right)_{v}^{2}\right] \frac{1}{m_{g}} q_{a c c}+\left(\frac{\partial p_{\text {sys }}}{\partial T_{g}}\right)_{v} \cdot \frac{1}{\tau_{w}}\left(T_{\infty}-T_{g}\right)
$$

Identification with equation (A.60) yields an expression for the capacitance according to equation (A.63). The last term in equation (A.62) represents the heat losses to the environment, which is ignored in the linear model since the temperature is not included as a state.

$$
\frac{1}{C}=\left[-\left(\frac{\partial p_{\text {sys }}}{\partial v}\right)_{T_{g}=T_{g 0}, v=\frac{V_{g 0}}{m_{g}}}+\frac{T_{g}}{c_{v}}\left(\frac{\partial p_{\text {sys }}}{\partial T_{g}}\right)_{T_{g}=T_{g 0}, v=\frac{V_{g 0}}{m_{g}}}^{2}\right] \frac{1}{m_{g}}
$$

where $T_{g 0}$ and $V_{g 0}$ are linearisation points with respect to gas temperature and gas volume, respectively. The partial derivatives, $\frac{\partial p_{s y s}}{\partial T_{g}}$ and $\frac{\partial p_{s y s}}{\partial v}$, may be derived from the Beattie-Bridgeman equation (A.57) according to equations (A.58) and (A.64), respectively.

$$
\begin{aligned}
\left(\frac{\partial p_{\text {sys }}}{\partial v}\right)_{T_{g}} & =-\frac{1}{v^{2}} R_{g} T_{g}+\frac{2}{T_{g}^{2} v^{3}}\left(C_{0} R_{g}+A_{0} T_{g}^{2}-B_{0} R_{g} T_{g}^{3}\right)+ \\
& \frac{3}{T_{g}^{2} v^{4}}\left(B_{0} C_{0} R_{g}-a_{0} A_{0} T_{g}^{2}+b_{0} B_{0} R_{g} T_{g}^{3}\right)-\frac{4}{T_{g}^{2} v^{5}} b_{0} B_{0} C_{0} R_{g}
\end{aligned}
$$


$m_{g}$ may be determined from the initial state of the gas, i.e. the gas precharge pressure, $p_{0}$, the pre-charge temperature, $T_{0}$, and the total accumulator volume, $V_{0}$. Assuming these are given, equation (A.57) may be solved for $m_{g}$. Figure A.9a illustrates the relationship between gas pressure and gas volume for different gas temperatures, calculated with the Beattie-Bridgeman equation (A.57) for different accumulator sizes. Due to the temperature dependency, the gas pressure may be both lower and higher than the pre-charge pressure, $p_{0}$, when the accumulator is empty. Figure A.9b shows the variation in hydraulic capacitance for the same conditions and indicates a strong influence from pressure and accumulator volume.

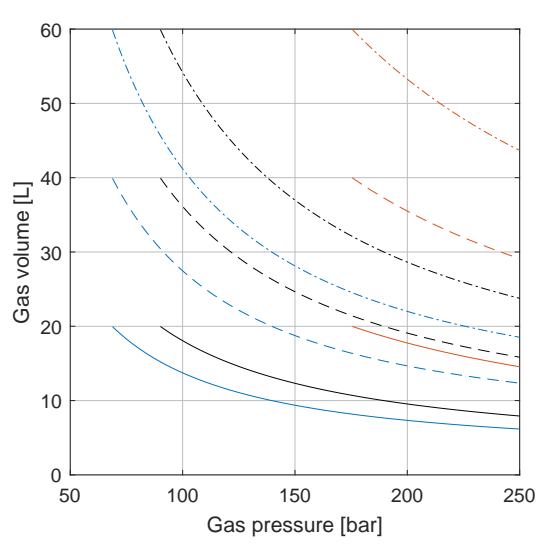

(a) Gas volume as function of gas pressure according to the Beattie-Bridgeman equation (A.57).

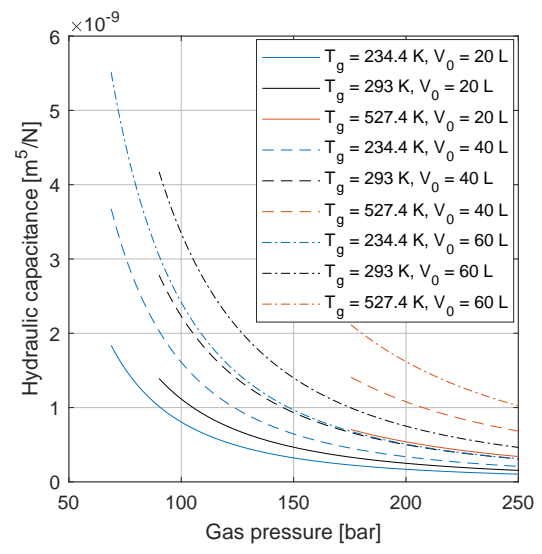

(b) Hydraulic capacitance as function of gas pressure.

Figure A.9 Illustration of the variation in gas volume and capacitance depending on gas pressure and gas temperature for different accumulator sizes. The gas mass was calculated under the assumption that $V_{g}=V_{0}$ at $T_{g}=T_{0}=293$ $K$ and $p_{\text {sys }}=p_{0}=90$ bar.

In Hopsan, the accumulator model derived above is implemented as a transmission line element with varying capacitance according to equation (A.63). This is combined with filters for calculating $V_{g}$ according to equation (A.56), and $T_{g}$ according to equation (A.54). $m_{g}$ is calculated iteratively in the initialisation, using the Newton-Raphson method with $m_{g}$ according to the ideal gas law as the initial guess. Figure A.10 shows a simulation of the accumulator model when it is first charged with a constant flow, then kept at constant gas volume and finally emptied with a constant flow. For comparison, the pressure curve for a linear model with constant capacitance subject to the same flow input is included as well. Clearly, the linear model does not capture the effect 
of considering the gas temperature and the thermal losses to the surroundings.

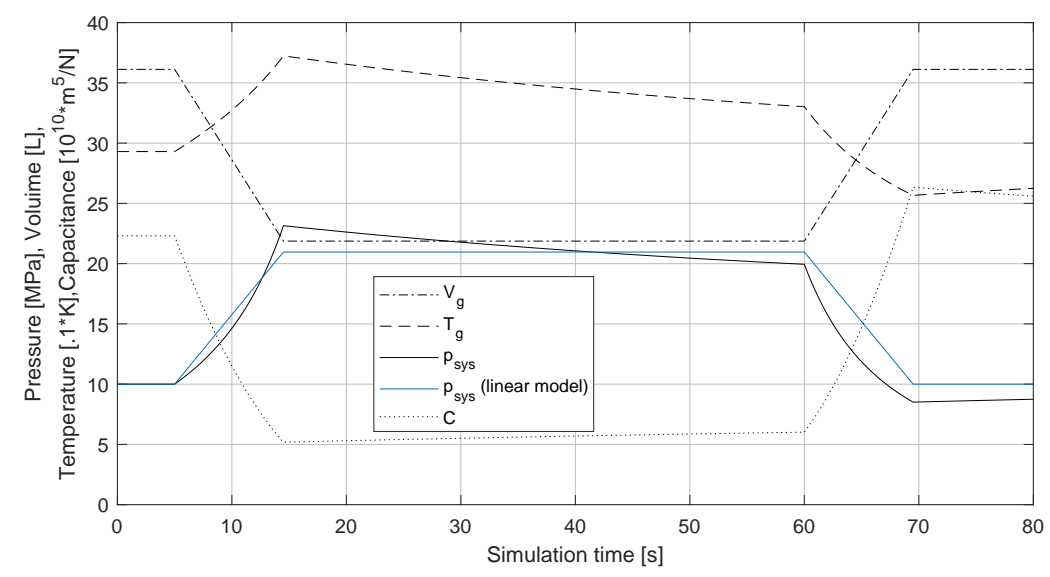

Figure A.10 Hopsan simulation of the non-linear and linear accumulator model for a charging and discharging cycle. Main simulation parameters: $T_{0}=$ $293 \mathrm{~K}, V_{0}=40 \mathrm{~L}, p_{0}=90 \mathrm{bar}, T_{\infty}=293 \mathrm{~K}, \tau_{w}=60 \mathrm{~s}, c_{v}=743 \mathrm{~J} /(\mathrm{Kg} \cdot \mathrm{K})$, $T=0.0001 \mathrm{~s}$ (simulation time step). For the linear model, $C=1.3 \cdot 10^{-9} \mathrm{~m}^{5} / \mathrm{N}$ was used.

\section{A.6 Hydrostatic Pump/Motors}

The component model described in this section was used to model the A11VO units in the HWIL simulation test rig. The units are modelled as Q-components in Hopsan, using the pump/motor component from the default library. The principal model layout is shown in figure A.11.

The shaft speed is determined by the equation of motion according to:

$$
T_{3}+B_{p m} \cdot \omega_{3}-\left(p_{1}-p_{2}\right) D \varepsilon=-J_{p m} \dot{\omega}_{3}
$$

The flows are calculated as:

$$
\left\{\begin{array}{l}
q_{1}=-\omega_{3} D \varepsilon-K_{c, p m} \cdot\left(p_{1}-p_{2}\right) \\
q_{2}=\omega_{3} D \varepsilon+K_{c, p m} \cdot\left(p_{1}-p_{2}\right)
\end{array}\right.
$$

The losses are included as viscous friction and laminar leakage coefficients. These coefficients are varied according to loss models. The modelling of losses in hydrostatic pump/motors is difficult due to their complex nature, and there are several attempts available in the literature, see for instance [106] for an overview. Here, the losses were modelled using a modified version of the Polymod model [107], in which the losses are represented by a polynomial depending 


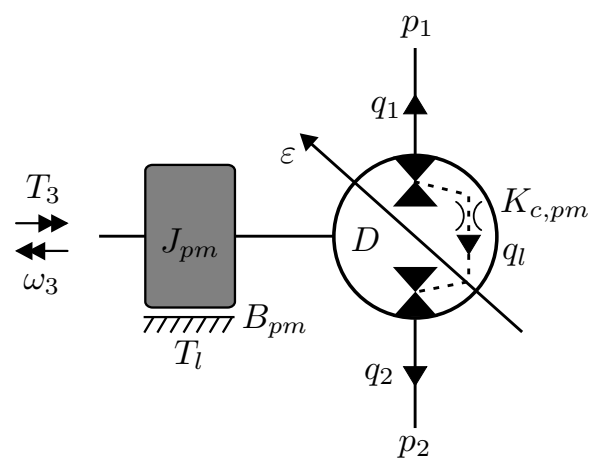

Figure A.11 Pump/motor with displacement $D$, relative displacement $\varepsilon$, shaft speed $\omega_{3}$, shaft torque $T_{3}$, pressures $p_{1}$ and $p_{2}$, flows $q_{1}$ and $q_{2}$ and rotational inertia $J_{p m}$. Torque losses $\left(T_{l}\right)$ are modelled as viscous friction $B_{p m}$, while leakage $\left(q_{l}\right)$ is modelled with laminar leakage coefficient $K_{c, p m}$. The pump/motor component is modelled as a Q-component with the corresponding sign conventions on the torques, speeds, pressures and flows.

on pressure, displacement setting and shaft speed. The modification consists of adding a turbulent leakage term and excluding some of the terms which were found to have little influence on the losses. The loss models with coefficient values used in the model are:

$$
\begin{gathered}
\begin{cases}T_{l}=B_{p m}\left|\omega_{3}\right|=k_{0}+k_{1}\left|p_{1}-p_{2}\right|+k_{2}\left|\omega_{3}\right|+k_{3} \omega_{3}^{2}+k_{4}\left|\left(p_{1}-p_{2}\right) \omega_{3}\right| \\
q_{l}=K_{c, p m}\left|p_{1}-p_{2}\right|=m_{1}\left|p_{1}-p_{2}\right| \omega_{3}^{2}+m_{2}\left|p_{1}-p_{2}\right|+m_{3}|\varepsilon|+m_{4} \sqrt{\left|p_{1}-p_{2}\right|} \\
k_{0}=9.2 \mathrm{Nm} & m_{1}=0.5 \cdot 10^{-16} \mathrm{~m}^{5} \mathrm{~s} / \mathrm{Nrad}^{2} \\
k_{1}=2.3 \cdot 10^{-7} \mathrm{~m}^{3} & m_{2}=-0.3 \cdot 10^{-12} \mathrm{~m}^{5} / \mathrm{Ns}^{2} \\
k_{2}=-0.13 \mathrm{Nms} / \mathrm{rad} & m_{3}=-1 \cdot 10^{-5} \mathrm{~m}^{3} / \mathrm{s} \\
k_{3}=7.5 \cdot 10^{-4} \mathrm{Nms}^{2} / \mathrm{rad}^{2} & m_{4}=3.0 \cdot 10^{-8} \mathrm{~m}^{4} / \mathrm{sN}^{1 / 2} \\
k_{4}=-0.9 \cdot 10^{-9} \mathrm{~m}^{3} \mathrm{~s} / \mathrm{rad} & \end{cases}
\end{gathered}
$$

The models in equation (A.67) were validated in [55] for a closed-circuit variable axial piston unit of the in-line design with a maximum displacement of 110 $\mathrm{cm}^{3} / \mathrm{rev}$. The units used in this thesis were of the same type and size, but were designed for open-circuit operation, which means that one side is constantly subject to tank pressure. Also, the unit in [55] was equipped with an internal boost pump, whereas the units used in this thesis were not. This difference was compensated for by reducing the constant torque loss term, $k_{0}$, by the corresponding value. 


\section{B \\ Test Rig Control}

This section describes the control strategy used in the test rig described in chapter 3. The control problems are equivalent in side 1 and side 2 of the rig, and therefore only the controller for side 1 is described here. The control problem, shown in figure B.1, is a valve-controlled motor with a disturbance torque [47]. The reference speed, $\omega_{1, r e f}$, is the output from the Hopsan model as shown in figure 3.8e. Since the majority of the inertial effects (vehicle mass and engine flywheel) are included in the Hopsan model, the shafts have very low inertia. This enables fast speed response, but also makes the controller sensitive to disturbances.

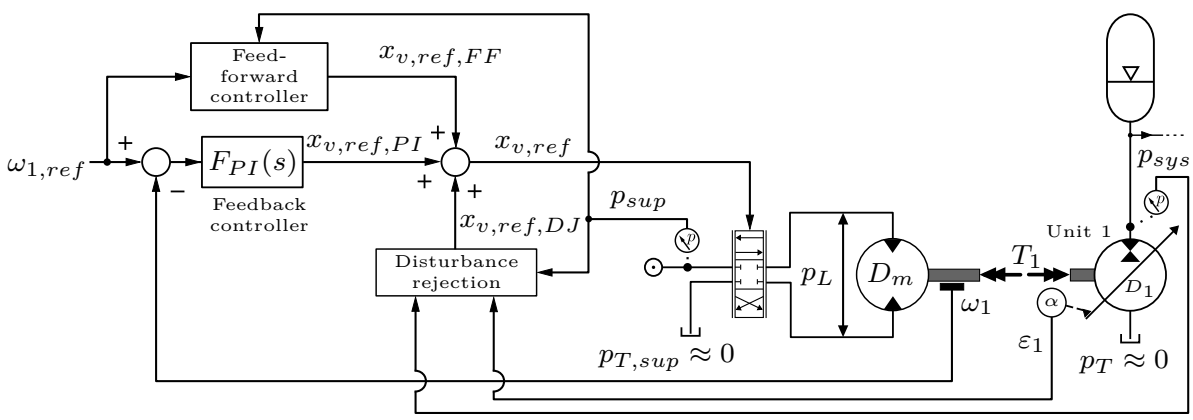

Figure B.1 Control strategy for side 1 in the test rig.

The controller is divided into a feedback part, a feedforward part and a disturbance rejection part:

$$
x_{v, r e f}=x_{v, r e f, P I}+x_{v, r e f, F F}+x_{v, r e f, D J}
$$

The feedback part is a standard proportional-integrator controller: 


$$
x_{v, r e f, P I}=F_{P I}(s)\left(\omega_{1, r e f}-\omega_{1}\right)=K_{P I}\left(1+\frac{\omega_{I}}{s}\right)\left(\omega_{1, r e f}-\omega_{1}\right)
$$

For the feedforward and disturbance rejection parts, a model for a 4-port symmetric, under-lapped valve is used [47]. The valve flow is directly translated to a shaft speed (the volumes between the valve and the motor and leakage are ignored):

$$
\omega_{1} D_{m}=C_{q} \pi d\left[\left(U_{v}+x_{v}\right) \sqrt{\frac{p_{\text {sup }}-p_{L}}{\rho_{\text {oil }}}}-\left(U_{v}-x_{v}\right) \sqrt{\frac{p_{\text {sup }}+p_{L}}{\rho_{\text {oil }}}}\right]
$$

where $U_{v}$ is the valve underlap $\left(\left|x_{v}\right|<U_{v}\right), \rho_{\text {oil }}$ is the oil density and $d$ is the valve spool diameter.

The feedforward and disturbance rejection parts are obtained by solving equation (B.3) for $x_{v}$ :

$$
x_{v}=\frac{-C_{q} d \pi\left(\sqrt{p_{\text {sup }}-p_{L}}-\sqrt{p_{\text {sup }}+p_{L}}\right) U_{v}+\sqrt{\rho_{\text {oil }}} D_{m} \omega_{1}}{C_{q} d \pi\left(\sqrt{p_{\text {sup }}-p_{L}}+\sqrt{p_{\text {sup }}+p_{L}}\right)}
$$

The feedforward part is then based on the term that includes $\omega_{1}$. For this term, the effect of $p_{L}$ is ignored $\left(p_{L} \approx 0\right)$. Furthermore, a lead-compensating filter is used to compensate for servo valve dynamics:

$$
x_{v, r e f, F F}=K_{F F} \frac{D_{m}}{2 C q d \pi \sqrt{\frac{p_{\text {sup }}}{\rho_{\text {oil }}}}} \cdot \frac{\frac{s}{\omega_{f f, 1}}+1}{\frac{s}{\omega_{f f, 2}}+1} \cdot \omega_{1, \text { ref }}
$$

where $K_{F F}$ is the feedforward gain. In the test rig, $p_{\text {sup }}$ is controlled with a pressure relief valve. Due to its static characteristics, the pressure varies significantly with the shaft speeds. Therefore, the measured pressure is used in the implementation of equation (B.5) to actively compensate for this variation.

The sensitivity on the control from the disturbance torque comes from the fact that $p_{L}$ changes with $T_{1}$, which in turn changes the valve flow. This is observed in the first term in equation (B.4), which is used to create the disturbance rejection part of the controller. Due to the high capacitance in the transmission circuit, the disturbance torque is directly determined by the transmission pressure and transmission unit displacement. These two parameters may then be used to estimate $p_{L}$ with lower risk of feedback loop instabilities compared to measuring $p_{L}$ directly. Ignoring shaft inertia and friction, $p_{L}$ may then be estimated as:

$$
\hat{p}_{L}=\frac{D_{1}}{D_{m}} p_{\text {sys }} \varepsilon_{1} K_{D J, 2}
$$

where $K_{D J, 2}$ is a gain that is used to compensate for estimation errors, and $p_{\text {sys }}$ and $\varepsilon_{1}$ are measured. The full disturbance rejection part is then determined according to: 


$$
x_{v, \text { ref }, D J}=\frac{\sqrt{p_{\text {sup }}+\hat{p}_{L}}-\sqrt{p_{\text {sup }}-\hat{p}_{L}}}{\sqrt{p_{\text {sup }}+\hat{p}_{L}}+\sqrt{p_{\text {sup }}-\hat{p}_{L}}} \cdot U_{v} \cdot K_{D J}
$$

where signed square roots are used in the rig implementation of equation (B.7) to ensure continuous function values at low supply pressures. $K_{D J}$ is the disturbance rejection gain.

Figure B.2 shows the performance of the speed control for steps in reference speed. The response is well damped and fast considering the relatively large step size. However, the proportional-integrator part of the signal is large in both static and dynamic parts of the measurements, which indicates that the feedforward part could be enhanced. It should also be noted that during HWIL simulation, the shaft speed reference does not change this rapidly, due to the inertial effects included in the model.

Figure B.3 shows the effect of the disturbance rejection part of the controller. Without the rejection part, the disturbance is handled by the feedback controller, which is relatively slow, thereby causing large disturbances in shaft speed. It should be noted that, during the tests presented in figure B.3, the step in displacement setting of unit 1 causes a flow into the accumulator, which increases the pressure throughout the measurement.
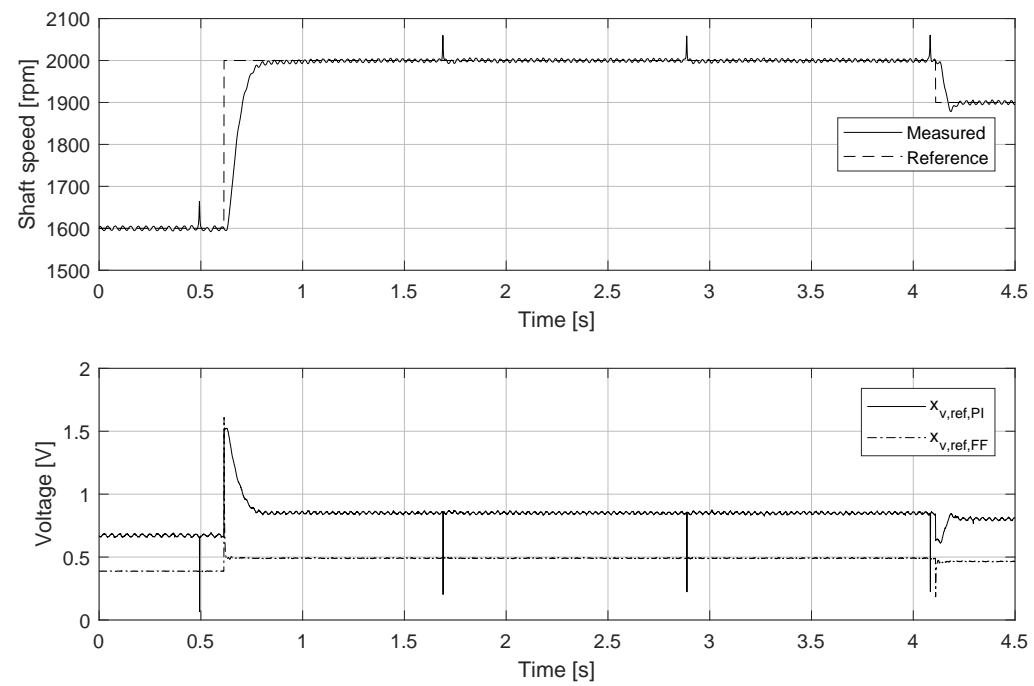

Figure B.2 Step response in shaft speed reference. The tests were carried out with a rig supply pressure of 240 bar. 

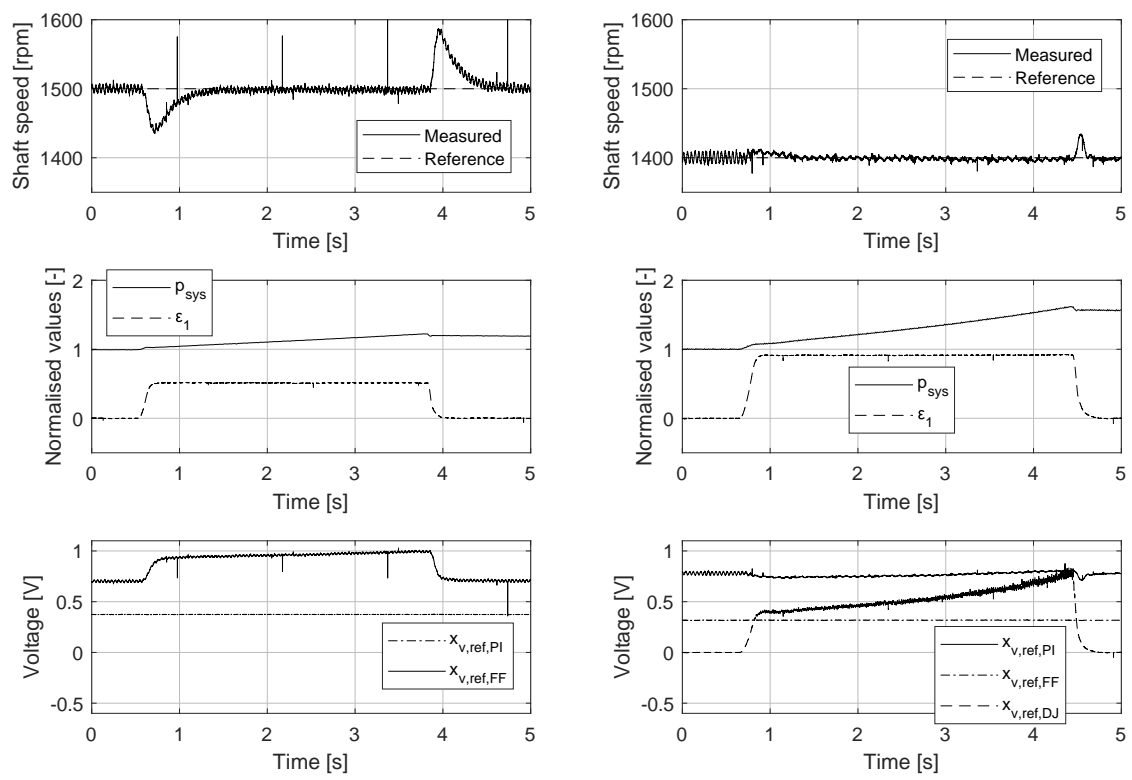

(a) Without disturbance rejection.

(b) With disturbance rejection.

Figure B.3 Illustration of the effect of disturbance rejection when steps are made in the displacement setting of unit 1. The transmission system pressure has been normalised with a value of 100 bar. The tests were carried out with a rig supply pressure of 240 bar.

The low inertia of the shafts also gives rise to a constant oscillation of the shaft speed when no load is applied. This phenomenon is presumably also influenced by some play present in the shaft connections. These oscillations are, however, assumed to have negligible influence on the results. Some noise spikes are also observable in some curves. These were removed with software filtering in the rig measurement system after these measurements were made.

Controller parameters used in the implemented controllers are provided in table B.1. The rig hardware components used for each side are listed in table B.2. 
Table B.1 Parameters values used in the rig controllers. Since the model was adapted for side 1, and side 2 has a smaller servo valve (see table B.2), there are differences in the control gains between the two sides. Both controllers were trimmed manually with tests similar to those in figures B.2 and B.3.

\begin{tabular}{|c|c|c|}
\hline Parameter (same in both controllers) & & Value \\
\hline$\omega_{f f, 1}$ & \multicolumn{2}{|c|}{$40 \mathrm{rad} / \mathrm{s}$} \\
\hline$\omega_{f f, 2}$ & \multicolumn{2}{|c|}{$500 \mathrm{rad} / \mathrm{s}$} \\
\hline$U_{v}$ & \multicolumn{2}{|c|}{$0.3067 \mathrm{~mm}$} \\
\hline$C_{q}$ & \multicolumn{2}{|c|}{0.67} \\
\hline$d$ & \multirow{4}{*}{\multicolumn{2}{|c|}{$\begin{array}{r}25 \mathrm{~mm} \\
880 \mathrm{~kg} / \mathrm{m}^{3} \\
110 \mathrm{~cm}^{3} / \mathrm{rev} \\
110 \mathrm{~cm}^{3} / \mathrm{rev}\end{array}$}} \\
\hline$\rho_{\text {oil }}$ & & \\
\hline$D_{1}=D_{2}$ & & \\
\hline$D_{m}$ & & \\
\hline Parameter (specific in each controller) & Side 1 & Side 2 \\
\hline$K_{P I}$ & 0.023 & 0.021 \\
\hline$\omega_{I}$ & 6 & 40 \\
\hline$K_{F F}$ & 0.58 & 0.96 \\
\hline$K_{D J}$ & 1.38 & 1.16 \\
\hline$K_{D J, 2}$ & 1.7 & 1.37 \\
\hline
\end{tabular}

Table B.2 Components used in the rig.

\section{Component}

Servo valve side 1

Servo valve side 2

Hydraulic motor

sides 1 and 2

Torque/speed transducer

sides 1 and 2
Brand and type

Bosch Rexroth 4WRDE25V350L-50/6L24EZ9/MR

Bosch Rexroth 4WRDE16V200L-50/6L24ETZ9/MR

Volvo F11-110-MF-CN-K

HBM T30FN 


\section{C \\ Full Decoupled System Matrix}

This section shows the derivation of the decoupled open-loop transfer function, $\tilde{G}_{O}(s)$ in equation (4.22), and the effect of assuming equally fast response of the two displacement controllers. Recall equation (4.15):

$$
\begin{aligned}
& G_{O}(s)= \\
& {\left[\begin{array}{ccc}
\frac{D_{1}\left(a_{m} \omega_{I C E, 0}+b_{m} \omega_{\text {out }, 0}\right) G_{\varepsilon, 1}(s)}{C s+K_{C}} & \frac{D_{2}\left(c_{m} \omega_{I C E, 0}+d_{m} \omega_{\text {out }, 0}\right) G_{\varepsilon, 2}(s)}{C s+K_{C}} & 0 \\
-\frac{b_{m} D_{1} p_{s y s, 0} G_{\varepsilon, 1}(s)}{J_{v} s+B_{y}} & -\frac{d_{m} D_{2} p_{s y s, 0} G_{\varepsilon, 2}(s)}{J_{v} s+B_{v}} & 0 \\
-\frac{a_{m} D_{1} p_{s y s, 0} G_{\varepsilon, 1}(s)}{J_{I C E} s+B_{I C E}} & -\frac{c_{m} D_{2} p_{s y s, 0} G_{\varepsilon, 2}(s)}{J_{I C E} s+B_{I C E}} & \frac{K_{I C E} G_{T}(s)}{J_{I C E} s+B_{I C E}}
\end{array}\right]}
\end{aligned}
$$

and equation (4.20):

$$
\begin{aligned}
W_{m}= & G_{t s, m}^{-1}(0)= \\
& {\left[\begin{array}{ccc}
\frac{d_{m}}{\left(a_{m} d_{m}-b_{m} c_{m}\right) D_{1} \omega_{I C E, 0}} & \frac{c_{m} \omega_{I C E, 0}+d_{m} \omega_{\text {out }, 0}}{\left(a_{m} d_{m}-b_{m} c_{m}\right) D_{1} p_{s y s} \omega_{I C E, 0}} & 0 \\
\frac{b_{m}}{\left(b_{m} c_{m}-a_{m} d_{m}\right) D_{2} \omega_{I C E, 0}} & \frac{a_{m} \omega_{I C E, 0}+b_{m} \omega_{\text {out }, 0}}{\left(b_{m} c_{m}-a_{m} d_{m}\right) D_{2} p_{s y s, 0} \omega_{I C E, 0}} & 0 \\
\frac{p_{s y s}, 0}{K_{I C E} \omega_{I C E, 0}} & \frac{\omega_{\text {out }, 0}}{K_{I C E} \omega_{I C E, 0}} & \frac{1}{K_{I C E}}
\end{array}\right] }
\end{aligned}
$$


This yields the following decoupled open-loop transfer function (also provided in paper $[\mathrm{IV}])$ :

$$
\tilde{G}_{O}(s)=G_{O}(s) W_{m}=\left[\begin{array}{ccc}
\tilde{g}_{1,1}(s) & \tilde{g}_{1,2}(s) & 0 \\
\tilde{g}_{2,1}(s) & \tilde{g}_{2,2}(s) & 0 \\
\tilde{g}_{3,1}(s) & \tilde{g}_{3,2}(s) & \tilde{g}_{3,3}(s)
\end{array}\right]
$$

where the matrix elements are determined by (the off-diagonal elements are not provided in paper [IV]):

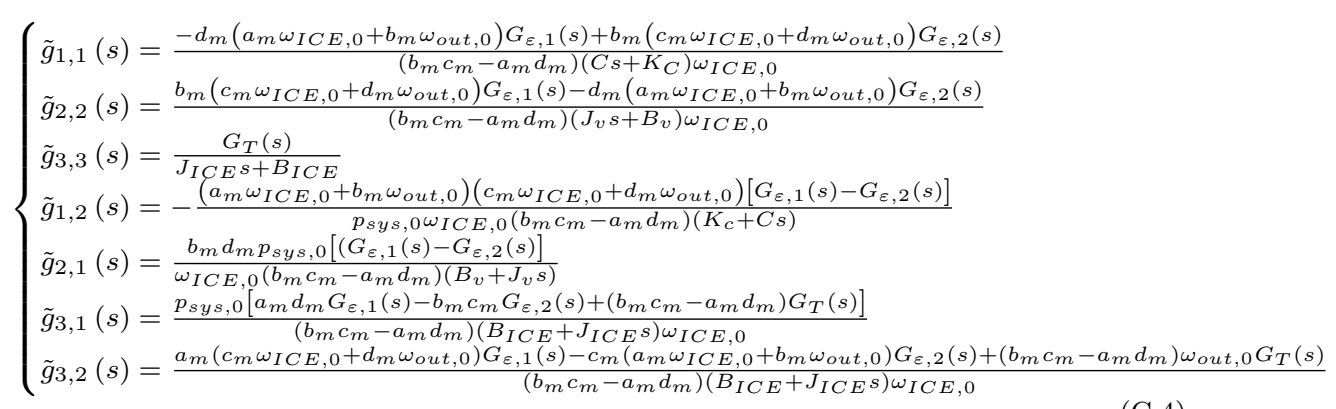

Assume equally fast displacement controllers (from equation (4.21)):

$$
G_{\varepsilon, 1}(s)=G_{\varepsilon, 2}(s)=G_{\varepsilon}(s)=\frac{1}{\frac{s^{2}}{\omega_{a}^{2}}+2 \frac{\delta_{a}}{\omega_{a}} s+1}
$$

The decoupled transfer function then becomes, as in equation (4.22):

$$
\begin{aligned}
\tilde{G}_{O}(s)= & G_{O}(s) W_{m}= \\
& {\left[\begin{array}{ccc}
\frac{G_{\varepsilon}(s)}{C s+K_{C}} & 0 & 0 \\
0 & \frac{G_{\varepsilon}(s)}{J_{v} s+B_{v}} & 0 \\
\frac{p_{s y s, 0}\left(G_{T}(s)-G_{\varepsilon}(s)\right)}{\omega_{I C E, 0}\left(J_{I C E} s+B_{I C E}\right)} & \frac{w_{\text {out }, 0}\left(G_{T}(s)-G_{\varepsilon}(s)\right)}{\omega_{I C E, 0}\left(J_{I C E} s+B_{I C E}\right)} & \frac{G_{T}(s)}{J_{I C E} s+B_{I C E}}
\end{array}\right] }
\end{aligned}
$$




\section{D \\ Additional Measurements}

This chapter presents some measurements that are not part of the primary findings in this thesis, but are provided for the interested reader.

\section{Adjusting Moment in Axial Piston Pumps}

In axial piston units, an oscillating adjusting moment, caused by the pistons entering and leaving the high- and low-pressure regions on the unit valve plate, acts on the swash plate [46]. This torque was modelled as its mean value in this thesis work (paper $[\mathrm{II}]$ ), as the oscillations were found to have no effect on the displacement setting itself. In the control piston pressure the oscillations were, however, observable, especially at low shaft speeds, as illustrated in figure D.1. The measurements shown in figure D.1 were carried out on unit 2 in the test rig, while unit 1 controlled the accumulator pressure and the shaft speed was controlled by the rig controller. Due to poor performance of the rig controllers at the time of the measurements, some variations are present in shaft speed and system pressure. The noise spikes observable in some curves were removed with software filtering in the rig measurement system after these measurements were made. 

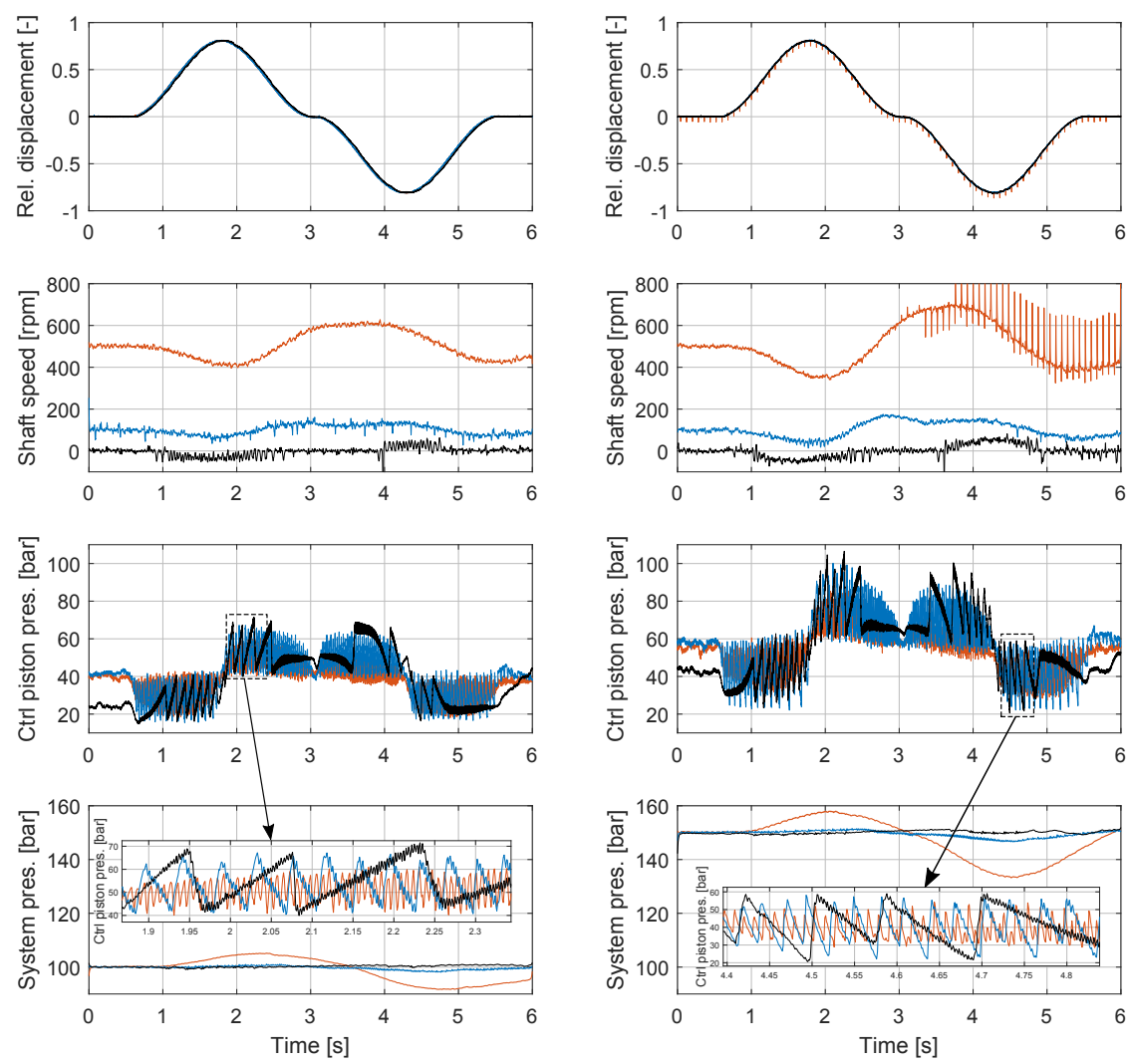

Figure D.1 Effect of the oscillating torque (control piston pressure) acting on the swash plate for a sweep in displacement during 100 bar (left) and 150 bar (right) in system pressure. Note that 1: the frequency of the oscillation is proportional to the shaft speed [46] ( $\left.\omega_{\text {ext }}=2 \omega_{\text {shaft }} n_{\text {pistons }}\right)$, and 2: the oscillation is only visible when the swash plate is moving (this is presumably caused by the friction which absorbs this torque when the swash plate stands still), and 3: for the low speed measurements (black), the slopes of the ramps in the control piston pressure change signs when the speed changes sign at $T=3$ seconds, and 4: the torque mean value changes with shaft speed and system pressure while its and amplitude value changes with the system pressure. 


\section{Bibliography}

[1] Kim Heybroek. "On Energy Efficient Mobile Hydraulic Systems - with Focus on Linear Actuation". PhD thesis. Linköping University, 2017. ISBN: 9789176855119. DOI: 10.3384/diss.diva-142326.

[2] Reno Filla. "Hybrid Power Systems for Construction Machinery: Aspects of System Design and Operability of Wheel Loaders". In: ASME 2009 International Mechanical Engineering Congress and Exposition Volume 13: New Developments in Simulation Methods and Software for Engineering, Lake Buena Vista, Florida, USA, November 13-19. 2009. DOI: 10.1115/IMECE2009-10458.

[3] Reno Filla. "Quantifying Operability of Working Machines". PhD thesis. Linköping University, 2011. ISBN: 9789173930871. DOI: 10.13140/ RG.2.1.4702.0004.

[4] Mikael Axin. "Mobile Working Hydraulic System Dynamics". PhD thesis. Linköping University, Linköping, Sweden, 2015. DOI: 10 . 3384 / diss.diva-121070.

[5] Karl Uebel. "Conceptual Design of Complex Hydromechanical Transmissions". PhD thesis. Linköping University, 2017. ISBN: 9789176854471. DOI: $10.3384 /$ diss .diva-142895.

[6] Karl-Erik Rydberg. "Hydrostatic Drives in Heavy Mobile Machinery - New Concepts and Development Trends". In: SAE Technical Paper 981989 (1998). DOI: 10.4271/981989.

[7] A. Pourmovahed. "Vehicle propulsion systems with hydraulic energy storage: a literature survey". In: International Journal of Vehicle Design 12.4 (1991), pp. 378-403. ISSN: 01433369. DOI: 10 . 1504/IJVD . 1991.061690.

[8] Jacek Stecki and Paul Matheson. "Advances in automotive hydraulic hybrid drives". In: Proceedings of the 6th JFPS International Symposium on Fluid Power. Tsukuba, Japan, 2005. DOI: 10.5739/isfp . 2005.664 . 
[9] Alberto Boretti and Jacek Stecki. "Hydraulic Hybrid Heavy Duty Vehicles - Challenges and Opportunities". In: SAE Technical Paper 201201-2036 (2012). DOI: 10.4271/2012-01-2036.

[10] David Scott and Jack Yamaguchi. "Regenerative braking for buses give big fuel saving". In: Automotive Engineering (SAE) 1984-92-10 (1984), pp. 95-99.

[11] Conny Hugosson. "Cumulo Hydrostatic Drive - a Vehicle Drive with Secondary Control". In: The Third Scandinavian International Conference on Fluid Power. Linköping, Sweden, 1993, pp. 475-494.

[12] Simon Baseley, Christine Ehret, Edward Greif, and Markus G. Kliffken. "Hydraulic Hybrid Systems for Commercial Vehicles". In: SAE Technical Paper 2007-01-4150 (2007). DOI: 10.4271/2007-01-4150.

[13] Bosch Rexroth AG. Hydraulic Flywheel HFW https : / / www . boschrexroth. com/en/xc/products/product-groups/mobilehydraulics / systems - and-functional-modules / hydraulicflywheel-hfw/index. Last visited on: 2019-08-0\%.

[14] Peter A. J. Achten, Georges E. M. Vael, and Kim Heybroek. "Efficient hydraulic pumps, motors and transformers for hydraulic hybrid systems in mobile machinery". In: VDI-Fachkonferenz Getriebe in Mobilen Arbeitsmaschinen, VDI-Wissensforum. 2011, pp. 1-19. ISBN: 9783942980036.

[15] Kim Heybroek, Georges Vael, and J.-O. Palmberg. "Towards Resistancefree Hydraulics in Construction Machinery". In: 8th International Fluid Power Conference. Dresden, Germany, 2012. DOI: 10.4271/2007-011455.

[16] Lorenzo Serrao et al. "A telehandler vehicle as mobile laboratory for hydraulic-hybrid powertrain technology development". In: 10th International Fluid Power Conference, Dresden, Germany, 10. IFK. Dresden, Germany, 2016, pp. 413-424.

[17] F. Wang, M. A. Mohd Zulkefli, Z. Sun, and K. A. Stelson. "Energy management strategy for a power-split hydraulic hybrid wheel loader". In: Proceedings of the Institution of Mechanical Engineers, Part D: Journal of Automobile Engineering (2015). DOI: 10.1177/0954407015600899.

[18] Karl Pettersson, Kim Heybroek, Per Mattsson, and Petter Krus. "A novel hydromechanical hybrid motion system for construction machines". In: International Journal of Fluid Power (2016). DOI: 10 . 1080/14399776.2016.1210423.

[19] Karl Uebel, Henrique Raduenz, Petter Krus, and Victor de Negri. "Design Optimisation Strategies for a Hydraulic Hybrid Wheel Loader". In: BATH/ASME 2018 Symposium on Fluid Power and Motion Control, Bath, Great Britain, September 12-14. 2018. DOI: 10.1115/FPMC20188802. 
[20] Per Mattsson. "Continuously Variable Split-Power Transmissions with Several Modes". PhD thesis. Chalmers University of Technology, Sweden, 1996. ISBN: 91-7197-356-7.

[21] Thomas Anderl, Jürgen Winkelhake, and Marcus Scherer. "Powersplit Transmissions For Construction Machinery". In: 8th International Fluid Power Conference (IFK2012). Dresden, Germany, 2012, pp. 189201.

[22] Rolf Kordak. Hydrostatic drives with secondary control. Mannesmann Rexroth GmbH, 1996.

[23] A. Pourmovahed and D. R. Otis. "An Experimental Thermal TimeConstant Correlation for Hydraulic Accumulators". In: Journal of Dynamic Systems, Measurement, and Control 112.1 (1990), p. 116. ISSN: 00220434. DOI: 10.1115/1.2894128.

[24] Karl-Erik Rydberg. "Gas-Charged Accumulators as Energy Storage Devices in Hydrostatic Drives". In: IASTED International Conference: Energy and Environmental Systems (EES'84). Nice, France, 1984.

[25] Göran Palmgren and Karl-Erik Rydberg. "Secondary Controlled Systems - Energy Aspects and Control Strategies". In: International Conference on Fluid Power. Tampere, Finland, 1987.

[26] D. R. Otis and A. Pourmovahed. "Energy Storage Capacity and Thermal Losses in Hydraulic Accumulators using Elastormeric Foams in the Charge-Gas Volume". In: International Conference on Fluid Power Transmission and Control. Hangzhou, China, 1985, pp. 1515-1527.

[27] Y M Jen and C B Lee. "Influence of an accumulator on the performance of a hydrostatic drive with control of the secondary unit". In: Journal of Systems and Control Engineering 207.13 (1993), pp. 173-184.

[28] J H Kress. "Hydrostatic Power-Splitting Transmissions for Wheeled Vehicles - Classification and Theory of Operation". In: SAE Technical Paper 680549 (1968). DOI: $10.4271 / 680549$.

[29] Kai Loon Cheong, Perry Y. Li, Stephen Sedler, and Thomas R. Chase. "Comparison between Input Coupled and Output Coupled Power-split Configurations in Hybrid Vehicles". In: Proceedings of the 52nd $\mathrm{Na}$ tional Conference on Fluid Power. Milwaukee, WI, USA, 2011, pp. 243252.

[30] Brad Pohl. "CVT Split Power Transmissions, A Configuration Versus Performance Study with an Emphasis on the Hydromechanical Type". In: SAE 2002 World Congress \& Exhibition. SAE International, Mar. 2002. DOI: $10.4271 / 2002-01-0589$. 
[31] Blake Carl, Monika Ivantysynova, and Kyle Williams. "Comparison of Operational Characteristics in Power Split Continuously Variable Transmissions". In: SAE Technical Paper 2006-01-3468 (2006), pp. 776 790. DOI: $10.4271 / 2006-01-3468$.

[32] K T Renius and R Resch. "Continuously Variable Tractor Transmissions". In: ASAE Distinguished Lecture Series Tractor design No. 29 (2005).

[33] Sanjay I. Mistry and Gregory E. Sparks. "Infinitely Variable Transmission (IVT) of John Deere 7000 TEN Series Tractors". In: ASME International Mechanical Engineering Congress \& Exposition (IMECE'2002). New Orleans, Louisiana, 2002, pp. 123-131. DOI: 10.1115/IMECE2002-39347.

[34] Jürgen Legner, Wolfgang Rebholz, and Robert Morrisson. "ZF cPower Hydrostatic-Mechanical Powersplit Transmission for Construction and Forest Machinery". In: 10th International Fluid Power Conference. Dresden, Germany, 2016.

[35] Stefano Mercati, Fabrizio Panizzolo, and Giovanni Profumo. "Power split Hydro-mechanical Variable Transmission ( HVT ) for off-highway application". In: 10th International Fluid Power Conference. Dresden, Germany, 2016.

[36] Markus Schneider, Oliver Koch, and Juergen Weber. "Green Wheel Loader - Operating Strategy of an Energy Efficient Hybrid Drive Train". In: SAE Technical Paper 2014-01-2400 (2014). DOI: 10.4271/ 2014-01-2400.

[37] Jonathan J. Meyer, Kim A. Stelson, Timothy O. Deppen, and Andrew G. Alleyne. "Developing an Energy Management Strategy for a FourMode Hydraulic Hybrid Passenger Vehicle". In: Proceedings of the 52nd National Conference on Fluid Power. Las Vegas, Nevada, USA, 2011.

[38] Michael Sprengel and Monica Ivantysynova. "Investigation and Energetic Analysis of a Novel Hydraulic Hybrid Architecture for On-Road Vehicles". In: The 13th Scandinavian International Conference on Fluid Power. Linköping, Sweden, 2013, pp. 87-98. DOI: 10.3384/ecp1392a9.

[39] Lino Guzella and Antonio Sciaretta. Vehicle Propulsion Systems. Springer Verlag Berlin Heidelberg, 2013. ISBN: 978-3-642-35912-5. DOI: 10.1007/978-3-642-35913-2.

[40] Mohammad Ali Karbaschian and Dirk Söffker. "Review and Comparison of Power Management Approaches for Hybrid Vehicles with Focus on Hydraulic Drives". In: Energies 7.6 (2014), pp. 3512-3536. ISSN: 1996-1073. DOI: 10.3390/en7063512.

[41] Torkel Glad and Lennart Ljung. Reglerteknik: Grundläggande teori. Studentlitteratur AB, 2006. ISBN: 978-91-44-02275-8. 
[42] H. Nikolaus. "Hydrostatische Fahr- und Windenantriebe mit Energierückgewinnung". In: Ölhydraulik und Pneumatik, nr. 3 (1981).

[43] Göran Palmgren. "On Secondary Controlled Hydraulic Systems". Licentiate thesis. Linköping University, 1988. ISBN: 91-7870-368-9.

[44] H Berg and M Ivantysynova. "Design and testing of a robust linear controller for secondary controlled hydraulic drive". In: Proceedings of the Institution of Mechanical Engineers, Part I: Journal of Systems and Control Engineering 213.5 (1999), pp. 375-386. ISSN: 0959-6518. DOI: $10.1243 / 0959651991540223$.

[45] Jaroslav Ivantysyn and Monika Ivantysynova. Hydrostatic Pumps and Motors. Akademia Books International, New Delhi, India, 2001. ISBN: 81-85522-16-2.

[46] Noah D. Manring. Fluid Power Pumps \& Motors. McGraw-Hill Education, 2013. ISBN: 0071812202.

[47] Herbert E Merritt. Hydraulic Control Systems. John Wiley \& Sons, Inc., 1967.

[48] Joerg Grabbel and Monika Ivantysynova. "An investigation of swash plate control concepts for displacement controlled actuators". In: International Journal of Fluid Power 6.2 (2005), pp. 19-36. ISSN: 14399776. DOI: $10.1080 / 14399776.2005 .10781217$.

[49] Monika Ivantysynova. "Technologies and Innovations for Hydraulic Pumps". In: 10th International Fluid Power Conference (IFK'10). Dresden, Germany, 2016.

[50] Liselott Ericson. "Swash Plate Oscillations due to Piston Forces in Variable In-line Pumps". In: The 9th International Fluid Power Conference, (9. IFK). Aachen, Germany, 2014.

[51] P. A. J. Achten, S Eggenkamp, and H. W. Potma. "Swash plate oscillation in a variable displacement floating cup pump". In: The 13th Scandinavian International Conference on Fluid Power. Linköping, Sweden, 2013, pp. 163-176. DOI: 10.3384/ecp1392a17.

[52] Per Mattsson. "Continuously Variable Split-Power TransmissionsConditions for a Mode Shift". In: SAE Technical Paper 933001 (1993). DOI: $10.4271 / 933001$.

[53] S. Mutschler, M. Müller, D. Möller, and F. Panizzolo. "HVT - The power split transmission for wheel loaders". In: Antriebstechnisches Kolloquium 2013 (ATK 2013). Aachen, Germany, 2013, pp. 743-759.

[54] Friedrich Jarchow et al. "Continuous-Acting Hydrostatic-Mechanical Power-Shift Transmission With Toothed Clutches". US5,052,986. 1991.

[55] L. Viktor Larsson and K. Viktor Larsson. "Simulation and Testing of Energy Efficient Hydromechanical Drivelines for Construction Machinery". Master's thesis. Linköping University, 2014. 
[56] Doug Fussner, Glenn Wendel, and Chris Wray. "Analysis of a Hybrid Multi-Mode Hydromechanical Transmission". In: SAE Technical Paper 2007-01-1455 (2007). DOI: 10.4271/2007-01-1455.

[57] Kai Loon Cheong, Zhekang Du, Perry Y. Li, and Thomas R. Chase. "Hierarchical control strategy for a hybrid hydromechanical transmission (HMT) power-train". In: Proceedings of the American Control Conference, Portland, OR, USA. 2014. DOI: 10 .1109/ACC . 2014 . 6859399.

[58] Lars Eriksson and Lars Nielsen. Modeling and Control of Engines and Drivelines. John Wiley \& Sons Ltd, 2014. ISBN: 9781118536186. DOI: 10.1002/9781118536186.

[59] Nils Berglund and Karl-Åke Svensson. Traktorboken. 2nd ed. Lantbruksförbundets tidskriftsaktiebolag, 1950.

[60] Ronald Feit. "Regulating engine speed - 1". In: Control engineering (1966).

[61] Constantine D. Rakopoulos and Evangelos G. Giakoumis. Multivariable Control Systems. Springer, London, 2009. ISBN: 978-1-84882-374-7. DOI: 10.1007/b97506.

[62] Perry Y. Li and Felicitas Mensing. "Optimization and Control of a Hydro-Mechanical Transmission based Hybrid Hydraulic Passenger Vehicle". In: 7th International Fluid Power Conference, Aachen, Germany. 2010.

[63] Teck Ping Sim and Perry Y. Li. "Analysis and Control Design of a Hydro-Mechanical Hydraulic Hybrid Passenger Vehicle". In: ASME 2009 Dynamic Systems and Control Conference, Volume 2. 2009, pp. 667-674. DOI: 10.1115/DSCC2009-2616.

[64] Johan Wahlström and Lars Eriksson. "Modelling diesel engines with a variable-geometry turbocharger and exhaust gas recirculation by optimization of model parameters for capturing non-linear system dynamics". In: Proceedings of the Institution of Mechanical Engineers, Part D: Journal of Automobile Engineering 225.7 (2011), pp. 960-986. ISSN: 0954-4070. DOI: $10.1177 / 0954407011398177$.

[65] Sixten Berglund. "Modeling Complex Engines as Dynamic Powertrain Members". PhD thesis. Chalmers University of Technology, 1999. ISBN: 91-628-3364-2.

[66] Vaheed Nezhadali, Martin Sivertsson, and Lars Eriksson. "Turbocharger Dynamics Influence on Optimal Control of Diesel Engine Powered Systems". In: SAE International Journal of Engines 7.1 (Apr. 2014), pp. 6-13. ISSN: 1946-3944. DOI: 10.4271/2014-01-0290. 
[67] P. Zeman, W. Kemmetmüller, and A. Kugi. "Energy-efficient Constrained Control of a Hydrostatic Power Split Drive". In: IFACPapersOnLine 50.1 (2017), pp. 4775-4780. ISSN: 2405-8963. DOI: 10.1016/j.ifacol.2017.08.959.

[68] Steffen Mutschler, Norman Brix, and Yusheng Xiang. "Torque Control for Mobile Machines". In: 11th International Fluid Power Conference, Aachen, Germany, 11. IFK, March 19 - 21. 2018, pp. 186-195. DOI: 10.18154/RWTH-2018-224783.

[69] Torkel Glad and Lennart Ljung. Reglerteknik: Flervariabla och olinjära metoder. 2nd ed. Studentlitteratur AB, 2003. ISBN: 978-97-44-03003-6.

[70] P. Albertos and A. Sala. Multivariable Control Systems. Springer Verlag Berlin Heidelberg, 2004. ISBN: 1-85233-738-9. DOI: 10.1007/b97506.

[71] Lennart Ljung and Torkel Glad. Modellbygge och simulering. Studentlitteratur AB, 2004. ISBN: 978-91-44-02443-1.

[72] Petter Krus. "On Load Sensing Fluid Power Systems - With Special Reference to Dynamic Properties and Control Aspects". PhD thesis. Linköping University, 1988.

[73] Jerker Lennevi. "Hydrostatic Transmission Control". PhD thesis. Linköping University, 1995. ISBN: 91-7871-597-0.

[74] Mikael Sannelius. "On Complex Hydrostatic Transmissions, Design of a Two-Motor Concept using Computer Aided Development Tools". PhD thesis. Linköping University, Linköping, Sweden, 1999.

[75] Peter Fritzson. Principles of Object Oriented Modeling and Simulation with Modelica 3.3: a cyber-physical approach. Wiley-IEEE Press, 2014. ISBN: 9781118859124. DOI: 10.1002/9781118989166.

[76] D. M. Auslander. "Distributed System Simulation With Bilateral Delay-Line Models". In: Journal of Basic Engineering (1968), pp. 195200. DOI: $10.1115 / 1.3605079$.

[77] Robert Braun. "Distributed System Simulation Methods For ModelBased Product Development". PhD thesis. Linköping, 2015. ISBN: 9789176858752. DOI: 10.3384/diss.diva-122754.

[78] Linköping University, Division of Fluid and Mechatronic Systems. Hopsan Project https: // liu. se/ en/research/hopsan. Last visited on: 2019-08-0\%.

[79] Björn Eriksson, Peter Nordin, and Petter Krus. "Hopsan NG, A C++ Implementation using the TLM Simulation Technique". In: SIMS 2010 Proceedings, The 51st Conference on Simulation and Modelling, 14-15 October 2010. Oulu, Finland, 2010.

[80] Katharina Baer. "Simulation-Based Optimization of a Series Hydraulic Hybrid Vehicle". PhD thesis. Linköping University, Linköping, Sweden, 2018. DOI: $10.3384 /$ diss.diva-145387. 
[81] Mikael Axin et al. "Next Generation Simulation Software using Transmission Line Elements". In: Fluid Power and Motion Control. Bath, UK, 2010, pp. 295-276.

[82] M. Steurer et al. "A Megawatt-Scale Power Hardware-in-the-Loop Simulation Setup for Motor Drives". In: IEEE Transactions on Industrial Electronics 57.4 (Apr. 2010), pp. 1254-1260. ISSN: 0278-0046. DOI: 10.1109/TIE.2009.2036639.

[83] Petter Krus and J.-O. Palmberg. "Integration of Simulation and Measurement in Time and Frequency Domains". In: International Conference on Fluid Power Transmission and Control. Hangzhou, China, 1989 .

[84] Arne Jansson, Jerker Lennevi, and J.-O. Palmberg. "Modelling, simulation and control of a load simulator for hydrostatic transmissions". In: 3rd Scandinavian International Conference on Fluid Power. Linköping, Sweden, 1993.

[85] Jerker Lennevi and Jan-Ove Palmberg. "Application and Implementation of LQ Design Method for the Velocity Control of Hydrostatic Transmissions". In: Proceedings of the Institution of Mechanical Engineers, Part I (1995).

[86] Rong Zhang, Andrew Alleyne, and Eko Prasetiawan. "Modeling and $\mathrm{H}_{2} / \mathrm{H}_{\infty}$ MIMO Control of an Earthmoving Vehicle Powertrain". In: Journal of Dynamic Systems, Measurement, and Control 124.4 (2002), pp. 625-636. DOI: 10.1115/1.1515326.

[87] Michael Sprengel and Monika Ivantysynova. "Hardware-in-the-Loop Testing of a Novel Blended Hydraulic Hybrid Transmission". In: 8th FPNI Ph. D Symposium on Fluid Power. Lappeenranta, Finland, 2014. DOI: $10.1115 /$ FPNI2014-7832.

[88] Hosam K. Fathy, Zoran S. Filipi, Jonathan Hagena, and Jeffrey L. Stein. "Review of Hardware-in-the-Loop Simulation and Its Prospects in the Automotive Area". In: Modeling and Simulation for Military Applications. Vol. 6228. Orlando, FL, USA, 2006. DOI: 10.1117/12. 667794.

[89] Zhekang Du, Perry Y. Li, Kai Loon Cheong, and Thomas R Chase. "Design and Experimental Validation of a Virtual Vehicle Control Concept for Testing Hybrid Vehicles using a Hydrostatic Dynamometer". In: Proceedings of the ASME 2014 Dynamic Systems and Control Conference. San Antonio, TX, USA, 2014. DOI: 10.1115/DSCC2014-6290.

[90] Zoran Filipi et al. "Engine-in-the-Loop Testing for Evaluating Hybrid Propulsion Concepts and Transient Emissions - HMMWV Case Study". In: SAE 2006 World Congress 86 Exhibition. SAE International, Apr. 2006. DOI: $10.4271 / 2006-01-0443$. 
[91] A. J. Martyr and M. A. Plint. Engine Testing: Theory and Practice. Elsevier Ltd., 2007.

[92] Petter Krus. "Robust Modelling using Bi-Lateral Delay Lines for Real Time and Faster Than Real Time System Simulation". In: ASME 2009 International Design Engineering Technical Conferences 8 Computers and Information in Engineering Conference. San Diego, California, USA, 2009. DOI: 10.1115/DETC2009-87495.

[93] Erik Forsberg and Stefan Ekström. "Modelling and Control of Hydrostatic Transmission for Construction Machine". Master's thesis. Linköping University, 2010.

[94] Prevas. Viking GUI - User Manual. Oct. 2010.

[95] Robert Braun and Petter Krus. "Multi-threaded real-time simulations of fluid power systems using transmission line elements". In: Proceedings of the 8th International Fluid Power Conference (IFK2012). Dresden, Germany, 2012.

[96] Jerker Lennevi and J.-O. Palmberg. "The Significance for Control Design of the Engine and Power Transmission Coupling in Hydrostatic Drivetrains". In: 8th Bath International Fluid Power Workshop on Design and Performance, Bath, UK. 1995.

[97] H. H. Rosenbrock. Computer-Aided Control System Design. Academic Press Inc. (London) Ltd., 1974. ISBN: 0125974507.

[98] A. Hedman. "Continuously Variable Split-Power Transmissions at Near-Zero Output Speeds". In: Eighth World Congress on the Theory of Machines and Mechanisms, Prague, Czechoslovakia. 1991.

[99] Jamie Taylor, Win Rampen, Alasdair Robertson, and Niall Caldwell. "Digital Displacement Hydraulic Hybrids - Parallel Hybrid Drives for Commercial Vehicles". In: JSAE Annual Congress. 1. 2011.

[100] Peter Achten et al. "Efficiency Measurements of the Hydrid Motor / Pump". In: The Twelfth Scandinavian International Conference on Fluid Power. Tampere, Finland, 2011.

[101] W.L. Green and T.R. Crossley. "An Analysis of the Control Mechanism used in Variable-Delivery Hydraulic Pumps". In: Proceedings of the Institution of Mechanical Engineers. 1970. DOI: 10.1243/PIME_PROC_ 1970_185_013_02.

[102] Petter Krus, Arne Jansson, Jan-Ove Palmberg, and Kenneth Weddfeldt. "Distributed Simulation of Hydromechanical Systems". In: Third Bath International Fluid Power Workshop, Bath, UK, Sept 13-14. 1990.

[103] Karl Pettersson and Petter Krus. "Design Optimization of Complex Hydromechanical Transmissions". In: Journal of Mechanical Design 135.9 (2013). DOI: 10.1115/1.4024732. 
[104] Volvo Construction Equipment. Volvo L90H wheel loader, product brochure https: //www. volvoce. com/-/media/volvoce/global/ products / wheel-loaders / compact-wheel-loader/brochures / brochure_l60h_l70h_l90h_t4f_sv_12_20045607_b.pdf? $v=$ 29AvPw. Last visited on: 2019-08-0\%.

[105] Yunus A. Çengel, Robert H. Turner, and John M. Cimbala. Fundamentals of Thermal-Fluid Sciences. 3rd ed. McGraw-Hill: New York NY, 2008. ISBN: 978-3-642-35912-5.

[106] Torsten Kohmäscher, Robert Rahmfeld, Hubertus Murrenhoff, and Eckhard Skirde. "Improved Loss Modeling of Hydrostatic Units - Requirement for Precise Simulation of Mobile Working Machine Drivelines". In: ASME International Mechanical Engineering Congress and Exposition (IMECE2007), Seattle, Washington, USA. Seattle, Washington,USA, 2007, pp. 195-206. DOI: 10.1115/IMECE2007-41803.

[107] Dusan Mikeska. "A Precise Steady-State Model of Displacement Machines for the Application in Virtual Prototyping of Power-Split Drives". In: 2nd International FPNI Ph.D. Symposium on Fluid Power. Modena, Italy, 2002. 


\section{Papers}

The papers associated with this thesis have been removed for copyright reasons. For more details about these see:

http://urn.kb.se/resolve?urn=urn:nbn:se:liu:diva-159771 
Där kaninerna är, där förblir ingenting som det har varit, där sker underverk och där är ingenting visst och säkert, där är det inte lönt att tala om vad som är rätt eller fel eller möjligt eller omöjligt. 


\section{FACULTY OF SCIENCE AND ENGINEERING}

Linköping Studies in Science and Technology, Dissertations No. 1992, 2019 Division of Fluid and Mechatronic Systems (Flumes]

Department of Management and Engineering [IEI]

\section{Linköping University}

SE-581 83 Linköping, Sweden

www.liu.se

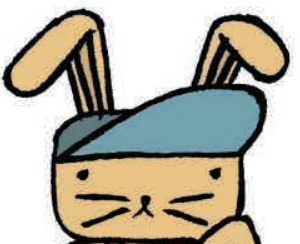

